Published in final edited form as:

Pacing Clin Electrophysiol. 2006 October ; 29(10): 1130-1159.

\title{
Brugada Syndrome
}

\author{
CHARLES ANTZELEVITCH, Ph.D. \\ Masonic Medical Research Laboratory, Utica, New York
}

\begin{abstract}
First introduced as a new clinical entity in 1992, the Brugada syndrome is associated with a relatively high risk of sudden death in young adults, and occasionally in children and infants. Recent years have witnessed a striking proliferation of papers dealing with the clinical and basic aspects of the disease. Characterized by a coved-type ST-segment elevation in the right precordial leads of the electrocardiogram (ECG), the Brugada syndrome has a genetic basis that thus far has been linked only to mutations in SCN5A, the gene that encodes the $\alpha$-subunit of the sodium channel. The Brugada ECG is often concealed, but can be unmasked or modulated by a number of drugs and pathophysiological states including sodium channel blockers, a febrile state, vagotonic agents, tricyclic antidepressants, as well as cocaine and propranolol intoxication. Average age at the time of initial diagnosis or sudden death is $40 \pm 22$, with the youngest patient diagnosed at 2 days of age and the oldest at 84 years. This review provides an overview of the clinical, genetic, molecular, and cellular aspects of the Brugada syndrome, incorporating the results of two recent consensus conferences. Controversies with regard to risk stratification and newly proposed pharmacologic strategies are discussed.
\end{abstract}

\section{Keywords}

ventricular arrhythmias; sudden cardiac death; atrial fibrillation; ventricular tachycardia; ventricular fibrillation; inherited disease

\section{Introduction}

Since its introduction as a new clinical entity by Pedro and Josep Brugada in $1992,{ }^{1}$ the Brugada syndrome has attracted great interest because of its high incidence in many parts of the world and its association with high risk of sudden death, especially in males as they enter their third and fourth decades of life. Recent years have witnessed a dramatic rise in the number of reported cases and a great proliferation of papers serving to define the clinical, genetic, cellular, ionic, and molecular aspects of the disease. ${ }^{2}$ A consensus conference report published in 2002 delineated diagnostic criteria for the syndrome. ${ }^{3,4}$ A second consensus conference report published in 2005 focused on risk stratification schemes and approaches to therapy. 5,6 This review provides an in-depth overview of the clinical, genetic, molecular, and cellular aspects of the Brugada syndrome, incorporating the results of the two consensus conference reports, and the numerous clinical and basic publications on the subject. Controversies with regard to the involvement of anatomic structural defects, the approach to risk stratification, and new data relative to proposed pharmacologic strategies are discussed in detail. The proposed terminology, diagnostic criteria, risk stratification schemes and device, and pharmacologic approach to therapy discussed are based on available clinical and basic studies, and should be

Address for reprints: Charles Antzelevitch, Ph.D., Gordon K. Moe Scholar, Masonic Medical Research Laboratory, 2150 Bleecker Street, Utica, NY 13501. Fax: (315) 735-5648; e-mail: ca@mmrl.edu 
considered a work-inprogress that will require significant fine-tuning as confirmatory data from molecular studies and prospective trials become available.

\section{Clinical Characteristics and Diagnostic Criteria}

Characterized by an ST-segment elevation in the right precordial electrocardiogram (ECG) leads and a high incidence of sudden death in patients with structurally normal hearts, the Brugada syndrome generally manifests during adulthood. The average age at the time of initial diagnosis or sudden death is $40 \pm 22$. The youngest patient diagnosed with the syndrome is 2 days of age, and the oldest is 84 years.

A recent report by Skinner et al. provides a direct link between sudden infant death syndrome and the Brugada syndrome. ${ }^{7}$ This 19-day-old infant was successfully resuscitated from ventricular fibrillation (VF). Although the basal ECG did not show features of Brugada syndrome, DNA analysis revealed a missense mutation (R1193Q) in SCN5A, previously linked with the Brugada syndrome.

Because the ECG is so dynamic and often concealed, it is difficult to estimate the true prevalence of the disease in the general population. ${ }^{8}$ The prevalence of the Brugada syndrome is estimated at 1-5 per 10,000 inhabitants worldwide. The frequency is lower in western countries and higher ( $\geq 5$ per 10,000) in Southeast Asia, especially in Thailand and the Philippines where Brugada syndrome is considered to be the major cause of sudden death in young individuals. In these countries, the syndrome is often referred to as sudden unexplained nocturnal death syndrome (SUNDS). ${ }^{9,10}$

The electrocardiographic manifestations of the Brugada syndrome when concealed can be unmasked by sodium channel blockers, a febrile state, or vagotonic agents. ${ }^{11-14}$ Three types of repolarization patterns in the right precordial leads are recognized (Table I and Fig. 1). 3,4 Type 1 ST-segment elevation is diagnostic of Brugada syndrome and is characterized by a coved ST-segment elevation $\geq 2 \mathrm{~mm}(0.2 \mathrm{mV})$ followed by a negative T wave. Type $2 \mathrm{ST}$ segment elevation has a saddleback appearance with a high take-off ST-segment elevation of $\geq 2 \mathrm{~mm}$ followed by a trough displaying $\geq 1 \mathrm{~mm}$ ST elevation followed by either a positive or biphasic T wave. Type 3 ST-segment elevation has either a saddleback or coved appearance with an ST-segment elevation of $<1 \mathrm{~mm}$. These three patterns may be observed sequentially in the same patient or following the introduction of specific drugs. Type 2 and 3 ST-segment elevation should not be considered diagnostic of the Brugada syndrome. A Brugada ECG refers to the manifestation of a Type 1 ST-segment elevation. Brugada syndrome is definitively diagnosed when a Type 1 ST-segment elevation (Brugada ECG) is observed in more than one right precordial lead (V1-V3), in the presence or absence of sodium channel blocking agent, and in conjunction with one or more of the following: documented VF, polymorphic ventricular tachycardia (VT); a family history of SCD ( $<45$ years old); coved-type ECGs in family members; inducibility of VT with programmed electrical stimulation (PES); syncope; or nocturnal agonal respiration. ${ }^{3-6}$

Differential diagnosis of the Brugada syndrome must be approached with care since STsegment elevation is associated with a wide variety of benign as well as malignant pathophysiologic conditions. Definitive diagnosis is difficult when the degree of basal STsegment elevation is relatively small and the specificity of sodium channel blockers, such as flecainide, ajmaline, procainamide, disopyramide, propafenone, and pilsicainide ${ }^{12,15,16}$ to identify patients at risk is uncertain. The recommended dosage regimens for the most frequently used agents are listed in Table II. A comparison of intravenous ajmaline and flecainide in the same cohort of patients revealed that ajmaline is more effective in unmasking the syndrome. 17 Flecainide failed in 7 of 22 cases $(32 \%)$ unmasked by ajmaline. A greater inhibition of $\mathrm{I}_{\mathrm{to}}$ by flecainide renders it less effective than ajmaline. 
The sodium challenge should be monitored with a continuous ECG recording (speed $10 \mathrm{~mm} /$ $\mathrm{s}$ and interposed $50 \mathrm{~mm} /$ ) and should be terminated when (1) the diagnostic Type $1 \mathrm{ST}$-segment elevation, or Brugada ECG, develops; (2) ST segment in Type 2 increases by $\geq 2 \mathrm{~mm}$; (3) premature ventricular beats or other arrhythmias develop; or (4) QRS widens to $\geq 130 \%$ of baseline. Sodium channel blockers should be used with particular caution in the presence of atrial and/or ventricular conduction disease (presence of wide QRS, wide $\mathrm{P}$ waves, or prolonged PR intervals). Isolated cases of mechano-electrical dissociation have been reported.

Isoproterenol and sodium lactate may be effective antidotes. 5,6

Confounding factor(s) that could account for the ECG abnormality need to be carefully excluded (Table III). Exaggerated ST-segment elevation is sometimes observed for a brief period following DC cardioversion, and this must be factored in when first evaluating a patient following defibrillation. ${ }^{18}$

Another important confounding factor is the ST-elevation encountered in well-trained athletes. The ST-segment elevation encountered in athletes can be distinguished by virtue of the fact that it is up-sloping rather than downsloping and is largely unaffected by challenge with a sodium channel blocker. In addition, a variety of drugs have been reported to produce a Brugada-like ST-segment elevation (Table IV). Myocarditis and some forms of arrhythmogenic right ventricular cardiomyopathy/dysplasia (ARVC/D) can lead to a Brugadalike phenotype (see below). The extent to which these acquired forms of Brugada syndromes have a genetic predisposition is the subject of intense investigation.

Diagnosis of Brugada syndrome is also considered positive when a Type 2 (saddleback pattern) or Type $3 \mathrm{ST}$-segment elevation is observed in more than one right precordial lead under baseline conditions and can be converted to the diagnostic Type 1 pattern occurs upon exposure to sodium channel blocker (ST-segment elevation should be $\geq 2 \mathrm{~mm}$ ). One or more of the clinical criteria described above should also be present. Drug-induced conversion of Type 3 to Type 2 ST-segment elevation is considered inconclusive for diagnosis of Brugada syndrome.

Most cases of Brugada syndrome display right precordial ST-segment elevation, although isolated cases of inferior lead ${ }^{19,20}$ or left precordial lead ${ }^{21}$ ST-segment elevation have been reported in Brugada-like syndromes, in some cases associated with SCN5A mutations. In rare cases, ST-segment elevation is observed in all precordial leads (unpublished observation).

Placement of the right precordial leads in a superior position (up to the $2^{\text {nd }}$ intercostal spaces above normal) can increase the sensitivity of the ECG for detecting the Brugada phenotype in some patients, both in the presence or absence of a drug challenge (Fig. 2). ${ }^{22,23}$ Studies are underway to ascertain whether the greater sensitivity is at the cost of a lower specificity and whether a Type I ECG in the elevated leads is as predictive of events as a Type I ECG in standard leads. A recent report demonstrates that as many as $1.3 \%$ of normal Korean males display a Type 2, but not Type 1, ST-segment elevation when the right precordial leads are recorded from a superior position. 24

A slight prolongation of the QT interval is sometimes observed associated with the ST-segment elevation. $16,25,26$ The QT interval is prolonged more in the right versus left precordial leads, presumably due to a preferential prolongation of action potential duration (APD) in right ventricular (RV) epicardium secondary to accentuation of the action potential (AP) notch. ${ }^{27}$ A corrected QT (QTc) $>460 \mathrm{~ms}$ in V2 has been shown to be associated with arrhythmic risk. 28 Depolarization abnormalities including prolongation of P-wave duration, PR and QRS intervals are frequently observed, particularly in patients linked to SCN5A mutations. ${ }^{29} \mathrm{PR}$ prolongation likely reflects HV conduction delay. 25 
More recent reports indicate that approximately $20 \%$ of Brugada syndrome patients develop supraventricular arrhythmias. ${ }^{30}$ It is as yet unknown whether atrial vulnerability is correlated with ventricular inducibility of arrhythmias or whether atrial arrhythmias may serve as triggering events for VT/VF, although the latter seems unlikely based on current knowledge. Slowed atrial conduction as well as atrial standstill have been reported in association with the syndrome. ${ }^{31}$

In many cases, arrhythmia initiation is bradycardia-related. ${ }^{32}$ This may contribute to the higher incidence of sudden death at night in individuals with the syndrome and may account for the success of pacing in controlling the arrhythmia in isolated cases of the syndrome. ${ }^{33}$ However, not all patients die at night and not all the cases are controlled with rapid ventricular pacing. South Asian patients who have the ECG pattern usually develop VT/VF during sleep at night. Makiyama and co-workers reported that loss-of-function SCN5A mutations resulting in Brugada syndrome are distinguished by profound bradyarrhythmias. ${ }^{34}$ Pertinent to this observation is the recent report by Scornik and co-workers ${ }^{35}$ demonstrating expression of the cardiac sodium channel gene, $S C N 5 A$, in intracardiac ganglia. This interesting finding suggests that loss-of-function mutations in SCN5A may not only create the substrate for reentry in ventricular myocardium, but may also increase vagal activity in intracardiac ganglia, thus facilitating the development of arrhythmias in patients with the Brugada syndrome.

A polymorphic VT resembling a rapid Torsade de Pointes (TdP) arrhythmia is most commonly associated with the Brugada syndrome. Monomorphic VT is observed infrequently and is generally more prevalent in children and infants. ${ }^{36-41}$

VT/VF often terminates spontaneously in patients with the Brugada syndrome, as first reported by Bjerregaard et al. ${ }^{42}$ This may explain why patients wake up at night after episodes of agonal respiration caused by the arrhythmia.

SUNDS, also known as SUDS, a disorder most prevalent in Southeast Asia, and Brugada syndrome have recently been shown to be phenotypically, genetically, and functionally the same disorder. ${ }^{10}$ Sudden and unexpected death of young adults during sleep, known in the Philippines as bangungut ("to rise and moan in sleep"), was first described in the Philippine medical literature in 1917. In Japan, this syndrome, known as pokkuri ("sudden and unexpectedly ceased phenomena"), was reported as early as $1959 .{ }^{43}$ In 1997 , Nademanee et al. ${ }^{44}$ reported that among 27 Thai men referred for aborted cases of what was known in Thailand as Lai Tai ("death during sleep"), as many as 16 had the ECG pattern of Brugada Syndrome. In their review of the literature in 1999, Alings and Wilde found that of the 163 patients who met the criteria for Brugada Syndrome, $58 \%$ were of Asian origin. ${ }^{25}$

\section{Relationship with Structural Heart Disease}

This issue has been the subject of much debate and one that is in a rapid course of evolution. Like the long-QT and short-QT syndromes, Brugada syndrome is traditionally thought of as a primary electrical cardiac disease arising in myocardium that is otherwise structurally normal. Although cardiac function may seem normal on noninvasive examination using echocardiography, more sophisticated tools including magnetic resonance imaging, positron emission tomography, and pathological evaluation of biopsies, have identified discrete anatomic abnormalities in many patients diagnosed with the Brugada syndrome. The somewhat ambiguous and complex relationship between clinical phenotype of Brugada syndrome, the presence of SCN5A gene mutations, and structural heart disease has been brought into sharper focus by recent clinical and basic studies.

The suggestion that patients with the clinical features of Brugada syndrome can have underlying structural abnormalities stems back to 1996 when Corrado et al. ${ }^{45}$ described a 
family with autosomal dominant inheritance of clinical features of Brugada syndrome, but in whom postmortem investigation disclosed RV dilation, fibrofatty replacement of the RV free wall, and fibrotic disruption of the right bundle branch. In 2001, Corrado and co-workers reported another study of 273 young sudden death victims from the Veneto region of Italy with the Brugada syndrome phenotype. ${ }^{46}$ Twelve-lead ECGs were available from 96 patients and $14 \%$ (12 males and 2 females) displayed right precordial ST-segment elevation. At autopsy, 12 of 13 showed pathological features of ARVC, and 1 had an apparently normal heart.

A recent study by Frustaci and co-workers ${ }^{47}$ examined 18 consecutive patients ( 15 males and 3 females) with typical ECG features of Brugada syndrome, who were found to have normal cardiac structure and function based on conventional noninvasive analysis using two-

dimensional echocardiography. VF was documented in seven patients, sustained polymorphic VT in seven, and syncope in four. All patients underwent biventricular endomyocardial biopsies obtained 1 to 3 months after the last known arrhythmic event in an effort to limit the possibility that any observed structural abnormalities might have been caused directly by the arrhythmia. In addition, the entire coding region of the $S C N 5 A$ gene was analyzed in all patients; and in some patients, the coding regions of $R y R 2$ (the cardiac ryanodine receptor) and the PKP2 (plakophilin-2) genes were screened. Surprisingly, pathological features were found in biopsies from all 18 patients included in this study. Most patients had evidence of myocarditis. Diffuse or localized RV inflammation was observed in 14 patients (78\%), and viral genomes were detectable by polymerase chain reaction in 4 of them (Coxsackie B3 in 2 patients, and Epstein-Barr virus and Parvovirus B-19 in single patients). Interestingly, the typical STsegment abnormalities in the right precordial leads that formed the basis of the diagnosis of Brugada syndrome disappeared a few weeks after hospital discharge and were not observed again at follow-up in eight patients in whom endomyocardial biopsy revealed myocardial inflammation. An SCN5A mutation was not identified in these patients. These observations serve to confirm the fact that myocarditis is capable of producing an acquired form of the Brugada syndrome. ${ }^{48}$ Other types of cardiac muscle pathology were observed in biopsies from the remaining four patients. One patient showed extensive fibrofatty replacement typical of ARVC in the RV biopsy and the other three nonspecific abnormalities consistent with diffuse muscle disease typically present in dilated cardiomyopathy. Overall, RV biopsy was abnormal in all 18 patients, whereas the left ventricle biopsy was considered normal in 10 patients.

Novel SCN5A mutations associated with loss of function were detected in 4 of the 18 patients (22\%). Interestingly, none had myocarditis on their biopsies, although three of the four exhibited myocyte hypertrophy and vacuolization, changes that should be viewed with some caution in that they are rather nonspecific, given the usual amount of artifactual tissue disruption that occurs during the endomyocardial biopsy procedure. ${ }^{49}$

Although the study by Frustaci and co-workers 47 is not conclusive, it is consistent with the notion that primary channelopathies can lead to cellular changes. ${ }^{50}$ Age-related development of myocardial fibrosis and progressive slowing of atrial and ventricular conduction have been reported in mice with a single null allele of the $S C N 5 A$ gene $\left(S C N 5 A+/-\right.$; mice). ${ }^{51}$

That $S C N 5 A$ mutations can be associated with structural cardiac defects in humans was reported by Bezzina and co-workers in 2003.52 This was a family whose members exhibited irregular widecomplex tachycardia and in whom mutational analysis revealed compound heterozygous mutations in SCN5A. Pathological analysis of the heart in one family member revealed changes of dilated cardiomyopathy with severe degenerative abnormalities of the cardiac conduction system.

Frustaci et al. ${ }^{47}$ suggested that deranged intracellular sodium homeostasis caused by a $S C N 5 A$ mutation could act via sodium-hydrogen and sodium-calcium exchangers to affect 
intracellular $\mathrm{pH}$ and calcium flux, which, in turn, could impair excitation-contraction coupling and energy production. Another hypothesis is that loss of the AP, which is thought to provide the arrhythmogenic substrate in Brugada syndrome, leads to a hibernation-like state that is associated with progressive cellular changes. ${ }^{50,53}$ The all-or-none repolarization at the end of phase 1 of the AP responsible for loss of the dome causes the calcium channel to inactivate very soon after it activates. As a consequence, calcium channel current is drastically reduced, the cell becomes depleted of calcium within seconds, and contractile function ceases. This leads to wall motion abnormalities, observed in many patients with Brugada syndrome. Loss of the AP dome, because it creates a hibernation-like state, may over long periods of time lead to mild structural changes, including intracellular lipid accumulation and vacuolization. These structural changes may in turn contribute to the arrhythmogenic substrate of the Brugada syndrome, although they are very different from those encountered in ARVC/D. 50,53

Whatever the mechanism, structural remodeling of the myocardium in a patient with an SCN5A mutation could help to explain the delay in manifestation of ECG abnormalities and arrhythmias, and may account for the eventual progression of some cases of Brugada syndrome to ones exhibiting structural abnormalities.

These studies also point to inflammatory processes as being primary and in some cases implicating myocarditis in the development of an acquired form of Brugada syndrome, whose manifestation may be transient. ${ }^{47}$ To what extent the electrocardiographic and arrhythmic manifestations of primary structural defects may have a genetic predisposition is not known and must await delineation of the 70-80\% of Brugada syndrome cases that have thus far not been linked to a genetic mutation.

These facts notwithstanding, the majority of congenital Brugada syndrome patients are believed to possess a structurally normal heart, consistent with the notion that this is a primary electrical heart disease. ${ }^{54}$ While fibrosis and myocarditis may exacerbate or indeed trigger events in patients with the Brugada syndrome, it seems clear that in the vast majority of cases these structural changes are unrelated to ARVC/D. ARVC and Brugada syndromes are distinct clinical entities, both with respect to the clinical presentation and genetic predisposition. ${ }^{4,55}$, 56 The only genes thus far linked to the Brugada syndrome are those that influence sodium channel current, whereas ARVC has been linked to nine different chromosomal loci and four putative genes (desmoplakin, plakoglobin, $R y R 2$, and plakophilin-2) independent of those responsible for the Brugada syndrome. $55,57,58$ Only the ARVC5 locus has been mapped to a region overlapping with the second locus for Brugada syndrome, but the responsible gene has not been identified. ${ }^{57,58}$ In Brugada syndrome, imaging techniques such as echocardiography, angiography, magnetic resonance imaging, and radionuclide scintigraphy show no evidence of overt structural heart disease, whereas ARVC patients characteristically display RV morphological and functional changes (such as global dilatation, bulgings/aneurysms, and wall motion abnormalities). Ventricular arrhythmias in ARVC are most commonly monomorphic VT, often precipitated by catecholamines or exercise, accounting for sudden death of young competitive athletes. In contrast, ST-segment elevation and arrhythmias in Brugada patients are enhanced by vagotonic agents or $\beta$-adrenergic blockers, and polymorphic VT most commonly occurs during rest or sleep. Unlike Brugada syndrome, the ECG abnormalities in ARVC are usually not dynamic, displaying a constant T-wave inversion, epsilon waves and, in the progressive stage, reduction of the $\mathrm{R}$ amplitude, which are largely unaffected by sodium channel blocker administration.

Recent studies report that electron beam computed tomography has uncovered wall motion abnormalities in a series of Brugada patients tested. ${ }^{59}$ Although such contractile abnormalities are commonly considered pathognomonic of structural disease, recent studies 53,60 suggest that such contractile dysfunction can result from loss of the AP dome in regions of RV 
epicardium, and, thus, may be unrelated to any type of morphological defect. Loss of the dome leads to contractile dysfunction, because calcium entry into the cells is greatly diminished and sarcoplasmic reticulum calcium stores are depleted.

The right ventricular outflow tract (RVOT) has been identified as the source of the electrocardiographic abnormalities and arrhythmic activity in patients with the Brugada syndrome. ${ }^{61}$ These manifestations have been attributed to the greater $\mathrm{I}_{\text {to }}$ mediated phase 1 and epicardial AP notch. Magnetic resonance imaging in patients with Brugada syndrome has shown that the RVOT is selectively dilated, ${ }^{62}$ reflecting the presence of an electrophysiological abnormality, such as loss of the AP dome and/or reflecting the presence of structural changes that contribute to the development of an arrhythmogenic substrate. The basis for the unique electrophysiological and anatomical features of the RVOT is not well defined, but may be related to the embryological origin of this region of the heart. Of the four chambers of the heart, the right ventricle is anatomically, phylogenetically, and developmentally the most complex. Formation of the RVOT involves the participation of an extra cardiac source of cells, i.e., neural crest cells. ${ }^{63,64}$ Ablation of specific points of the cardiac neural crest in chicken embryos was shown by Kirby et al., 64 to lead to outflow tract malformations. Although the exact nature of neural crest cells in the outflow tract has been a matter of some debate, recent studies involving transgenic mice provide support for the theory that these cells are important in the development of the RVOT and septation of the outflow tracts. 65

Connexin $43(\mathrm{Cx} 43)$ has been shown to modulate the development of the neural crest, ${ }^{66}$ and recent studies have shown that conditional knockout (CKO) of $\mathrm{Cx} 43$ in neural crest cells leads to selective dilatation or bulging of the outflow tracts in the mouse. $\mathrm{Cx} 43$ is expressed in the cardiac neural crest and neural tube, and its absence is known to result in aberrant cardiac infundibulum and neural crest formation. ${ }^{66}$ Germline knockout $(\mathrm{KO})$ of $\mathrm{Cx} 43$ in the mouse results in abnormal cardiac morphogenesis, including RVOT abnormalities and perinatal death. 67

Liu et al. recently tested the hypothesis that $\mathrm{Cx} 43$ expression in the cardiac neural crest is critical to normal development of the outflow tracts using a CKO strategy to generate mice with neural-crest-restricted $\mathrm{KO}$ of $\mathrm{Cx} 43$. The $\mathrm{CKO}$ mice displayed marked dilatation or bulging of the outflow tracts. The results suggested that $\mathrm{Cx} 43$ expression is not required in the neural crest or dorsal neural tube for normal outflow tract morphogenesis, but is critically important in the remainder of the neural tube, where it may regulate the plasticity of non-crest neuronepithelial cells that mediate the development of the outflow tracts. ${ }^{68}$ It is tempting to speculate that $\mathrm{Cx} 43$ defects limited to this region of the heart may contribute to the development of the Brugada syndrome phenotype by impairing electrotonic communication in the RVOT. This would exacerbate repolarization heterogeneities which contribute prominently to the arrhythmogenic substrate, as well as to slowing of conduction, which may facilitate the development of reentry.

\section{Risk Stratification}

A great deal of focus and debate has centered around the issue of risk stratification of patients at risk for sudden cardiac death. It is generally accepted that Brugada syndrome patients presenting with aborted sudden death are at high risk for recurrence and that they should be protected by an implantable cardioverter defibrillator (ICD). There is also little argument that patients presenting with syncope, particularly those with a spontaneously abnormal (Type 1) ECG, are at higher risk.

In contrast, risk stratification of asymptomatic patients diagnosed with the disease has met with considerable debate. ${ }^{69-73}$ Several invasive and noninvasive parameters have been proposed 
for identification of patients at risk of sudden death, including the presence of spontaneous Type 1 ST-segment elevation, the characteristics of the $S$ wave, ${ }^{74}$ the presence of late potentials, ${ }^{75}$ and inducibility of VT/VF using PES. Inducibility has been the subject of several recent studies, and although the results of the divergent groups are gradually coming together, the positive predictive value of the procedure continues to generate lively debate.

Before discussing the usefulness of these procedures in the assignment of risk, it would be helpful to review the extent of the problem. In 1998, Brugada et al. ${ }^{76}$ reported that over a $34-$ month-follow-up period, $27 \%$ of previously asymptomatic patients experienced a first VF or sudden cardiac death. This figure corresponds to an occurrence of life-threatening events of approximately $10 \%$ /year. In 2002, with a mean follow-up of $27 \pm 29$ months, the same authors ${ }^{69}$ reported that $8 \%$ of previously asymptomatic patients had become symptomatic; an occurrence of a life-threatening event of 3.5\%/year. In 2005, Brugada et al. ${ }^{71}$ reported that only $6 \%$ of asymptomatic patients displayed a first event during a mean follow-up of $42 \pm 42$ months, corresponding to an event rate of $1.7 \%$ /year. This progressive decline in first event rate in previously asymptomatic patients most likely reflects a reduced severity of phenotypes referred to the Brugada registry in subsequent years.

In contrast, Priori et al. in $2002^{70}$ reported that asymptomatic patients have a cumulative probability of $14 \%$ for developing a cardiac arrest by age 40 , corresponding to an incidence of cardiac arrest of $0.35 \%$ /year. In 2005, the same authors reported a first event rate of $3 \%(4 / 132)$ over a 31-month-follow-up period, corresponding to an event rate of $1 \% /$ year. 72

The reason behind the disparity in the data generated by these two groups is not clearly evident. It was suggested by Brugada et al. ${ }^{71}$ that the difference may be due to the inclusion by Priori and co-workers of patients with Type 2 and 3 ST-segment elevation, which is not considered diagnostic of the Brugada syndrome. ${ }^{3-6}$ Priori and Napolitano argue that exclusion of Type 2 and 3 from the diagnosis of the syndrome can lead to missed diagnosis of the disease. ${ }^{72}$ While this is clearly the case, it may be a rare occurrence, and the exclusion appears justified on the basis that it avoids a large number of false positive diagnoses. The failure to exclude individuals with Type 2 and 3 ST-segment elevation suggests that the European registry may contain many individuals who do not have the syndrome.

While it stands to reason that this difference may contribute to the discrepancy in the incidence of first events among asymptomatic patients reported by the two largest registries of Brugada syndrome patients, a recent report by Eckardt and co-workers ${ }^{73}$ suggests that other factors may be involved. These authors report that 1 out of 123 asymptomatic individuals with a Type 1 ECG $(0.8 \%)$ had a first arrhythmic event during a $40 \pm 50$ month follow-up. This translates into a first event rate of $0.24 \%$ per year, considerably less than the other two registries.

The major registry studies all agree that Brugada syndrome patients at higher risk for the development of subsequent events are those presenting with a spontaneous Type 1 ST-segment elevation or Brugada ECG and/or those with a previous VT/VF or SCD. ${ }^{73}$ The registries also agree that PES inducibility is greatest among patients with previous VT/VF or syncope. Approximately onethird of asymptomatic patients are inducible. In the Priori and Napolitano 72 and Eckardt et al. ${ }^{73}$ studies, inducibility of VT/VF in asymptomatic patients was not associated with risk. The lack of association between inducibility and spontaneous VF in Brugada patients was also reported by a number of smaller studies, such as that of Kanda et al. ${ }^{77}$ In sharp contrast, Brugada et al. ${ }^{78}$ found that the risk for developing VT/VF is much greater in patients who were inducible during PES, whether or not a Type 1 ST-segment elevation was spontaneously present and whether or not they were symptomatic. The reason for the marked disparity in the predictive power of PES inducibility among the different studies is not immediately apparent. The discrepancies may be due to differences in patient 
characteristics and the use of multiple testing centers with non-standardized or non-comparable stimulation protocols. ${ }^{79}$ Additional studies are needed to further define risk stratification strategies for asymptomatic patients.

It is noteworthy that in experimental models of the Brugada syndrome involving the coronaryperfused wedge preparation, polymorphic VT is readily inducible with a single S2, but only when applied on the epicardial surface of the wedge. Inducibility is not possible or much more difficult when extra-stimulation is applied to the endocardial surface. The shorter refractory period of epicardium allows extra-stimuli direct access to the vulnerable window across the ventricular wall, thus facilitating the induction of reentry. These relationships suggest that PES applied to the epicardium may provide a more accurate assessment of risk than the current approach in which stimuli are applied to the endocardial surface. In support of this hypothesis, Carlsson et al. reported that a Brugada syndrome patient with recurrent syncope due to polymorphic VT could not be induced with RV endocardial stimulation. However, epicardial stimulation from a left ventricular site through the coronary sinus led to the development of polymorphic VT. 80

Recent studies have suggested that combined electrocardiographic markers may be helpful in risk stratification. Atarashi and Ogawa ${ }^{74}$ used the width of the S wave and the ST-segment elevation magnitude, whereas Morita et al. ${ }^{75}$ combined ST-segment elevation and the presence of late potentials.

Gehi et al. ${ }^{81}$ recently reported the results of a meta-analysis of 30 prospective prognostic studies, including 1,545 patients with a Brugada ECG, to assess predictors of events. The overall event rate at an average of 32 months follow-up was 10.0\%, much higher for patients of Asian versus European origin. The meta-analysis suggested that a history of syncope or SCD, the presence of a spontaneous Type I Brugada ECG, and male gender predict a more malignant natural history. The findings did not support the use of a family history of SCD, the presence of an SCN5A gene mutation, or electrophysiologic study (EPS) to guide the management of patients with a Brugada ECG.

The meta-analysis by Gehi et al. ${ }^{81}$ pooled data from studies that used very different criteria to identify patients with Brugada syndrome. Moreover, the six studies that were used to evaluate the role of EPS in risk stratification of patients were quite heterogeneous. Consequently, the results should be viewed with some reservation. A prospective study termed PRELUDE (PRogrammed ElectricaL stimUlation preDictivE), currently underway in Italy, is designed to provide further insight into the ongoing debate.

Transmural dispersion of repolarization (TDR) within the ventricular myocardium has been suggested to underlie arrhythmogenesis in a number of syndromes, including Brugada, ShortQT, and Long-QT syndromes. ${ }^{82}$ Differences in the timecourse of repolarization of these three ventricular myocardial cell types (endocardial, epicardial, and M cells) contribute prominently to inscription of the electrocardiographic T wave. ${ }^{83}$ In isolated ventricular wedge preparations, the peak of the $\mathrm{T}$ wave was shown to coincide with epicardial repolarization, and the end of the $\mathrm{T}$ wave with repolarization of the $\mathrm{M}$ cells, so that Tpeak-end (Tp-e) interval provides a measure of TDR. ${ }^{83-85}$ Although Tp-e on the surface ECG may not be equivalent to TDR, this interval is thought to provide an index of TDR and thus be helpful in forecasting risk for the development of life-threatening arrhythmias. ${ }^{83,84,86-88}$ Evidence in support of this hypothesis has been provided in hypertrophic cardiomyopathy, congenital and acquired long QT, and other pathophysiological conditions. ${ }^{83,84,86-89}$

Hevia and co-workers ${ }^{28}$ recently evaluated Tp-e as a risk factor for recurrence of lifethreatening cardiac events in patients with the Brugada syndrome. Twenty-nine patients with the ECG pattern of Brugada syndrome and 29 healthy age- and sex-matched controls were 
studied. QT, QTc, QT dispersion, Tp-e, and Tp-e dispersion were measured. Eleven patients with the ECG pattern of Brugada syndrome had a prolonged ( $>460 \mathrm{~ms}$ ) QTc in V2, but usually not in inferior or left leads. No patient had abnormally prolonged QT dispersion. Tp-e and Tpe dispersion were significantly prolonged in patients with recurrences versus patients without events. Thus, there was a significant correlation between $\mathrm{Tp}$-e and $\mathrm{Tp}$-e dispersion and occurrence of life-threatening arrhythmic events in patients with the Brugada syndrome, suggesting that these parameters may be useful in risk stratification of patients with the syndrome.

\section{Genetic Factors Underlying the Brugada Syndrome}

Brugada syndrome is inherited via an autosomal dominant mode of transmission. The first gene to be linked to the Brugada syndrome is SCN5A, the gene encoding for the $\alpha$-subunit of the cardiac sodium channel gene. ${ }^{90}$ Figure 3 highlights the diversity of SCN5A mutations associated with the Brugada syndrome. Of note, mutations in $S C N 5 A$ are also responsible for the LQT3 form of the long-QT syndrome and cardiac conduction disease. A number of mutations have been reported to cause overlapping syndromes; in some cases, all three phenotypes are present. 91

Over one hundred mutations in $S C N 5 A$ have been linked to the syndrome in recent years (see Antzelevitch et al. ${ }^{61}$ for references; also see www.fsm.it/cardmoc). Only a fraction of these mutations have been studied in expression systems and shown to result in loss of function due either to: (1) failure of the sodium channel to express; (2) a shift in the voltage- and timedependence of sodium channel current $\left(\mathrm{I}_{\mathrm{Na}}\right)$ activation, inactivation, or reactivation; (3) entry of the sodium channel into an intermediate state of inactivation from which it recovers more slowly; or (4) accelerated inactivation of the sodium channel. In in vitro expression systems, the premature inactivation of the sodium channel is sometimes observed at physiological temperatures, but not at room temperature. ${ }^{92}$ Acceleration of $\mathrm{I}_{\mathrm{Na}}$ inactivation was still more accentuated at higher than physiological temperatures, suggesting that the syndrome may be unmasked, and that patients with the Brugada syndrome may be at an increased risk, during a febrile state. ${ }^{92}$ A number of Brugada patients displaying fever-induced polymorphic VT have been identified since the publication of this report. ${ }^{14,38,93-100}$

Mutations in the $S C N 5 A$ gene account for approximately $18-30 \%$ of Brugada syndrome cases. A higher incidence of $S C N 5 A$ mutations has been reported in familial than in sporadic cases. 101 Of note, negative $S C N 5 A$ results generally do not rule out causal gene mutations, since the promoter region, cryptic splicing mutations, or presence of gross rearrangements are generally not part of routine investigation. A recent report by Hong et al. ${ }^{102}$ provided the first report of a dysfunctional sodium channel created by an intronic mutation giving rise to cryptic splice site activation in SCN5A in a family with the Brugada syndrome. The deletion of fragments of segments 2 and 3 of Domain IV of SCN5A caused complete loss of function.

Bezzina and co-workers recently provided interesting evidence in support of the hypothesis that an SCN5A promoter polymorphism common in Asians modulates variability in cardiac conduction, and may contribute to the high prevalence of Brugada syndrome in the Asian population. ${ }^{103}$ Sequencing of the SCN5A promoter identified a haplotype variant consisting of 6 polymorphisms in near-complete linkage disequilibrium that occurred at an allele frequency of $22 \%$ in Asian subjects and was absent in whites and blacks. The results of the study demonstrate that sodium channel transcription in the human heart may vary considerably among individuals and races, and be associated with variable conduction velocity and arrhythmia susceptibility.

A second locus on chromosome 3, close to but distinct from SCN5A, has been linked to the syndrome ${ }^{57}$ in a large pedigree in which the syndrome is associated with progressive 
conduction disease, a low sensitivity to procainamide, and a relatively good prognosis. The gene was recently identified as the Glycerol-3-Phosphate Dehydrogenase 1-Like Gene $(G P D 1 L)$. A mutation in GPD1L has been shown to result in a partial reduction of $\mathrm{I}_{\mathrm{Na}} 104$

Knowledge thus far gained through genetic analysis suggests that identification of specific mutations may not be very helpful in formulating a diagnosis or providing a prognosis. There are no clear hotspots and mutations have been reported throughout the SCN5A gene. It is not clear whether some mutations are associated with a greater risk of arrhythmic events or sudden death. Genetic testing is recommended for support of the clinical diagnosis, for early detection of relatives at potential risk, and particularly for the purpose of advancing research and consequently our understanding of genotype-phenotype relations.

\section{Cellular and lonic Mechanisms Underlying the Development of the Brugada Phenotype}

The concept of phase 2 reentry, which is a known trigger for the Brugada syndrome, was described in the early 1990s and evolved in parallel with the clinical discovery of the Brugada syndrome. ${ }^{105-108}$ Studies conducted over the past decade suggest that rebalancing of the currents active at the end of phase 1, leading to an accentuation of the AP notch in RV epicardium is responsible for the accentuated $\mathrm{J}$ wave or ST-segment elevation associated with the Brugada syndrome. ${ }^{105-115}$ Under normal conditions, the appearance of the epicardial AP notch is due principally to the interaction of two ion channel currents. The transient outward current $\left(\mathrm{I}_{\mathrm{to}}\right)$, which activates during phase 0 , contributes most prominently to phase 1 of the $\mathrm{AP}$, whereas the calcium inward current is largely responsible for the second upstroke, giving rise to the $\mathrm{AP}$ dome.

Amplification of epicardial and TDR secondary to the presence of genetic defects, pathophysiologic factors, and pharmacologic influences, leads to accentuation of the $\mathrm{J}$ wave and eventually to loss of the AP dome, giving rise to extrasystolic activity in the form of phase 2 reentry. Activation of $\mathrm{I}_{\text {to }}$ leads to a paradoxical prolongation of APD in canine ventricular tissues, 116 but to abbreviation of ventricular APD in species that normally exhibit brief APs (e.g., mouse and rat). ${ }^{117}$ Pathophysiologic conditions (e.g., ischemia, metabolic inhibition) and some pharmacologic interventions (e.g., $\mathrm{I}_{\mathrm{Na}}$ or $\mathrm{I}_{\mathrm{Ca}}$ blockers or $\mathrm{I}_{\mathrm{K}-\mathrm{ATP}}, \mathrm{I}_{\mathrm{t}}, \mathrm{I}_{\mathrm{kr}}$, or $\mathrm{I}_{\mathrm{ks}}$ activators) can lead to marked abbreviation of the AP in canine and feline ${ }^{118}$ ventricular cells where $\mathrm{I}_{\text {to }}$ is prominent. Under these conditions, canine ventricular epicardium exhibits an allor-none repolarization as a result of the shift in the balance of currents flowing at the end of phase 1 of the AP. When phase 1 reaches approximately $-30 \mathrm{mV}$, all-or-none repolarization of the AP ensues, leading to loss of the dome as the outward currents overwhelm the inward currents. Loss of the AP dome generally occurs at some epicardial sites but not others, resulting in the development of a marked dispersion of repolarization within the epicardium as well as transmurally, between epicardium and endocardium. Propagation of the AP dome from the epicardial site at which it is maintained to sites at which it is abolished can cause local reexcitation of the preparation. This mechanism, termed phase 2 reentry, produces extrasystolic beats capable of initiating circus movement reentry ${ }^{119}$ (Fig. 4). Phase 2 reentry has been shown to occur when RV epicardium is exposed to: (1) $\mathrm{K}+$ channel openers such as pinacidil ${ }^{120}$; (2) sodium channel blockers such as flecainide ${ }^{121}$; (3) increased $[\mathrm{Ca} 2+] \mathrm{o}^{122}$; (4) calcium channel blockers such as verapamil; (5) metabolic inhibition ${ }^{123}$; and (6) simulated ischemia. ${ }^{119}$

Exaggerated or otherwise abnormal $\mathrm{J}$ waves have long been linked to idiopathic VF and the Brugada syndrome. ${ }^{1,19,42,112,124,125}$ The Brugada syndrome is characterized by exaggerated J wave that manifests as an ST-segment elevation in the right precordial leads. ${ }^{1}$ A number of studies have highlighted the similarities between the conditions that predispose to phase 2 reentry and those that attend the appearance of the Brugada syndrome. Loss of the AP dome in epicardium, but not endocardium, generates a transmural current that manifests on the ECG as an ST-segment elevation, similar to that encountered in patients with the 
Brugada syndrome. ${ }^{105,123,126}$ Evidence in support of a phase 2 reentrant mechanism in humans was recently provided by Thomsen et al. ${ }^{127}$ and Antzelevitch. 128

Autonomic neurotransmitters like acetylcholine facilitate loss of the AP dome ${ }^{129}$ by suppressing $\mathrm{I}_{\mathrm{ca}}$ and/or augmenting potassium current. $\beta$-adrenergic agonists restore the dome by augmenting $\mathrm{I}_{\mathrm{Ca}}$. Sodium channel blockers also facilitate loss of the canine RV AP dome via a negative shift in the voltage at which phase 1 begins. ${ }^{121,130}$ These findings are consistent with accentuation of ST-segment elevation in patients with the Brugada syndrome following vagal maneuvers or Class I antiarrhythmic agents, as well as normalization of the ST-segment elevation following $\beta$-adrenergic agents and phosphodiesterase III inhibitors. ${ }^{13,105,131}$ Loss of the AP dome is much more readily induced in right versus left canine ventricular epicardium ${ }^{123,126,132}$ because of the more prominent $\mathrm{I}_{\mathrm{to}}$-mediated phase 1 in APs in this region of the heart. This distinction is believed to be the basis for why the Brugada syndrome is a RV disease.

Thus, accentuation of the RV epicardial AP notch underlies the ST-segment elevation. Eventual loss of the dome of the RV epicardial AP further exaggerates ST-segment elevation. The vulnerable window created within the epicardium, as well as transmurally, serves as the substrate and phase 2 reentry provides the extrasystole that serves as the trigger which precipitates episodes of VT and VF in the Brugada syndrome. Evidence in support of this hypothesis was recently provided in an arterially perfused canine RV experimental model of the Brugada syndrome (Fig. 5). ${ }^{106}$ The VT and VF generated in these preparations is usually polymorphic, resembling a rapid form of TdP. This activity may be mechanistically related to the migrating spiral wave shown to generate a pattern resembling TdP associated with a normal or long-QT interval. ${ }^{133,134}$

Much of the focus in the past has been on the ability of a reduction in sodium channel current to unmask the Brugada syndrome and create an arrhythmogenic substrate. A recent report shows that a combination of $\mathrm{I}_{\mathrm{Na}}$ and $\mathrm{I}_{\mathrm{Ca}}$ block is more effective than $\mathrm{I}_{\mathrm{Na}}$ inhibition alone in precipitating the Brugada syndrome in the arterially perfused wedge preparation (Fig. 6). ${ }^{107}$ High concentrations of terfenadine $(5 \mu \mathrm{M})$ produce a potent block of $\mathrm{I}_{\mathrm{Na}}$ and $\mathrm{I}_{\mathrm{Ca}}$, leading to accentuation of the epicardial AP notch following acceleration of the rate from a basic cycle length of 800 to $400 \mathrm{~ms}$. The dramatic accentuation of the notch was due to the effect of the drug to depress phase 0 , augment the magnitude of phase 1 , and delay the appearance of the second upstroke. With continued rapid pacing, phase 1 becomes more accentuated, until allor-none repolarization occurs at the end of phase 1 at some epicardial sites but not others, leading to the development of both epicardial dispersion of repolarization (EDR) and TDR (Fig. 6C). Propagation of the dome from the region where it is maintained to the region at which it is lost results in the development of local phase 2 reentry (Fig. 6D). Figure 7 shows the ability of terfenadine-induced phase 2 reentry to generate an extrasystole, couplet, and polymorphic VT/VF. Figure 7D illustrates an example of PES to initiate VT/VF under similar conditions.

The electrocardiographic manifestations of the Brugada syndrome have been attributed to: (1) conduction delay in the RV epicardial free wall in the region of the outflow tract (RVOT) 135 and/or (2) premature repolarization of the RV epicardial AP secondary to loss of the AP dome, or a combination of the two. ${ }^{136}$ The cellular mechanisms thought to be responsible for the development of the Brugada phenotype via hypothesis 2 is schematically illustrated in Figure $8 .{ }^{137,138}$

Under physiological conditions, the ST segment is isoelectric because of the absence of transmural voltage gradients at the level of the AP plateau (Fig. 8A). Accentuation of the RV notch under pathophysiologic conditions leads to exaggeration of transmural voltage gradients 
and thus to accentuation of the $\mathrm{J}$ wave or to $\mathrm{J}$ point elevation. When epicardial repolarization precedes repolarization of the cells in the $\mathrm{M}$ and endocardial regions, the $\mathrm{T}$ wave remains positive. The result is a saddleback configuration of the repolarization waves (Fig. 8B). Further accentuation of the notch may be accompanied by a prolongation of the epicardial AP such that the direction of repolarization across the RV wall and transmural voltage gradients are reversed, leading to the development of a coved-type ST-segment elevation and inversion of the T wave (Fig. 8C), typically observed in the ECG of Brugada patients. A delay in epicardial activation may also contribute to inversion of the $\mathrm{T}$ wave. The downsloping ST-segment elevation observed in the experimental wedge models often appears as an R', suggesting that the appearance of a right bundle branch block (RBBB) morphology in Brugada patients may be due at least in part to early repolarization of RV epicardium, rather than major impulse conduction block in the right bundle.

A rigorous application of RBBB criteria reveals that a large majority of RBBB-like morphologies encountered in cases of Brugada syndrome do not fit the criteria for RBBB. 139 Moreover, attempts by Miyazaki and co-workers to record delayed activation of the RV in Brugada patients met with failure. ${ }^{13}$

It is important to point out that although the typical Brugada morphology is present in Figure $8 \mathrm{~B}, \mathrm{C}$, an arrhythmogenic substrate is absent. The arrhythmogenic substrate is thought to develop when a further shift in the balance of current leads to loss of the AP dome at some epicardial sites but not others (Fig. 8D)). Loss of the AP dome in epicardium but not endocardium results in the development of a marked TDR and refractoriness, responsible for the development of a vulnerable window during which a premature impulse or extrasystole can induce a reentrant arrhythmia. Conduction of the AP dome from sites at which it is maintained to sites at which it is lost causes local re-excitation via a phase 2 reentry mechanism, leading to the development of a very closely coupled extrasystole, which captures the vulnerable window across the wall, thus triggering a circus movement reentry in the form of VT/VF (Fig. 8E). ${ }^{106,119}$ The phase 2 reentrant beat fuses with the negative T wave of the basic response. Because the extrasystole originates in epicardium, the QRS complex is largely comprised of a $\mathrm{Q}$ wave, which serves to accentuate the negative deflection of the inverted $\mathrm{T}$ wave, giving the ECG a more symmetrical appearance. This morphology is often observed in the clinic preceding the onset of polymorphic VT.

Studies involving the arterially perfused RV wedge preparation provide evidence in support of these hypotheses. ${ }^{106} \mathrm{~A}$ high resolution optical mapping system that allows simultaneous recording of transmembrane APs from 256 sites along the transmural surface of the arterially perfused canine RV wedge preparation has been used by Shimizu et al. ${ }^{140}$ to demonstrate that a steep repolarization gradient between the region at which the dome is lost and the region at which it is maintained is essential for the development of a closely coupled phase 2 reentrant extrasystole. This study also showed that reentry initially rotates in the epicardium and gradually shifts to a transmural orientation, responsible for nonsustained polymorphic VT or VF.

A recent report by Kurita et al., in which monophasic AP electrodes were positioned on the epicardial and endocardial surfaces of the RVOT in patients with the Brugada syndrome, provides further support. 111

The marked accentuation of the epicardial AP dome and the development of concealed phase 2 reentry suggest that activation forces may extend beyond the QRS in Brugada patients. Indeed, signal averaged ECG (SAECG) recordings have demonstrated late potentials in patients with the Brugada syndrome, especially in the anterior wall of the RVOT. ${ }^{60,141-145}$ The basis for these late potentials, commonly ascribed to delayed conduction within the 
ventricle, is largely unknown. Endocardial recordings have been unrevealing. Nagase and coworkers 143 introduced a guide wire into the conus branch of the right coronary artery to record signals from the epicardial surface of the anterior wall of the RVOT in patients with the Brugada syndrome. The unipolar recordings displayed delayed potentials, which coincided with late potentials recorded in the SAECG, particularly after administration of Class IC antiarrhythmic agents. The authors conclude that recordings from the conus branch of the right coronary artery can identify an "epicardial abnormality" in the RVOT, which is accentuated in the presence of IC agents, thus uncovering part of the arrhythmogenic substrate responsible for VT/VF in Brugada syndrome, which may be related to the second upstroke or a concealed phase 2 reentrant beat. Late potentials are often regarded as being representative of delayed activation of the myocardium, but in the case of the Brugada syndrome, other possibilities exist as discussed above. For example, the second upstroke of the epicardial AP, thought to be greatly accentuated in Brugada syndrome, ${ }^{137}$ might be capable of generating late potentials when RVOT activation is otherwise normal. Moreover, the occurrence of phase 2 reentry, especially when concealed (i.e., when it fails to trigger transmural reentry), may contribute to the generation of delayed unipolar and late SAECG potentials.

The rate-dependence of the ECG sign can be used to discriminate between these two hypotheses. If the Brugada ECG sign is due to delayed conduction in the RVOT, acceleration of the rate would be expected to further aggravate conduction and thus accentuate the STsegment elevation and the RBBB morphology of the ECG. If, on the other hand, the Brugada ECG sign is secondary to accentuation of the epicardial AP notch, at some point leading to loss of the AP dome, acceleration of the rate would be expected to normalize the ECG, by restoring the AP dome and reducing the notch. This occurs because the transient outward current, which is at the heart of this mechanism, is slow to recover from inactivation and is less available at faster rates. The fact of the matter is that Brugada patients usually display a normalization of their ECG or no change when heart rate is increased, thus favoring the second hypothesis. Further evidence in support of this hypothesis derives from the recent observations of Shimizu and co-workers. ${ }^{146}$ Using a unipolar catheter introduced into the great cardiac vein, they recorded unipolar activation recovery intervals (ARI), a measure of local APD, from the epicardial surface of the RVOT in a 53-year-old Brugada patient. ARI in the RVOT was observed to abbreviate dramatically whenever the ST segment was elevated in V2 following a pause or the administration of a sodium channel blocker. Additional support for the hypothesis derives from the demonstration by Watanabe and co-workers ${ }^{147}$ that quinidine suppresses late potentials recorded in a patient with Brugada syndrome. This effect of the drug is presumably due to inhibition of $\mathrm{I}_{\mathrm{to}}$, leading to diminution of the epicardial AP notch and normalization of the repolarization heterogeneities. If the late potentials were due to delayed conduction, quinidine-induced $\mathrm{I}_{\mathrm{Na}}$ inhibition would be expected to accentuate the appearance of the late potentials.

Thus, the available data, both basic and clinical, point to transmural voltage gradients that develop secondary to accentuation of the epicardial notch and loss of the AP dome as being in large part responsible for the Brugada ECG signature.

\section{Gender-Based Differences in the Manifestation of Brugada Syndrome}

Although the genetic mutation responsible for the Brugada syndrome is equally distributed between the sexes, the clinical phenotype is 8 to 10 times more prevalent in males than in females. The basis for this sex-related distinction has been shown to be due to a more prominent $\mathrm{I}_{\mathrm{to}_{\mathrm{o}}}$-mediated AP notch in the RV epicardium of males versus females ${ }^{148}$ (Figs. 9 and 10). The more prominent $\mathrm{I}_{\text {to }}$ causes the end of phase 1 of the RV epicardial AP to repolarize to more negative potentials in tissue and arterially perfused wedge preparations from males, facilitating loss of the AP dome and the development of phase 2 reentry and polymorphic VT. 
The proposed cellular mechanism for the Brugada syndrome is summarized in Figure 11. The available data support the hypothesis that the Brugada syndrome results from amplification of heterogeneities intrinsic to the early phases of the AP among the different transmural cell types. The amplification is secondary to a rebalancing of currents active during phase 1, including a decrease in $\mathrm{I}_{\mathrm{Na}}$ or $\mathrm{I}_{\mathrm{Ca}}$, or augmentation of any one of a number of outward currents. ST-segment elevation similar to that observed in patients with the Brugada syndrome occurs as a consequence of the accentuation of the AP notch, eventually leading to loss of the AP dome in RV epicardium, where $\mathrm{I}_{\mathrm{to}}$ is most prominent. Loss of the dome gives rise to both a TDR as well as EDR. The transmural dispersion is responsible for the development of ST-segment elevation and the creation of a vulnerable window across the ventricular wall, whereas the epicardial dispersion gives to phase 2 reentry which provides the extrasystole that captures the vulnerable window, thus precipitating VT/VF. The VT generated is usually polymorphic, resembling a very rapid form of $\mathrm{TdP}$.

\section{Modulating Factors and Acquired Forms of Brugada Syndrome}

A number of factors modulate the electrocardiographic and arrhythmic manifestations of the Brugada syndrome. ST-segment elevation in the Brugada syndrome is often dynamic. The Brugada ECG may often be concealed, but can be unmasked or modulated by sodium channel blockers, a febrile state, vagotonic agents, $\alpha$-adrenergic agonists, $\beta$-adrenergic blockers, tricyclic or tetracyclic antidepressants, first generation antihistaminics (dimenhydrinate), a combination of glucose and insulin, hyperkalemia, hypokalemia, hypercalcemia, and by alcohol and cocaine toxicity (Fig. 12). $11-13,149-156$ These agents may also induce acquired forms of the Brugada syndrome (Table IV). Although a definitive list of drugs to avoid in the Brugada syndrome has not yet been formulated, the list of agents in Table IV may provide some guidance. One of the more recent additions to this group is Lithium. This widely used drug is a potent blocker of cardiac sodium channels and can unmask patients with the Brugada syndrome. 157

Myocardial infarction or acute ischemia due to vasospasm involving the RVOT mimics STsegment elevation similar to that in Brugada syndrome. This effect is secondary to the depression of $\mathrm{I}_{\mathrm{Ca}}$ and the activation of $\mathrm{I}_{\mathrm{K}-\mathrm{ATP}}$ during ischemia, and suggests that patients with congenital and possibly acquired forms of Brugada syndrome may be at a higher risk for ischemia-related sudden cardiac death. ${ }^{158}$ Although the coexistence of Brugada syndrome and vasospastic angina in the same patient is not rare, Chinushi et al. have failed to observe an enhanced susceptibility to VF nor a proarrhythmic effect of Ca-antagonist in this setting. ${ }^{159}$

VT/VF and sudden death in the Brugada syndrome usually occur at rest and at night. Circadian variation of sympathovagal balance, hormones, and other metabolic factors are likely to contribute to this circadian pattern. Bradycardia, due to altered sympathovagal balance or other factors, may contribute to arrhythmia initiation. ${ }^{32,160,161}$ Abnormal $^{123}$ I-MIBG uptake in 8 (17\%) of the 17 Brugada syndrome patients but none in the control group was demonstrated by Wichter et al. ${ }^{162}$ There was segmental reduction of ${ }^{123}$ I-MIBG in the inferior and the septal left ventricular wall, indicating presynaptic sympathetic dysfunction. Of note, imaging of the right ventricle, particularly the RVOT, is difficult with this technique, so that insufficient information is available concerning sympathetic function in the regions known to harbor the arrhythmogenic substrate. Moreover, it remains unclear what role the reduced uptake function plays in the arrhythmogenesis of the Brugada syndrome. If indeed the RVOT is similarly affected, this defect may indeed alter the symapthovagal balance in favor of the development of an arrhythmogenic substrate. ${ }^{106,129}$

Hypokalemia has been implicated as a contributing cause for the high prevalence of SUDS in the Northeastern region of Thailand where potassium deficiency is endemic. ${ }^{163155}$ Serum 
potassium in the Northeastern population is significantly lower than that of the population in Bangkok, which lies in the central part of Thailand where potassium is abundant in the food. A recent case report highlights the ability of hypokalemia to induce VF in a 60-year-old man who had asymptomatic Brugada syndrome, without a family history of sudden cardiac death. 155 This patient was initially treated for asthma by steroids, which lowered serum potassium from $3.8 \mathrm{mmol} / \mathrm{L}$ on admission to 3.4 and $2.9 \mathrm{mmol} / \mathrm{L}$ on the $7^{\text {th }}$ day and $8^{\text {th }}$ day of admission, respectively. Both were associated with unconsciousness. VF was documented during the last episode, which reverted spontaneously to sinus rhythm.

The Thai Ministry of Public Health Report (1990) found an association between a large meal of glutinous rice ("sticky rice") or carbohydrates ingested on the night of death in SUNDS patients. ${ }^{163}$ Consistent with this observation, a recent study by Nogami et al. found that glucose and insulin could unmask the Brugada ECG. ${ }^{154}$ Another possibility is that sudden death in these patients is due to the increased vagal tone produced by the stomach distention. A recent study by Ikeda et al. ${ }^{164}$ has shown that a full stomach after a large meal can unmask a Type I ECG, particularly in Brugada syndrome patients at high risks for arrhythmic events, thus suggesting that this technique may be of diagnostic and prognostic value.

Premature inactivation of the sodium channel in SCN5A mutations associated with the Brugada syndrome has been shown to be accentuated at higher temperatures, ${ }^{92}$ suggesting that a febrile state may unmask the Brugada syndrome. Indeed, several case reports have emerged recently, demonstrating that febrile illness could reveal the Brugada ECG and precipitate VF. ${ }^{14,93 \text {, }}$ 94,165-167 A recent report from Keller et al. ${ }^{168}$ has identified a missense mutation, F1344S, in SCN5A in a patient with Brugada syndrome and fever-induced VT/VF. Expression of F1344S showed a shift in the voltage-dependence of activation, which was further accentuated at high temperatures mimicking fever. Thus fever may also cause a loss of function in $\mathrm{I}_{\mathrm{Na}}$ by producing a shift in the voltage-dependence of activation.

Anecdotal data point to hot baths as a possible precipitating factor. Of note, the Northeastern part of Thailand, where the Brugada syndrome is most prevalent, is known for its very hot climate. A study is underway to assess whether this extreme climate influences the prognosis of the disease.

\section{Approach to Therapy}

\section{Device Therapy}

An ICD is the only proven effective device treatment for the disease (Table V). ${ }^{169,170}$

Recommendations for ICD implantation 5,6 are presented in Table VI (from reference 5 with permission) and summarized as follows:

(1) Symptomatic patients displaying the Type $1 \mathrm{ST}$-segment elevation or Brugada ECG (either spontaneously or after sodium channel blockade) who present with aborted sudden death should receive an ICD as a Class I indication without additional need for EPS. Similar patients presenting with related symptoms such as syncope, seizure, or nocturnal agonal respiration should also undergo ICD implantation as a Class I indication after non-cardiac causes of these symptoms have been carefully ruled out. EPS is recommended in symptomatic patients only for the assessment of supraventricular arrhythmia.

(2) Asymptomatic patients displaying a Brugada ECG (spontaneously or after sodium channel block) should undergo EPS if there is a family history of sudden cardiac death suspected to be due to Brugada syndrome. EPS may be justified when the family history is negative for sudden cardiac death if the Type 1 ST-segment elevation occurs spontaneously. If inducible for ventricular arrhythmia, the patient should receive an 
ICD. This was recommended as a Class IIa indication for patients presenting with a spontaneous Type I ST-segment elevation and as a Class IIb for patients who display a Type I ST-segment elevation only after sodium block challenge. More recent data (discussed above) have called these recommendations into question and suggest that it might be more appropriate to consider both as Class IIb indications.

Asymptomatic patients who have no family history and who develop a Type 1 ST-segment elevation only after sodium channel blockade should be closely followed-up. As additional data become available, these recommendations will no doubt require further fine-tuning.

Although arrhythmias and sudden cardiac death generally occur during sleep or at rest and have been associated with slow heart rates, a potential therapeutic role for cardiac pacing remains largely unexplored. Haissaguerre and co-workers ${ }^{171}$ reported that focal radiofrequency ablation aimed at eliminating the ventricular premature beats that trigger VT/ VF in the Brugada syndrome may be useful in controlling arrhythmogenesis. However, data relative to a cryosurgical approach or the use of ablation therapy are very limited at this point in time.

\section{Pharmacologic Approach to Therapy}

ICD implantation is the mainstay of therapy for the Brugada syndrome. Although feasible, implantation is challenging in infants and is not an adequate solution for patients residing in regions of the world where an ICD is unaffordable. A pharmacologic solution is desirable as an alternative to device therapy in these cases, as well as in minimizing the firing of the ICD in patients with frequent events. $5,61,172$

The quest for a pharmacologic treatment has been focused on rebalancing of the ion channel current active during the early phases of the epicardial AP in the right ventricle, so as to reduce the magnitude of the AP notch and/or restore the AP dome. Table V lists the various pharmacologic agents thus far investigated. Antiarrhythmic agents, such as amiodarone and $\beta$ blockers, have been shown to be ineffective. ${ }^{76}$ Class IC antiarrhythmic drugs (such as flecainide and propafenone) and Class IA agents, such as procainamide, are contraindicated because of their effects to unmask the Brugada syndrome and induce arrhythmogenesis. Disopyramide is a Class IA antiarrhythmic that has been demonstrated to normalize STsegment elevation in some Brugada patients but to unmask the syndrome in others. ${ }^{173}$

Because the presence of a prominent transient outward current, $\mathrm{I}_{\mathrm{to}}$, is fundamental to the mechanism underlying the Brugada syndrome, the most prudent general approach to therapy, regardless of the ionic or genetic basis for the disease, is to partially inhibit $\mathrm{I}_{\mathrm{to}}$. Cardioselective and $\mathrm{I}_{\mathrm{to}}$-specific blockers are not currently available. 4-aminopyridine is an agent that is ionchannel specific at low concentrations, but is not cardioselective in that it inhibits $\mathrm{I}_{\mathrm{to}}$ in the nervous system. Although it is effective in suppressing arrhythmogenesis in wedge models of the Brugada syndrome ${ }^{106}$ (Fig. 13), it is unlikely to be of clinical benefit because of neurally mediated adverse effects.

An agent currently on the market in the United States and other regions of the world with significant $\mathrm{I}_{\text {to }}$ blocking properties is quinidine. Accordingly, we suggested several years ago that this agent may be of therapeutic value in the Brugada syndrome. ${ }^{50}$ Quinidine has been shown to be effective in restoring the epicardial AP dome, thus normalizing the ST segment and preventing phase 2 reentry and polymorphic VT in experimental models of the Brugada syndrome (Fig. 13). ${ }^{106,174}$ Clinical evidence of the effectiveness of quinidine in normalizing ST-segment elevation in patients with the Brugada syndrome has been reported as well (Fig. 14). ${ }^{175-178}$ Quinidine has also been reported to be effective in suppressing arrhythmogenesis in an infant too young to receive an ICD. 40 
A prospective study of 25 Brugada syndrome patients orally administered quinidine bisulfate $(1483 \pm 240 \mathrm{mg})$, reported by Belhassen and Viskin, ${ }^{177}$ evaluated the effectiveness of quinidine in preventing inducible and spontaneous VF. There were 15 symptomatic patients ( 7 cardiac arrest survivors and 7 with unexplained syncope) and 10 asymptomatic patients. All 25 patients had inducible VF at baseline electrophysiological study. Quinidine prevented VF induction in 22 of the 25 patients (88\%). After a follow-up period of 6 months to 22.2 years, all patients were alive. Of 19 patients treated with oral quinidine for 6 to 219 months (56 \pm 67 months), none developed arrhythmic events. Administration of quinidine was associated with a $36 \%$ incidence of side effects, principally diarrhea, which resolved after drug discontinuation. The authors concluded that quinidine effectively suppresses VF induction as well as spontaneous arrhythmias in patients with Brugada syndrome, and may be useful as an adjunct to ICD therapy or as an alternative to ICD in cases in which an ICD is refused, is unaffordable, or under other circumstances in which ICD implantation is not feasible. These results are consistent with those reported for the same group in prior years 175,179 and more recently by other investigators. ${ }^{180-182}$ The study by Hermida and co-workers was the first to report the results of prospective, although relatively small, clinical trials. ${ }^{180}$ A recent relatively small study by Mizusawa et al. ${ }^{183}$ showed that low-dose quinidine $(300-600 \mathrm{mg})$ can prevent electrophysiologic induction of VF and has a potential as an adjunctive therapy for Brugada syndrome in patients with frequent ICD discharges. There is a clear need for a large, randomized, controlled clinical trial to assess the effectiveness of quinidine, preferably in patients with frequent events who have already received an ICD.

There is a clear need for a more cardioselective and $\mathrm{I}_{\mathrm{to}}$-specific blocker as an addition to the limited therapeutic armamentarium currently available to combat this disease. Another agent being considered for this purpose is the drug tedisamil, currently being evaluated for the treatment of atrial fibrillation. Tedisamil may be more potent than quinidine because it lacks the inward current blocking actions of quinidine, while potently blocking $\mathrm{I}_{\mathrm{to}}$. The effect of tedisamil to suppress phase 2 reentry and VT in a wedge model of the Brugada syndrome is illustrated in Figure 15. 184

Quinidine and tedisamil are both capable of suppressing the substrate and trigger for the Brugada syndrome via their inhibition of $\mathrm{I}_{\mathrm{to}}$. Both, however, also block $\mathrm{I}_{\mathrm{Kr}}$ and thus have the potential to induce an acquired form of the long-QT syndrome. Thus, these agents may substitute one form of polymorphic VT for another, particularly under conditions that promote $\mathrm{TdP}$, such as bradycardia and hypokalemia. This effect of quinidine is minimized at high plasma levels, because at these concentrations quinidine block of $\mathrm{I}_{\mathrm{Na}}$ counters the effect of $\mathrm{I}_{\mathrm{Kr}}$ block to increase TDR, the substrate for the development of TdP arrhythmias. ${ }^{84,185,186}$ High doses of quinidine (1,000-1,500 mg/day) are recommended in order to effect $\mathrm{I}_{\text {to }}$ block, without inducing TdP.

Another potential therapeutic candidate is an agent reported to be a relatively selective $\mathrm{I}_{\text {to }}$ and $\mathrm{I}_{\text {Kur }}$ blocker, AVE0118. ${ }^{187}$ Figure 16 shows the effect of AVE0118 to normalize the ECG and suppress phase 2 reentry in a wedge model of the Brugada syndrome. This drug has the advantage that it does not block $\mathrm{I}_{\mathrm{Kr}}$, and therefore does not prolong the QT interval or have the potential to induce TdP. The disadvantage of this particular drug is that it undergoes firstpass hepatic metabolism and is therefore not effective with oral administration.

Appropriate clinical trials are needed to establish the effectiveness of all of the above pharmacologic agents, as well as the possible role of pacemakers.

Agents that increase the calcium current, such as $\beta$-adrenergic agents like isoproterenol, are useful as well. ${ }^{106,131,137}$ Isoproterenol, sometimes in combination with quinidine, has been shown to be effective in normalizing ST-segment elevation in patients with the Brugada 


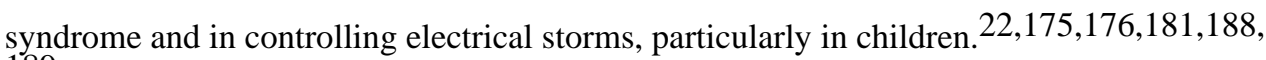
189 A recent addition to the pharmacological armamentarium is the phosphodiesterase III inhibitor, cilostazol, ${ }^{131}$ which normalizes the ST segment, most likely by augmenting calcium current $\left(\mathrm{I}_{\mathrm{Ca}}\right)$, as well as by reducing $\mathrm{I}_{\mathrm{to}}$ secondary to an increase in heart rate.

Another pharmacologic approach is to augment a component of $\mathrm{I}_{\mathrm{Na}}$ that is active during phase 1 of the epicardial AP. Dimethyl Lithospermate B (dmLSB) is an extract of Danshen, a traditional Chinese herbal remedy, which slows inactivation of $\mathrm{I}_{\mathrm{Na}}$, leading to increased inward current during the early phases of the AP. Figure 17 shows the effectiveness of dmLSB in eliminating the arrhythmogenic substrate responsible for the Brugada syndrome in three different experimental models of the syndrome. ${ }^{115}$ The Brugada syndrome phenotype was created in canine arterially perfused RV wedge preparations using either terfenadine or verapamil to inhibit $\mathrm{I}_{\mathrm{Na}}$ and $\mathrm{I}_{\mathrm{Ca}}$, or pinacidil to activate $\mathrm{I}_{\mathrm{K}-\mathrm{ATP}}$. Terfenadine, verapamil, and pinacidil each induced all-or-none repolarization at some epicardial sites but not others, leading to ST-segment elevation, as well as an increase in both EDR and TDR from $12.9 \pm 9.6 \mathrm{~ms}$ to $107.0 \pm 54.8 \mathrm{~ms}$ and $22.4 \pm 8.1 \mathrm{~ms}$ to $82.2 \pm 37.4 \mathrm{~ms}$, respectively $(\mathrm{P}<0.05, \mathrm{n}=9)$. Under these conditions, phase 2 reentry developed, as the epicardial AP dome propagated from sites where it was maintained to sites at which it was lost, generating closely coupled extrasystoles and VT/VF. Addition of dmLSB $(10 \mu \mathrm{M})$ to the coronary perfusate restored the epicardial AP dome, reduced both EDR and TDR, and abolished phase 2 reentry-induced extrasystoles and VT/VF in $9 / 9$ preparations. Our data suggest that dmLSB may be a candidate for pharmacologic treatment of Brugada syndrome in cases in which an ICD is not feasible or affordable, or as an adjunct to ICD use.

\section{Acknowledgements}

Supported by grant HL47678 from NHLBI and NYS and Florida Grand Lodge F. \& A. M.

\section{References}

1. Brugada P, Brugada J. Right bundle branch block, persistent ST segment elevation and sudden cardiac death: A distinct clinical and electrocardiographic syndrome: A multicenter report. J Am Coll Cardiol 1992;20:1391-1396. [PubMed: 1309182]

2. Antzelevitch C, Brugada P, Brugada J, Brugada R, Shimizu W, Gussak I, Perez Riera AR. Brugada syndrome. A decade of progress. Circ Res 2002;91:1114-1119. [PubMed: 12480811]

3. Wilde AA, Antzelevitch C, Borggrefe M, et al. Proposed diagnostic criteria for the Brugada syndrome: Consensus report. Eur Heart J 2002;23:1648-1654. [PubMed: 12448445]

4. Wilde AA, Antzelevitch C, Borggrefe M, et al. Proposed diagnostic criteria for the Brugada syndrome: Consensus report. Circulation 2002;106:2514-2519. [PubMed: 12417552]

5. Antzelevitch C, Brugada P, Borggrefe M, et al. Brugada syndrome. Report of the second consensus conference. Endorsed by the Heart Rhythm Society and the European Heart Rhythm Association. Circulation 2005;111:659-670. [PubMed: 15655131]

6. Antzelevitch C, Brugada P, Borggrefe M, et al. Brugada syndrome: Report of the second consensus conference. Heart Rhythm 2005;2:429-440. [PubMed: 15898165]

7. Skinner JR, Chung SK, Montgomery D, McCulley CH, Crawford J, French J, Rees MI. Near-miss SIDS due to Brugada syndrome. Arch Dis Child 2005;90:528-529. [PubMed: 15851440]

8. Brugada, P.; Brugada, R.; Antzelevitch, C.; Nademanee, K.; Towbin, J.; Brugada, J. The Brugada syndrome. In: Gussak, I.; Antzelevitch, C., editors. Cardiac Repolarization Bridging Basic and Clinical Sciences. Totowa, NJ: Humana Press; 2003. p. 427-446.

9. Nademanee K. Sudden unexplained death syndrome in southeast Asia. Am J Cardiol 1997;79(6A): 10-11. [PubMed: 9080856]

10. Vatta M, Dumaine R, Varghese G, et al. Genetic and biophysical basis of sudden unexplained nocturnal death syndrome (SUNDS), a disease allelic to Brugada syndrome. Hum Mol Genet 2002;11:337-345. [PubMed: 11823453] 
11. Brugada P, Brugada J, Brugada R. Arrhythmia induction by antiarrhythmic drugs. Pacing Clin Electrophysiol 2000;23:291-292. [PubMed: 10750126]

12. Brugada R, Brugada J, Antzelevitch C, Kirsch GE, Potenza D, Towbin JA, Brugada P. Sodium channel blockers identify risk for sudden death in patients with ST-segment elevation and right bundle branch block but structurally normal hearts. Circulation 2000;101:510-515. [PubMed: 10662748]

13. Miyazaki T, Mitamura H, Miyoshi S, Soejima K, Aizawa Y, Ogawa S. Autonomic and antiarrhythmic drug modulation of ST segment elevation in patients with Brugada syndrome. J Am Coll Cardiol 1996;27:1061-1070. [PubMed: 8609322]

14. Antzelevitch C, Brugada R. Fever and the Brugada syndrome. Pacing Clin Electrophysiol 2002;25:1537-1539. [PubMed: 12494608]

15. Shimizu W, Antzelevitch C, Suyama K, et al. Effect of sodium channel blockers on ST segment, QRS duration, and corrected QT interval in patients with Brugada syndrome. J Cardiovasc Electrophysiol 2000;11:1320-1329. [PubMed: 11196553]

16. Priori SG, Napolitano C, Gasparini M, et al. Clinical and genetic heterogeneity of right bundle branch block and ST-segment elevation syndrome: A prospective evaluation of 52 families. Circulation 2000;102:2509-2515. [PubMed: 11076825]

17. Wolpert $C$, Echternach $C$, Veltmann $C$, et al. Intravenous drug challenge using flecainide and ajmaline in patients with Brugada syndrome. Heart Rhythm 2005;2:254-260. [PubMed: 15851314]

18. Gurevitz O, Glikson M. Cardiac resynchronization therapy: A new frontier in the management of heart failure. Isr Med Assoc J 2003;5:571-575. [PubMed: 12929296]

19. Kalla H, Yan GX, Marinchak R. Ventricular fibrillation in a patient with prominent J (Osborn) waves and ST segment elevation in the inferior electrocardiographic leads: A Brugada syndrome variant? J Cardiovasc Electrophysiol 2000;11:95-98. [PubMed: 10695469]

20. Ogawa M, Kumagai K, Yamanouchi Y, Saku K. Spontaneous onset of ventricular fibrillation in Brugada syndrome with J wave and ST-segment elevation in the inferior leads. Heart Rhythm 2005;2:97-99. [PubMed: 15851273]

21. Horigome H, Shigeta O, Kuga K, Isobe T, Sakakibara Y, Yamaguchi I, Matsui A. Ventricular fibrillation during anesthesia in association with $\mathrm{J}$ waves in the left precordial leads in a child with coarctation of the aorta. J Electrocardiol 2003;36:339-343. [PubMed: 14661171]

22. Shimizu W, Matsuo K, Takagi M, et al. Body surface distribution and response to drugs of ST segment elevation in Brugada syndrome: Clinical implication of eighty-seven-lead body surface potential mapping and its application to twelve-lead electrocardiograms. J Cardiovasc Electrophysiol 2000;11:396-404. [PubMed: 10809492]

23. Sangwatanaroj S, Prechawat S, Sunsaneewitayakul B, Sitthisook S, Tosukhowong P, Tungsanga K. New electrocardiographic leads and the procainamide test for the detection of the Brugada sign in sudden unexplained death syndrome survivors and their relatives. Eur Heart J 2001;22:2290-2296. [PubMed: 11728150]

24. Shin SC, Ryu S, Lee JH, et al. Prevalence of the Brugada-type ECG recorded from higher intercostal spaces in healthy Korean males. Circ J 2005;69:1064-1067. [PubMed: 16127187]

25. Alings M, Wilde A. "Brugada" syndrome: Clinical data and suggested pathophysiological mechanism. Circulation 1999;99:666-673. [PubMed: 9950665]

26. Bezzina C, Veldkamp MW, van Den Berg MP, et al. A single $\mathrm{Na}(+)$ channel mutation causing both long-QT and Brugada syndromes. Circ Res 1999;85:1206-1213. [PubMed: 10590249]

27. Pitzalis MV, Anaclerio M, Iacoviello M, et al. QT-interval prolongation in right precordial leads: An additional electrocardiographic hallmark of Brugada syndrome. J Am Coll Cardiol 2003;42:16321637. [PubMed: 14607451]

28. Castro Hevia J, Antzelevitch C, Tornes Bárzaga F, Dorantes Sanche M, Dorticos Balea F, Zayas Molina R, Qvinones Perez MA, Rodriguezy Faya. Tpeak-Tend and Tpeak-Tend dispersion as risk factors for Ventricular tachycardia/ventricular fibrillation in patients with the Brugada syndrome. $\mathrm{J}$ Am Coll Cardiol 2006;47:1828-34. [PubMed: 16682308]

29. Smits JP, Eckardt L, Probst V, et al. Genotype-phenotype relationship in Brugada syndrome: Electrocardiographic features differentiate SCN5A-related patients from non-SCN5A-related patients. J Am Coll Cardiol 2002;40:350-356. [PubMed: 12106943] 
30. Morita H, Kusano-Fukushima K, Nagase S, et al. Atrial fibrillation and atrial vulnerability in patients with Brugada syndrome. J Am Coll Cardiol 2002;40:1437-1444. [PubMed: 12392834]

31. Takehara N, Makita N, Kawabe J, Sato N, Kawamura Y, Kitabatake A, Kikuchi K. A cardiac sodium channel mutation identified in Brugada syndrome associated with atrial standstill. J Intern Med 2004;255:137-142. [PubMed: 14687250]

32. Kasanuki H, Ohnishi S, Ohtuka M, et al. Idiopathic ventricular fibrillation induced with vagal activity in patients without obvious heart disease. Circulation 1997;95:2277-2285. [PubMed: 9142005]

33. Proclemer A, Facchin D, Feruglio GA, Nucifora R. Recurrent ventricular fibrillation, right bundlebranch block and persistent ST segment elevation in V1-V3: A new arrhythmia syndrome? A clinical case report. G Ital Cardiol 1993;23:1211-1218. [PubMed: 8174872]see comments

34. Makiyama T, Akao M, Tsuji K, et al. High risk for bradyarrhythmic complications in patients with Brugada syndrome caused by SCN5A gene mutations. J Am Coll Cardiol 2005;46:2100-2106. [PubMed: 16325048]

35. Scornik FS, Desai M, Brugada R, Guerchicoff A, Pollevick GD, Antzelevitch C, Perez GJ. Functional expression of "cardiac-type" $\mathrm{Na}(\mathrm{v}) 1.5$ sodium channel in canine intracardiac ganglia. Heart Rhythm 2006;3:842-850. [PubMed: 16818219]

36. Shimada M, Miyazaki T, Miyoshi S, Soejima K, Hori S, Mitamura H, Ogawa S. Sustained monomorphic ventricular tachycardia in a patient with Brugada syndrome. Jpn Circ J 1996;60:364370. [PubMed: 8844303]

37. Pinar BE, Garcia-Alberola A, Martinez SJ, Sanchez Munoz JJ, Valdes CM. Spontaneous sustained monomorphic ventricular tachycardia after administration of ajmaline in a patient with Brugada syndrome. Pacing Clin Electrophysiol 2000;23:407-409. [PubMed: 10750146]see comments

38. Dinckal MH, Davutoglu V, Akdemir I, Soydinc S, Kirilmaz A, Aksoy M. Incessant monomorphic ventricular tachycardia during febrile illness in a patient with Brugada syndrome: Fatal electrical storm. Europace 2003;5:257-261. [PubMed: 12842640]

39. Mok NS, Chan NY. Brugada syndrome presenting with sustained monomorphic ventricular tachycardia1. Int J Cardiol 2004;97:307-309. [PubMed: 15458701]

40. Probst V, Evain S, Gournay V, Marie A, Schott JJ, Boisseau P, Le MH. Monomorphic ventricular tachycardia due to brugada syndrome successfully treated by hydroquinidine therapy in a 3-year-old child. J Cardiovasc Electrophysiol 2006;17:97-100. [PubMed: 16426410]

41. Sastry BK, Narasimhan C, Soma RB. Brugada syndrome with monomorphic ventricular tachycardia in a one-year-old child. Indian Heart J 2001;53:203-205. [PubMed: 11428478]

42. Bjerregaard P, Gussak I, Kotar SL, Gessler JE. Recurrent syncope in a patient with prominent J-wave. Am Heart J 1994;127:1426-1430. [PubMed: 8172079]

43. Sugai MA. Pathological study on sudden and unexpected death, especially on the cardiac death autopsied by medical examiners in Tokyo. Acta Pathol Jpn 1959;9(Suppl):723-752. [PubMed: 13918176]

44. Nademanee K, Veerakul G, Nimmannit S, et al. Arrhythmogenic marker for the sudden unexplained death syndrome in Thai men. Circulation 1997;96:2595-2600. [PubMed: 9355899]

45. Corrado D, Nava A, Buja G, et al. Familial cardiomyopathy underlies syndrome of right bundle branch block, ST segment elevation and sudden death. J Am Coll Cardiol 1996;27:443-448. [PubMed: 8557918]

46. Corrado D, Basso C, Buja G, Nava A, Rossi L, Thiene G. Right bundle branch block, right precordial ST-segment elevation, and sudden death in young people. Circulation 2001;103:710-717. [PubMed: 11156883]

47. Frustaci A, Priori SG, Pieroni M, et al. Cardiac histological substrate in patients with clinical phenotype of Brugada syndrome. Circulation 2005;112:3680-3687. [PubMed: 16344400]

48. Thiene G, Basso C, Calabrese F, Angelini A, Valente M. Twenty years of progress and beckoning frontiers in cardiovascular pathology. Cardiovasc Pathol 2005;14:165-169. [PubMed: 16009312]

49. Saffitz JE. Structural heart disease, SCN5A gene mutations, and Brugada syndrome: A complex menage a trois. Circulation 2005;112:3672-3674. [PubMed: 16344397]

50. Antzelevitch, C.; Brugada, P.; Brugada, J.; Brugada, R.; Nademanee, K.; Towbin, JA. The Brugada Syndrome. Armonk, NY: Futura Publishing Company, Inc; 1999. Clinical Approaches to Tachyarrhythmias. 
51. Royer A, van Veen TA, Le BS, et al. Mouse model of SCN5A-linked hereditary Lenegre's disease: Age-related conduction slowing and myocardial fibrosis. Circulation 2005;111:1738-1746. [PubMed: 15809371]

52. Bezzina CR, Rook MB, Groenewegen WA, et al. Compound heterozygosity for mutations (W156X and $\mathrm{R} 225 \mathrm{~W}$ ) in SCN5A associated with severe cardiac conduction disturbances and degenerative changes in the conduction system. Circ Res 2003;92:159-168. [PubMed: 12574143]

53. Antzelevitch C. Brugada syndrome: Historical perspectives and observations. Eur Heart J 2002;23:676-678. [PubMed: 11969284]

54. Remme CA, Wever EFD, Wilde AAM, Derksen R, Hauer RNW. Diagnosis and long-term followup of Brugada syndrome in patients with idiopathic ventricular fibrillation. Eur Heart J 2001;22:400409. [PubMed: 11207082]

55. Perez Riera AR, Antzelevitch C, Schapacknik E, Dubner S, Ferreira C. Is there an overlap between Brugada syndrome and arrhythmogenic right ventricular cardiomyopathy/dysplasia? J Electrocardiol 2005;38:260-263. [PubMed: 16003713]

56. Antzelevitch C, Brugada P, Brugada J, Brugada R. The Brugada syndrome. From cell to bedside. Curr Probl Cardiol 2005;30:9-54. [PubMed: 15627121]

57. Weiss R, Barmada MM, Nguyen T, et al. Clinical and molecular heterogeneity in the Brugada syndrome. A novel gene locus on chromosome 3. Circulation 2002;105:707-713. [PubMed: 11839626]

58. Ahmad F, Li D, Karibe A, et al. Localization of a gene responsible for arrhythmogenic right ventricular dysplasia to chromosome 3p23. Circulation 1998;98:2791-2795. [PubMed: 9860777]

59. Takagi M, Aihara N, Kuribayashi S, et al. Localized right ventricular morphological abnormalities detected by electron-beam computed tomography represent arrhythmogenic substrates in patients with the Brugada syndrome. Eur Heart J 2001;22:1032-1041. [PubMed: 11428838]

60. Antzelevitch C. Late potentials and the Brugada syndrome. J Am Coll Cardiol 2002;39:1996-1999. [PubMed: 12084599]

61. Antzelevitch, C.; Brugada, P.; Brugada, J.; Brugada, R. The Brugada Syndrome: From Bench to Bedside. Oxford: Blackwell Futura; 2005.

62. Papavassiliu T, Wolpert C, Fluchter S, et al. Magnetic resonance imaging findings in patients with Brugada syndrome. J Cardiovasc Electrophysiol 2004;15:1133-1138. [PubMed: 15485435]

63. Bartelings MM, Gittenbergerde Groot AC. The outflow tract of the heart-Embryologic and morphologic correlations. Int J Cardiol 1989;22:289-300. [PubMed: 2651326]

64. Kirby ML, Gale TF, Stewart DE. Neural crest cells contribute to normal aorticopulmonary septation. Science 1983;220:1059-1061. [PubMed: 6844926]

65. Gittenbergerde Groot AC, Bartelings MM, DeRuiter MC, Poelmann RE. Basics of cardiac development for the understanding of congenital heart malformations. Pediatr Res 2005;57:169-176. [PubMed: 15611355]

66. Ewart JL, Cohen MF, Meyer RA, et al. Heart and neural tube defects in transgenic mice overexpressing the Cx43 gap junction gene. Development 1997;124:1281-1292. [PubMed: 9118799]

67. Reaume AG, De Sousa PA, Kulkarni S, et al. Cardiac malformation in neonatal mice lacking connexin43. Science 1995;267:1831-1834. [PubMed: 7892609]

68. Liu F, Shneider A, Liu S, Shah B, St Amand T, Epstein AE, Gutstein DE. Loss of Connexin43 in the neural tube leads to a late phase of delamination and migration of neural tube cells and cardiac abnormalities. Proceedings of Keystone Symposium: "Molecular Mechanisms of Cardiac Disease and Regeneration". 2006 abstractin press

69. Brugada J, Brugada R, Antzelevitch C, Towbin J, Nademanee K, Brugada P. Long-term follow-up of individuals with the electrocardiographic pattern of right bundle-branch block and ST-segment elevation in precordial leads V(1) to V(3). Circulation 2002;105:73-78. [PubMed: 11772879]

70. Priori SG, Napolitano C, Gasparini M, et al. Natural history of Brugada syndrome: Insights for risk stratification and management. Circulation 2002;105:1342-1347. [PubMed: 11901046]

71. Brugada P, Brugada R, Brugada J. Patients with an asymptomatic Brugada electrocardiogram should undergo pharmacological and electrophysical testing. Circulation 2005;112:279-285. [PubMed: 16009809] 
72. Priori SG, Napolitano C. Management of patients with Brugada syndrome should not be based on programmed electrical stimulation. Circulation 2005;112:285-291.

73. Eckardt L, Probst V, Smits JP, et al. Long-term prognosis of individuals with right precordial STsegment-elevation Brugada syndrome. Circulation 2005;111:257-263. [PubMed: 15642768]

74. Atarashi H, Ogawa S, for the Idiopathic Ventricular Fibrillation Investigators. New ECG criteria for high-risk Brugada syndrome. Circ J 2003;67:8-10. [PubMed: 12520143]

75. Morita H, Takenaka-Morita S, Fukushima-Kusano K, et al. Risk stratification for asymptomatic patients with brugada syndrome. Circ J 2003;67:312-316. [PubMed: 12655161]

76. Brugada J, Brugada R, Brugada P. Right bundle-branch block and ST-segment elevation in leads $\mathrm{V}_{1}$ through $\mathrm{V}_{3}$. A marker for sudden death in patients without demonstrable structural heart disease. Circulation 1998;97:457-460. [PubMed: 9490240]

77. Kanda M, Shimizu W, Matsuo K, et al. Electrophysiologic characteristics and implications of induced ventricular fibrillation in symptomatic patients with Brugada syndrome. J Am Coll Cardiol 2002;39:1799-1805. [PubMed: 12039494]

78. Brugada J, Brugada R, Brugada P. Determinants of sudden cardiac death in individuals with the electrocardiographic pattern of Brugada syndrome and no previous cardiac arrest. Circulation 2003;108:3092-3096. [PubMed: 14623800]

79. Eckardt L, Kirchhof P, Johna R, Haverkamp W, Breithardt G, Borggrefe M. Wolff-Parkinson-White syndrome associated with Brugada syndrome. Pacing Clin Electrophysiol 2001;24:1423-1424. [PubMed: 11584469]

80. Carlsson J, Erdogan A, Schulte B, Neuzner J, Pitschner HF. Possible role of epicardial left ventricular programmed stimulation in Brugada syndrome. Pacing Clin Electrophysiol 2001;24:247-249. [PubMed: 11270709]

81. Gehi AK, Duong TD, Metz LD, Gomes JA, Mehta D. Risk stratification of individuals with the brugada electrocardiogram: A meta-analysis. J Cardiovasc Electrophysiol 2006;17:577-583. [PubMed: 16836701]

82. Antzelevitch C. Tpeak-Tend interval as an index of transmural dispersion of repolarization. Eur J Clin Invest 2001;31:555-557. [PubMed: 11454006]

83. Yan GX, Antzelevitch C. Cellular basis for the normal T wave and the electrocardiographic manifestations of the long QT syndrome. Circulation 1998;98:1928-1936. [PubMed: 9799215]

84. Antzelevitch C, Shimizu W, Yan GX, et al. The M cell: Its contribution to the ECG and to normal and abnormal electrical function of the heart. J Cardiovasc Electrophysiol 1999;10:1124-1152. [PubMed: 10466495]

85. Fish JM, Di Diego JM, Nesterenko VV, Antzelevitch C. Epicardial activation of left ventricular wall prolongs QT interval and transmural dispersion of repolarization: Implications for biventricular pacing. Circulation 2004;109:2136-2142. [PubMed: 15078801]

86. Emori T, Antzelevitch C. Cellular basis for complex T waves and arrhythmic activity following combined I(Kr) and I(Ks) block. J Cardiovasc Electrophysiol 2001;12:1369-1378. [PubMed: 11797994]

87. Watanabe N, Kobayashi Y, Tanno K, et al. Transmural dispersion of repolarization and ventricular tachyarrhythmias. J Electrocardiol 2004;37:191-200. [PubMed: 15286932]

88. Milberg P, Reinsch N, Wasmer K, et al. Transmural dispersion of repolarization as a key factor of arrhythmogenicity in a novel intact heart model of LQT3. Cardiovasc Res 2005;65:397-404. [PubMed: 15639478]

89. Shimizu M, Ino H, Okeie K, et al. T-peak to T-end interval may be a better predictor of high-risk patients with hypertrophic cardiomyopathy associated with a cardiac troponin I mutation than QT dispersion. Clin Cardiol 2002;25:335-339. [PubMed: 12109867]

90. Chen Q, Kirsch GE, Zhang D, et al. Genetic basis and molecular mechanisms for idiopathic ventricular fibrillation. Nature 1998;392:293-296. [PubMed: 9521325]

91. Grant AO, Carboni MP, Neplioueva V, Starmer CF, Memmi M, Napolitano C, Priori SG. Long QT syndrome, Brugada syndrome, and conduction system disease are linked to a single sodium channel mutation. J Clin Invest 2002;110:1201-1209. [PubMed: 12393856] 
92. Dumaine R, Towbin JA, Brugada P, et al. Ionic mechanisms responsible for the electrocardiographic phenotype of the Brugada syndrome are temperature dependent. Circ Res 1999;85:803-809. [PubMed: 10532948]

93. Saura D, Garcia-Alberola A, Carrillo P, Pascual D, Martinez-Sanchez J, Valdes M. Brugada-like electrocardiographic pattern induced by fever. Pacing Clin Electrophysiol 2002;25:856-859. [PubMed: 12049381]

94. Porres JM, Brugada J, Urbistondo V, Garcia F, Reviejo K, Marco P. Fever unmasking the Brugada syndrome. Pacing Clin Electrophysiol 2002;25:1646-1648. [PubMed: 12494626]

95. Mok NS, Priori SG, Napolitano C, Chan NY, Chahine M, Baroudi G. A newly characterized SCN5A mutation underlying Brugada syndrome unmasked by hyperthermia. J Cardiovasc Electrophysiol 2003;14:407-411. [PubMed: 12741714]

96. Ortega-Carnicer J, Benezet J, Ceres F. Fever-induced ST-segment elevation and T-wave alternans in a patient with Brugada syndrome. Resuscitation 2003;57:315-317. [PubMed: 12804811]

97. Patruno N, Pontillo D, Achilli A, Ruggeri G, Critelli G. Electrocardiographic pattern of Brugada syndrome disclosed by a febrile illness: Clinical and therapeutic implications. Europace 2003;5:251255. [PubMed: 12842639]

98. Peng J, Cui YK, Yuan FH, Yi SD, Chen ZM, Meng SR. Fever and Brugada syndrome: Report of 21 cases. Di Yi Jun Yi Da Xue Xue Bao 2005;25:432-434. [PubMed: 15837648]

99. Dulu A, Pastores SM, McAleer E, Voigt L, Halpern NA. Brugada electrocardiographic pattern in a postoperative patient. Crit Care Med 2005;33:1634-1637. [PubMed: 16003074]

100. Aramaki K, Okumura H, Shimizu M. Chest pain and ST elevation associated with fever in patients with asymptomatic Brugada syndrome fever and chest pain in Brugada syndrome. Int J Cardiol 2005;103:338-339. [PubMed: 16098400]

101. Schulze-Bahr E, Eckardt L, Breithardt G, et al. Sodium channel gene (SCN5A) mutations in 44 index patients with Brugada syndrome: Different incidences in familial and sporadic disease. Hum Mutat 2003;21:651-652. [PubMed: 14961552]

102. Hong K, Guerchicoff A, Pollevick GD, et al. Cryptic 5' splice site activation in SCN5A associated with Brugada syndrome. J Mol Cell Cardiol 2005;38:555-560. [PubMed: 15808832]

103. Bezzina CR, Shimizu W, Yang P, et al. Common sodium channel promoter haplotype in Asian subjects underlies variability in cardiac conduction. Circulation 2006;113:338-344. [PubMed: 16415376]

104. London B, Sanyal S, Michalec M, et al. AB16-1: A mutation in the glycerol-3-phosphate dehydrogenase 1-like gene (GPD1L) causes Brugada syndrome. Heart Rhythm 2006;3:S32.abstract

105. Yan GX, Antzelevitch C. Cellular basis for the electrocardiographic J wave. Circulation 1996;93:372-379. [PubMed: 8548912]

106. Yan GX, Antzelevitch C. Cellular basis for the Brugada syndrome and other mechanisms of arrhythmogenesis associated with ST segment elevation. Circulation 1999;100:1660-1666. [PubMed: 10517739]

107. Fish JM, Antzelevitch C. Role of sodium and calcium channel block in unmasking the Brugada syndrome. Heart Rhythm 2004;1:210-217. [PubMed: 15851155]

108. Fish JM, Antzelevitch C. Cellular and ionic basis for the sex-related difference in the manifestation of the Brugada syndrome and progressive conduction disease phenotypes. J Electrocardiol 2003;36:173-179. [PubMed: 14716629]

109. Antzelevitch C, Fish J. Electrical heterogeneity within the ventricular wall. Basic Res Cardiol 2001;96:517-527. [PubMed: 11770069]

110. Gima K, Rudy Y. Ionic current basis of electrocardiographic waveforms: A model study. Circ Res 2002;90:889-896. [PubMed: 11988490]

111. Kurita T, Shimizu W, Inagaki M, et al. The electrophysiologic mechanism of ST-segment elevation in Brugada syndrome. J Am Coll Cardiol 2002;40:330-334. [PubMed: 12106940]

112. Yan GX, Lankipalli RS, Burke JF, Musco S, Kowey PR. Ventricular repolarization components on the electrocardiogram: Cellular basis and clinical significance. J Am Coll Cardiol 2003;42:401409. [PubMed: 12906963]

113. Antzelevitch C. Modulation of transmural repolarization. Ann N Y Acad Sci 2005;1047:314-323. [PubMed: 16093507] 
114. Fish JM, Antzelevitch C. Link between hypothermia and the Brugada syndrome. J Cardiovasc Electrophysiol 2004;15:942-944. [PubMed: 15333092]

115. Fish JM, Welchons D, Kim YS, Lee SH, Ho WK, Antzelevitch C. Dimethyl lithospermate B, an extract of Danshen, suppresses arrhythmogenesis associated with the Brugada syndrome. Circulation 2006;113:1393-400. [PubMed: 16534004]

116. Litovsky SH, Antzelevitch C. Rate dependence of action potential duration and refractoriness in canine ventricular endocardium differs from that of epicardium: Role of the transient outward current. J Am Coll Cardiol 1989;14:1053-1066. [PubMed: 2551947]

117. Kilborn MJ, Fedida D. A study of the developmental changes in outward currents of rat ventricular myocytes. J Physiol (Lond) 1990;430:37-60. [PubMed: 2086767]

118. Furukawa Y, Akahane K, Ogiwara Y, Chiba S. K+-Channel blocking and anti-muscarinic effects of a novel piperazine derivative, INO 2628, on the isolated dog atrium. Eur J Pharm 1991;193:217222.

119. Lukas A, Antzelevitch C. Phase 2 reentry as a mechanism of initiation of circus movement reentry in canine epicardium exposed to simulated ischemia. Cardiovasc Res 1996;32:593-603. [PubMed: 8881520]

120. Di Diego JM, Antzelevitch C. Pinacidil-induced electrical heterogeneity and extrasystolic activity in canine ventricular tissues. Does activation of ATP-regulated potassium current promote phase 2 reentry? Circulation 1993;88:1177-1189. [PubMed: 7689041]

121. Krishnan SC, Antzelevitch C. Flecainide-induced arrhythmia in canine ventricular epicardium. Phase 2 reentry? Circulation 1993;87:562-572. [PubMed: 8425300]

122. Di Diego JM, Antzelevitch C. High $\left[\mathrm{Ca}^{2+}\right]$-induced electrical heterogeneity and extrasystolic activity in isolated canine ventricular epicardium. Phase 2 reentry. Circulation 1994;89:1839-1850. [PubMed: 7511994]

123. Antzelevitch, C.; Sicouri, S.; Lukas, A., et al. Clinical implications of electrical heterogeneity in the heart: The electrophysiology and pharmacology of epicardial, M, and endocardial cells. In: Podrid, PJ.; Kowe, PR., editors. Cardiac Arrhythmia: Mechanism, Diagnosis and Management. Baltimore, MD: William \& Wilkins; 1995. p. 88-107.

124. Aizawa Y, Tamura M, Chinushi M, et al. Idiopathic ventricular fibrillation and bradycardiadependent intraventricular block. Am Heart J 1993;126:1473-1474. [PubMed: 8249808]

125. Aizawa Y, Tamura M, Chinushi M, et al. An attempt at electrical catheter ablation of the arrhythmogenic area in idiopathic ventricular fibrillation. Am Heart J 1992;123:257-260. [PubMed: 1729844]

126. Lukas A, Antzelevitch C. Differences in the electrophysiological response of canine ventricular epicardium and endocardium to ischemia: Role of the transient outward current. Circulation 1993;88:2903-2915. [PubMed: 8252704]

127. Thomsen PE, Joergensen RM, Kanters JK, et al. Phase 2 reentry in man. Heart Rhythm 2005;2:797803. [PubMed: 16051112]

128. Antzelevitch C. In vivo human demonstration of phase 2 reentry. Heart Rhythm 2005;2:804-806. [PubMed: 16051113]

129. Litovsky SH, Antzelevitch C. Differences in the electrophysiological response of canine ventricular subendocardium and subepicardium to acetylcholine and isoproterenol. A direct effect of acetylcholine in ventricular myocardium. Circ Res 1990;67:615-627. [PubMed: 2397572]

130. Krishnan SC, Antzelevitch C. Sodium channel block produces opposite electrophysiological effects in canine ventricular epicardium and endocardium. Circ Res 1991;69:277-291. [PubMed: 1650294]

131. Tsuchiya T, Ashikaga K, Honda T, Arita M. Prevention of ventricular fibrillation by cilostazol, an oral phosphodiesterase inhibitor, in a patient with Brugada syndrome. J Cardiovasc Electrophysiol 2002;13:698-701. [PubMed: 12139296]

132. Di Diego JM, Sun ZQ, Antzelevitch C. $\mathrm{I}_{\text {to }}$ and action potential notch are smaller in left vs. right canine ventricular epicardium. Am J Physiol 1996;271:H548-H561. [PubMed: 8770096]

133. Pertsov AM, Davidenko JM, Salomonsz R, Baxter WT, Jalife J. Spiral waves of excitation underlie reentrant activity in isolated cardiac muscle. Circ Res 1993;72:631-650. [PubMed: 8431989] 
134. Asano Y, Davidenko JM, Baxter WT, Gray RA, Jalife J. Optical mapping of drug-induced polymorphic arrhythmias and torsade de pointes in the isolated rabbit heart. J Am Coll Cardiol 1997;29:831-842. [PubMed: 9091531]

135. Tukkie R, Sogaard P, Vleugels J, De Groot IK, Wilde AA, Tan HL. Delay in right ventricular activation contributes to Brugada syndrome. Circulation 2004:1272-1277. [PubMed: 14993143]

136. Antzelevitch, C.; Fish, J.; Di Diego, JM. Cellular mechanisms underlying the Brugada syndrome. In: Antzelevitch, C.; Brugada, P.; Brugada, J.; Brugada, R., editors. The Brugada Syndrome: From Bench to Bedside. Oxford: Blackwell Futura; 2004. p. 52-77.

137. Antzelevitch $\mathrm{C}$. The Brugada syndrome: Ionic basis and arrhythmia mechanisms. J Cardiovasc Electrophysiol 2001;12:268-272. [PubMed: 11232628]

138. Antzelevitch C. The Brugada syndrome: Diagnostic criteria and cellular mechanisms. Eur Heart J 2001;22:356-363. [PubMed: 11207076]

139. Gussak I, Antzelevitch C, Bjerregaard P, Towbin JA, Chaitman BR. The Brugada syndrome: Clinical, electrophysiologic, and genetic aspects. J Am Coll Cardiol 1999;33:5-15. [PubMed: 9935001]

140. Shimizu W, Aiba T, Kamakura S. Mechanisms of disease: Current understanding and future challenges in Brugada syndrome. Nat Clin Pract Cardiovasc Med 2005;2:408-414. [PubMed: 16119703]

141. Futterman LG, Lemberg L. Brugada. Am J Crit Care 2001;10:360-364. [PubMed: 11548570]

142. Fujiki A, Usui M, Nagasawa H, Mizumaki K, Hayashi H, Inoue H. ST segment elevation in the right precordial leads induced with class IC antiarrhythmic drugs: Insight into the mechanism of Brugada syndrome. J Cardiovasc Electrophysiol 1999;10:214-218. [PubMed: 10090224]

143. Nagase S, Kusano KF, Morita H, et al. Epicardial electrogram of the right ventricular outflow tract in patients with the Brugada syndrome: Using the epicardial lead. J Am Coll Cardiol 2002;39:19921995. [PubMed: 12084598]

144. Eckardt L, Bruns HJ, Paul M, et al. Body surface area of ST elevation and the presence of late potentials correlate to the inducibility of ventricular tachyarrhythmias in Brugada syndrome. $\mathrm{J}$ Cardiovasc Electrophysiol 2002;13:742-749. [PubMed: 12212690]

145. Ikeda T, Takami M, Sugi K, Mizusawa Y, Sakurada H, Yoshino H. Noninvasive risk stratification of subjects with a Brugada-type electrocardiogram and no history of cardiac arrest. Ann Noninvasive Electrocardiol 2005;10:396-403. [PubMed: 16255748]

146. Shimizu W, Aiba T, Kurita T, Kamakura S. Paradoxic abbreviation of repolarization in epicardium of the right ventricular outflow tract during augmentation of Brugada-type ST segment elevation. J Cardiovasc Electrophysiol 2001;12:1418-1421. [PubMed: 11798001]

147. Watanabe H, Chinushi M, Osaki A, et al. Elimination of late potentials by quinidine in a patient with Brugada syndrome. J Electrocardiol 2006;39:63-66. [PubMed: 16387054]

148. Di Diego JM, Cordeiro JM, Goodrow RJ, et al. Ionic and cellular basis for the predominance of the Brugada syndrome phenotype in males. Circulation 2002;106:2004-2011. [PubMed: 12370227]

149. Babaliaros VC, Hurst JW. Tricyclic antidepressants and the Brugada syndrome: An example of Brugada waves appearing after the administration of desipramine. Clin Cardiol 2002;25:395-398. [PubMed: 12173907]

150. Goldgran-Toledano D, Sideris G, Kevorkian JP. Overdose of cyclic antidepressants and the Brugada syndrome. N Engl J Med 2002;346:1591-1592. [PubMed: 12015405]

151. Tada H, Sticherling C, Oral H, Morady F. Brugada syndrome mimicked by tricyclic antidepressant overdose. J Cardiovasc Electrophysiol 2001;12:275. [PubMed: 11232630]

152. Pastor A, Nunez A, Cantale C, Cosio FG. Asymptomatic Brugada syndrome case unmasked during dimenhydrinate infusion. J Cardiovasc Electrophysiol 2001;12:1192-1194. [PubMed: 11699532]

153. Ortega-Carnicer J, Bertos-Polo J, Gutierrez-Tirado C. Aborted sudden death, transient Brugada pattern, and wide QRS dysrrhythmias after massive cocaine ingestion. J Electrocardiol 2001;34:345-349. [PubMed: 11590577]

154. Nogami A, Nakao M, Kubota S, et al. Enhancement of J-ST-segment elevation by the glucose and insulin test in Brugada syndrome. Pacing Clin Electrophysiol 2003;26:332-337. [PubMed: 12687840] 
155. Araki T, Konno T, Itoh H, Ino H, Shimizu M. Brugada syndrome with ventricular tachycardia and fibrillation related to hypokalemia. Circ J 2003;67:93-95. [PubMed: 12520160]

156. Akhtar M, Goldschlager NF. Brugada electrocardiographic pattern due to tricyclic antidepressant overdose. J Electrocardiol 2006;39:336-339. [PubMed: 16777522]

157. Darbar D, Yang T, Churchwell K, Wilde AA, Roden DM. Unmasking of Brugada syndrome by lithium. Circulation 2005;112:1527-1531. [PubMed: 16144991]

158. Noda T, Shimizu W, Taguchi A, et al. ST-segment elevation and ventricular fibrillation without coronary spasm by intracoronary injection of acetylcholine and/or ergonovine maleate in patients with Brugada syndrome. J Am Coll Cardiol 2002;40:1841-1847. [PubMed: 12446069]

159. Chinushi M, Furushima H, Tanabe Y, Washizuka T, Aizawaz Y. Similarities between Brugada syndrome and ischemia-induced ST-segment elevation. Clinical correlation and synergy. J Electrocardiol 2005;38(Suppl):18-21. [PubMed: 16226069]

160. Proclemer A, Facchin D, Feruglio GA, Nucifora R. Recurrent ventricular fibrillation, right bundlebranch block and persistent ST segment elevation in V1-V3: A new arrhythmia syndrome? A clinical case report. G Ital Cardiol 1993;23:1211-1218. [PubMed: 8174872]see comments

161. Mizumaki K, Fujiki A, Tsuneda T, Sakabe M, Nishida K, Sugao M, Inoue H. Vagal activity modulates spontaneous augmentation of ST elevation in daily life of patients with Brugada syndrome. J Cardiovasc Electrophysiol 2004;15:667-673. [PubMed: 15175062]

162. Wichter T, Matheja P, Eckardt L, et al. Cardiac autonomic dysfunction in Brugada syndrome. Circulation 2002;105:702-706. [PubMed: 11839625]

163. Nimmannit S, Malasit P, Chaovakul V, Susaengrat W, Vasuvattakul S, Nilwarangkur S. Pathogenesis of sudden unexplained nocturnal death (lai tai) and endemic distal renal tubular acidosis. Lancet 1991;338:930-932. [PubMed: 1681278]

164. Ikeda T, Abe A, Yusa S, et al. The full stomach test as a novel diagnostic technique for identifying patients at risk for Brugada Syndrome. J Cardiovasc Electrophysiol 2006;17:602-607. [PubMed: 16836706]

165. Gonzalez Rebollo G, Madrid H, Harcia A, Garcia de Casto A, Moro AM. Reccurrent ventricular fibrillation during a febrile illness in a patient with the Brugada syndrome. Rev Esp Cardiol 2000;53:755-757. [PubMed: 10816181]

166. Madle A, Kratochvil Z, Polivkova A. The Brugada syndrome. Vnitr Lek 2002;48:255-258. [PubMed: 11968588]

167. Kum L, Fung JWH, Chan WWL, Chan GK, Chan YS, Sanderson JE. Brugada syndrome unmasked by febrile illness. Pacing Clin Electrophysiol 2002;25:1660-1661. [PubMed: 12494630]

168. Keller DI, Huang H, Zhao J, et al. A novel SCN5A mutation, F1344S, identified in a patient with Brugada syndrome and fever-induced ventricular fibrillation. Cardiovasc Res 2006;70:521-529. [PubMed: 16616735]

169. Brugada J, Brugada R, Brugada P. Pharmacological and device approach to therapy of inherited cardiac diseases associated with cardiac arrhythmias and sudden death. J Electrocardiol 2000;33 (Suppl):41-47. [PubMed: 11265735]

170. Brugada P, Brugada R, Brugada J, Geelen P. Use of the prophylactic implantable cardioverter defibrillator for patients with normal hearts. Am J Cardiol 1999;83:98D-100D. [PubMed: 10073791]

171. Haissaguerre M, Extramiana F, Hocini M, et al. Mapping and ablation of ventricular fibrillation associated with long-QT and Brugada syndromes. Circulation 2003;108:925-928. [PubMed: 12925452]

172. Antzelevitch, C.; Fish, JM. Therapy for the Brugada syndrome. In: Kass, R.; Clancy, CE., editors. Handbook of Experimental Pharmacology. New York: Springer-Verlag; 2006. p. 305-330.

173. Chinushi M, Aizawa Y, Ogawa Y, Shiba M, Takahashi K. Discrepant drug action of disopyramide on ECG abnormalities and induction of ventricular arrhythmias in a patient with Brugada syndrome. J Electrocardiol 1997;30:133-136. [PubMed: 9141608]

174. Grant AO. Electrophysiological basis and genetics of Brugada syndrome. J Cardiovasc Electrophysiol 2005;16(Suppl 1):S3-S7. [PubMed: 16138883] 
175. Belhassen B, Viskin S, Antzelevitch C. The Brugada syndrome: Is an implantable cardioverter defibrillator the only therapeutic option? Pacing Clin Electrophysiol 2002;25:1634-1640. [PubMed: 12494624]

176. Alings M, Dekker L, Sadee A, Wilde A. Quinidine induced electrocardiographic normalization in two patients with Brugada syndrome. Pacing Clin Electrophysiol 2001;24:1420-1422. [PubMed: 11584468]

177. Belhassen, B.; Viskin, S. Pharmacologic approach to therapy of Brugada syndrome: Quinidine as an alternative to ICD therapy?. In: Antzelevitch, C.; Brugada, P.; Brugada, J.; Brugada, R., editors. The Brugada Syndrome: From Bench to Bedside. Oxford: Blackwell Futura; 2004. p. 202-211.

178. Marquez MF, Rivera J, Hermosillo AG, Iturralde P, Colin L, Moragrega JL, Cardenas M. Arrhythmic storm responsive to quinidine in a patient with Brugada syndrome and vasovagal syncope. Pacing Clin Electrophysiol 2005;28:870-873. [PubMed: 16105018]

179. Belhassen B, Viskin S, Fish R, Glick A, Setbon I, Eldar M. Effects of electrophysiologic-guided therapy with Class IA antiarrhythmic drugs on the long-term outcome of patients with idiopathic ventricular fibrillation with or without the Brugada syndrome. J Cardiovasc Electrophysiol 1999;10:1301-1312. [PubMed: 10515552]

180. Hermida JS, Denjoy I, Clerc J, et al. Hydroquinidine therapy in Brugada syndrome. J Am Coll Cardiol 2004;43:1853-1860. [PubMed: 15145111]

181. Mok NS, Chan NY, Chi-Suen CA. Successful use of quinidine in treatment of electrical storm in Brugada syndrome. Pacing Clin Electrophysiol 2004;27:821-823. [PubMed: 15189543]

182. Marquez MF, Rivera J, Hermosillo AG, Iturralde P, Colin L, Moragrega JL, Cardenas M. Arrhythmic storm responsive to quinidine in a patient with Brugada syndrome and vasovagal syncope. Pacing Clin Electrophysiol 2005;28:870-873. [PubMed: 16105018]

183. Mizusawa Y, Sakurada H, Nishizaki M, Hiraoka M. Effects of low-dose quinidine on ventricular tachyarrhythmias in patients with Brugada syndrome: Low-dose quinidine therapy as an adjunctive treatment. J Cardiovasc Pharmacol 2006;47:359-364. [PubMed: 16633076]

184. Fish JM, Extramiana F, Antzelevitch C. Tedisamil abolishes the arrhythmogenic substrate responsible for VT/VF in an experimental model of the Brugada syndrome. Heart Rhythm 2004;1 (1S):S158.abstract

185. Antzelevitch C, Shimizu W. Cellular mechanisms underlying the long QT syndrome. Curr Opin Cardiol 2002;17:43-51. [PubMed: 11790933]

186. Belardinelli L, Antzelevitch C, Vos MA. Assessing predictors of drug-induced torsade de pointes. Trends Pharmacol Sci 2003;24:619-625. [PubMed: 14654302]

187. Fish JM, Extramiana F, Antzelevitch C. AVE0118, an $\mathrm{I}_{\text {to }}$ and $\mathrm{I}_{\mathrm{Kur}}$ blocker, suppresses VT/VF in an experimental model of the Brugada syndrome. Circulation 2004;110:III-193.abstract

188. Suzuki H, Torigoe K, Numata O, Yazaki S. Infant case with a malignant form of Brugada syndrome. J Cardiovasc Electrophysiol 2000;11:1277-1280. [PubMed: 11083249]

189. Tanaka H, Kinoshita O, Uchikawa S, et al. Successful prevention of recurrent ventricular fibrillation by intravenous isoproterenol in a patient with Brugada syndrome. Pacing Clin Electrophysiol 2001;24:1293-1294. [PubMed: 11523620]

190. Nademanee, K.; Veerakul, G.; Schwab, M. Predisposing factors in the Brugada syndrome. In: Antzelevitch, C.; Brugada, P., editors. Brugada Syndrome. Elmsford: Blackwell Publishing; 2004. p. $157-165$.

191. Wang K, Asinger RW, Marriott HJ. ST-segment elevation in conditions other than acute myocardial infarction. N Engl J Med 2003;349:2128-2135. [PubMed: 14645641]

192. Myers GB. Other QRS-T patterns that may be mistaken for myocardial infarction. IV. Alterations in blood potassium; myocardial ischemia; subepicardial myocarditis; distortion associated with arrhythmias. Circulation 1950;2:75-93. [PubMed: 15427197]

193. Abbott JA, Cheitlin MD. The nonspecific camel-hump sign. JAMA 1976;235:413-414. [PubMed: 946087]

194. Hersch C. Electrocardiographic changes in head injuries. Circulation 1961;23:853-860. [PubMed: 13713781] 
195. Perloff JK, Henze E, Schelbert HR. Alterations in regional myocardial metabolism, perfusion, and wall motion in Duchenne muscular dystrophy studied by radionuclide imaging. Circulation 1984;69:33-42. [PubMed: 6605817]

196. Read DH, Harrington DD. Experimentally induced thiamine deficiency in beagle dogs: Clinical observations. Am J Vet Res 1981;42:984-991. [PubMed: 7197132]

197. Notarstefano P, Pratola C, Toselli T, Ferrari R. Atrial fibrillation and recurrent ventricular fibrillation during hypokalemia in Brugada syndrome. Pacing Clin Electrophysiol 2005;28:1350-1353. [PubMed: 16403168]

198. Merrill JP, Levine HD, Somerville W, Smith S. Clinical recognition and treatment of acute potassium intoxication. Ann Intern Med 1950;33:797-830. [PubMed: 14771753]

199. Ortega-Carnicer J, Benezet J, Ruiz-Lorenzo F, Alcazar R. Transient Brugada-type electrocardiographic abnormalities in renal failure reversed by dialysis. Resuscitation 2002;55:215219. [PubMed: 12413761]

200. Douglas PS, Carmichael KA, Palevsky PM. Extreme hypercalcemia and electrocardiographic changes. Am J Cardiol 1984;54:674-675. [PubMed: 6475795]

201. Sridharan MR, Horan LG. Electrocardiographic J wave of hypercalcemia. Am J Cardiol 1984;54:672-673. [PubMed: 6475794]

202. Osborn JJ. Experimental hypothermia: Respiratory and blood $\mathrm{pH}$ changes in relation to cardiac function. Am J Physiol 1953;175:389-398. [PubMed: 13114420]

203. Noda T, Shimizu W, Tanaka K, Chayama K. Prominent J wave and ST segment elevation: Serial electrocardiographic changes in accidental hypothermia. J Cardiovasc Electrophysiol 2003;14:223. [PubMed: 12693512]

204. Tarin N, Farre J, Rubio JM, Tunon J, Castro-Dorticos J. Brugada-like electrocardiographic pattern in a patient with a mediastinal tumor. Pacing Clin Electrophysiol 1999;22:1264-1266. [PubMed: 10461308]

205. Tomcsanyi J, Simor T, Papp L. Images in cardiology. Haemopericardium and Brugada-like ECG pattern in rheumatoid arthritis. Heart 2002;87:234. [PubMed: 11847160]

206. Sanatani S, Mahkseed N, Vallance H, Brugada R. The Brugada ECG pattern in a neonate. J Cardiovasc Electrophysiol 2005;16:342-344. [PubMed: 15817096]

207. Krishnan SC, Josephson ME. ST segment elevation induced by class IC antiarrhythmic agents: Underlying electrophysiologic mechanisms and insights into drug-induced proarrhythmia. $\mathrm{J}$ Cardiovasc Electrophysiol 1998;9:1167-1172. [PubMed: 9835260]

208. Gasparini M, Priori SG, Mantica M, Napolitano C, Galimberti P, Ceriotti C, Simonini S. Flecainide test in Brugada syndrome: A reproducible but risky tool. Pacing Clin Electrophysiol 2003;26:338341. [PubMed: 12687841]

209. Takenaka S, Emori T, Koyama S, Morita H, Fukushima K, Ohe T. Asymptomatic form of Brugada syndrome. Pacing Clin Electrophysiol 1999;22:1261-1263. [PubMed: 10461307]

210. Matana A, Goldner V, Stanic K, Mavric Z, Zaputovic L, Matana Z. Unmasking effect of propafenone on the concealed form of the Brugada phenomenon. Pacing Clin Electrophysiol 2000;23:416-418. [PubMed: 10750149]

211. Rolf S, Bruns HJ, Wichter T, et al. The ajmaline challenge in Brugada syndrome: Diagnostic impact, safety, and recommended protocol. Eur Heart J 2003;24:1104-1112. [PubMed: 12804924]

212. Tada H, Nogami A, Shimizu W, Naito S, Nakatsugawa M, Oshima S, Taniguchi K. ST segment and T wave alternans in a patient with Brugada syndrome. Pacing Clin Electrophysiol 2000;23:413415. [PubMed: 10750148]

213. Sarkozy A, Caenepeel A, Geelen P, Peytchev P, de Zutter M, Brugada P. Cibenzoline induced Brugada ECG pattern. Europace 2005;7:537-539. [PubMed: 16216754]

214. Aouate P, Clerc J, Viard P, Seoud J. Propranolol intoxication revealing a Brugada syndrome. J Cardiovasc Electrophysiol 2005;16:348-351. [PubMed: 15817098]

215. Matsuo K, Shimizu W, Kurita T, Inagaki M, Aihara N, Kamakura S. Dynamic changes of 12-lead electrocardiograms in a patient with Brugada syndrome. J Cardiovasc Electrophysiol 1998;9:508512. [PubMed: 9607459]

216. Bigwood B, Galler D, Amir N, Smith W. Brugada syndrome following tricyclic antidepressant overdose. Anaesth Intensive Care 2005;33:266-270. [PubMed: 15960413] 
217. Bolognesi R, Tsialtas D, Vasini P, Conti M, Manca C. Abnormal ventricular repolarization mimicking myocardial infarction after heterocyclic antidepressant overdose. Am J Cardiol 1997;79:242-245. [PubMed: 9193039]

218. Rouleau F, Asfar P, Boulet S, Dube L, Dupuis JM, Alquier P, Victor J. Transient ST segment elevation in right precordial leads induced by psychotropic drugs: Relationship to the Brugada syndrome. J Cardiovasc Electrophysiol 2001;12:61-65. [PubMed: 11204086]

219. Lopez-Barbeito B, Lluis M, Delgado V, Jimenez S, az-Infante E, Nogue-Xarau S, Brugada J. Diphenhydramine overdose and Brugada sign. Pacing Clin Electrophysiol 2005;28:730-732. [PubMed: 16008813]

220. Littmann L, Monroe MH, Svenson RH. Brugada-type electrocardiographic pattern induced by cocaine. Mayo Clin Proc 2000;75:845-849. [PubMed: 10943241]

221. Shimizu W. Acquired forms of the Brugada syndrome. J Electrocardiol 2005;38(Suppl):22-25. [PubMed: 16226070]

222. van Den Berg MP, Wilde AA, Viersma TJW, Brouwer J, et al. Possible bradycardic mode of death and successful pacemaker treatment in a large family with features of long QT syndrome type 3 and Brugada syndrome. J Cardiovasc Electrophysiol 2001;12:630-636. [PubMed: 11405394]

223. Haghjoo M, Arya A, Heidari A, Sadr-Ameli MA. Suppression of electrical storm by oral quinidine in a patient with Brugada syndrome. J Cardiovasc Electrophysiol 2005;16:674. [PubMed: $15946371]$ 

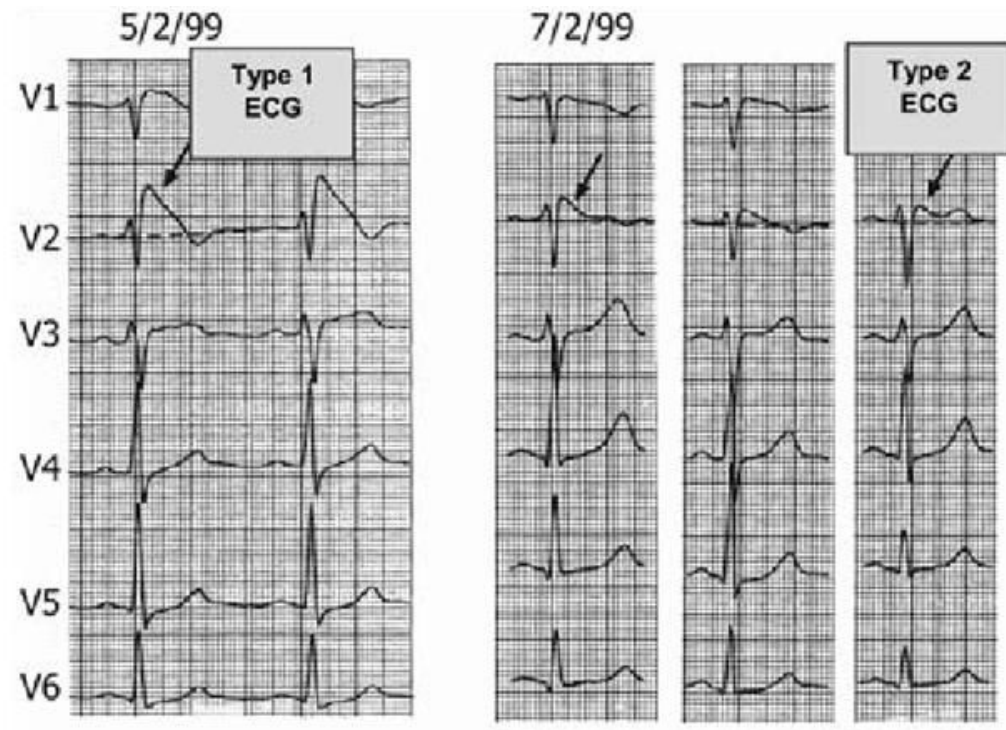

$13 / 2 / 99$

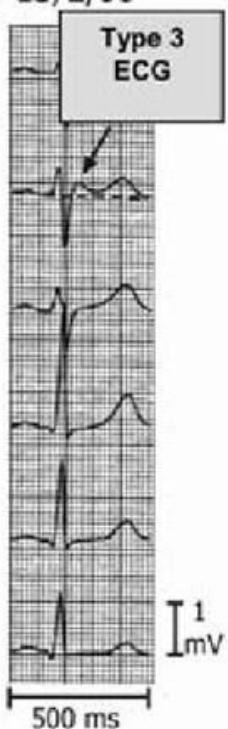

Figure 1.

Three Types of ST-segment elevation generally observed in patients with the Brugada syndrome. Shown are precordial leads recorded from a patient diagnosed with the Brugada syndrome. Note the dynamic ECG changes occurring over a period of 2 days. The left panel shows a clear Type 1 ECG, which is diagnostic of the Brugada syndrome. A saddleback STsegment elevation (Type 2) is observed on February 7,1999. The ST segment is further normalized on February 13, 1999, showing a Type 3 ECG. Modified from Wilde et al. ${ }^{4}$ with permission. 


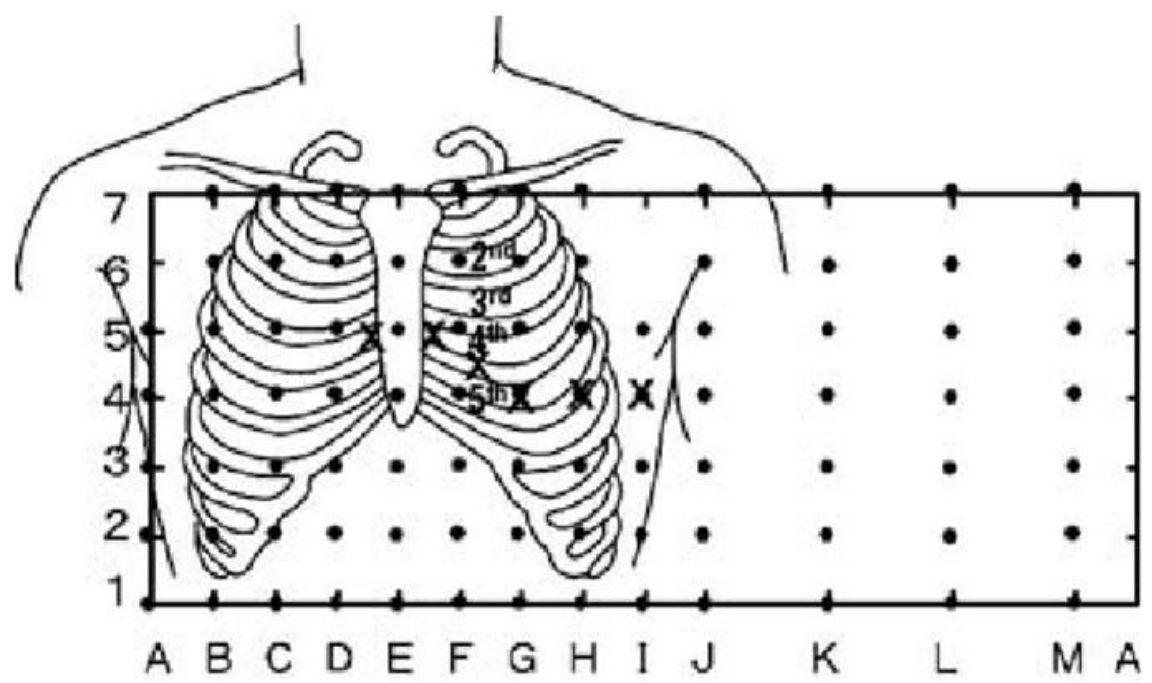

Upper Inter-costal Space
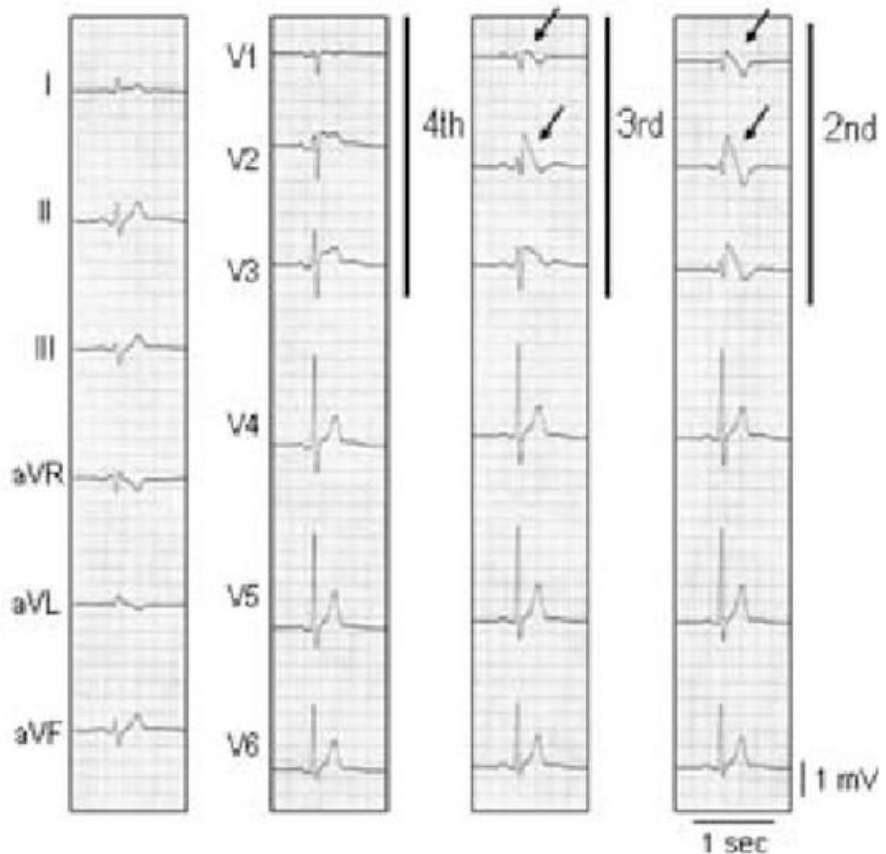

Figure 2.

Shift of right precordial leads to $2^{\text {nd }}$ and $3^{\text {rd }}$ intercostal space unmasks a Type 1 Brugada ECG. (Top) Plot of 87 unipolar electrode sites (dots) and of 6 precordial electrocardiograms (ECG) (crosses). Eighty seven-lead points are arranged in a lattice-like pattern ( $13 \times 7$ matrix), except for four lead points on both mid-axillary lines and covered the entire thoracic surface. V1 and V2 leads of the ECG are located between D5 and E5, and between E5 and F5, respectively, whereas V4, V5, and V6 are coincident with G4, H4, and I4, respectively. (Bottom) Twelveleads electrocardiograms (ECG) in a patient with Brugada syndrome. Type 2 saddleback STsegment elevation was observed in V1 and V2 of the standard 12-lead ECG $\left(4^{\text {th }}\right.$ intercostal space), whereas typical Type 1 coved-type ST-segment elevation was apparent in V1 and V2 
recorded from the $2^{\text {nd }}$ and $3^{\text {rd }}$ intercostal space (arrows). Modified from Antzelevitch et al. 5 , 6 with permission. 


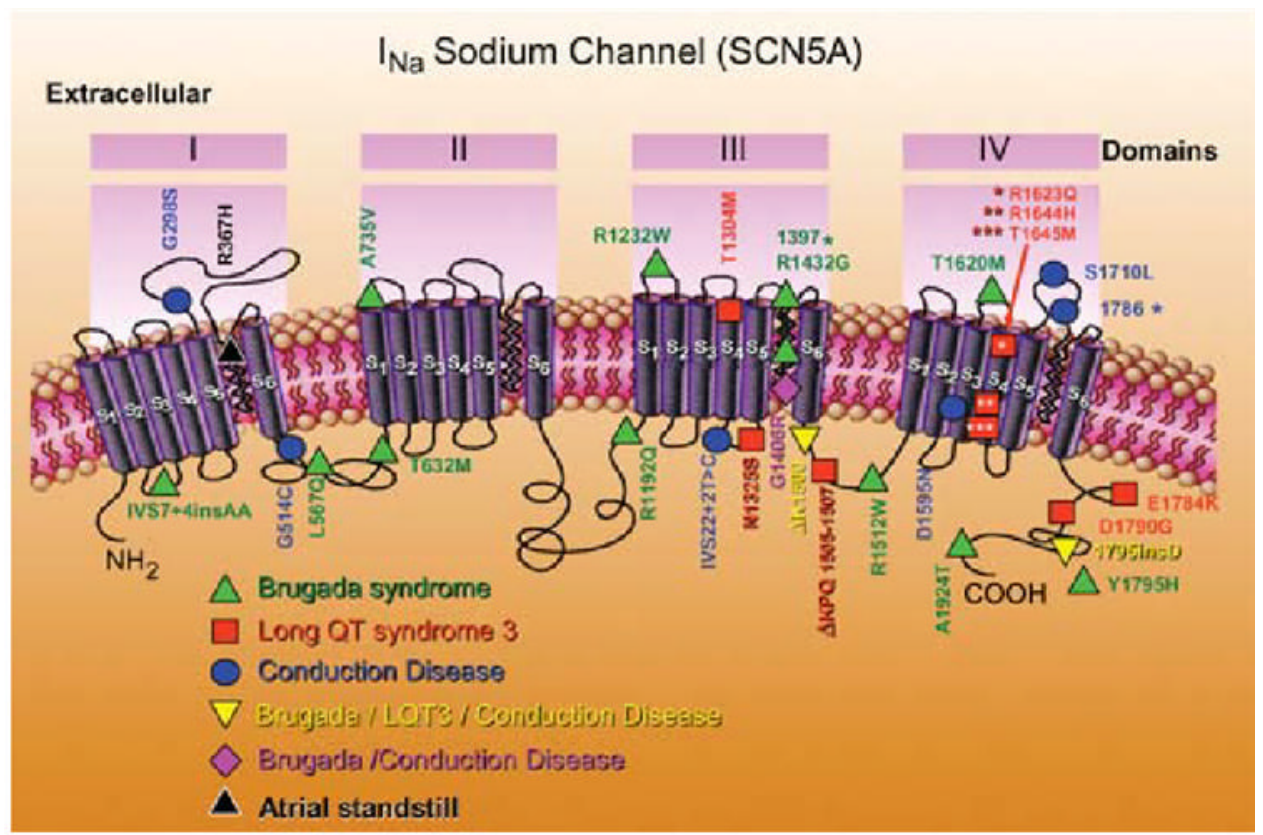

Figure 3.

Schematic of SCN5A, the gene that encodes the (-subunit of the sodium channel, illustrating mutations linked to Brugada syndrome, long-QT3 syndrome, conduction disease, and atrial standstill. Some mutations are associated with combined phenotypes. $\alpha=$ subunit 


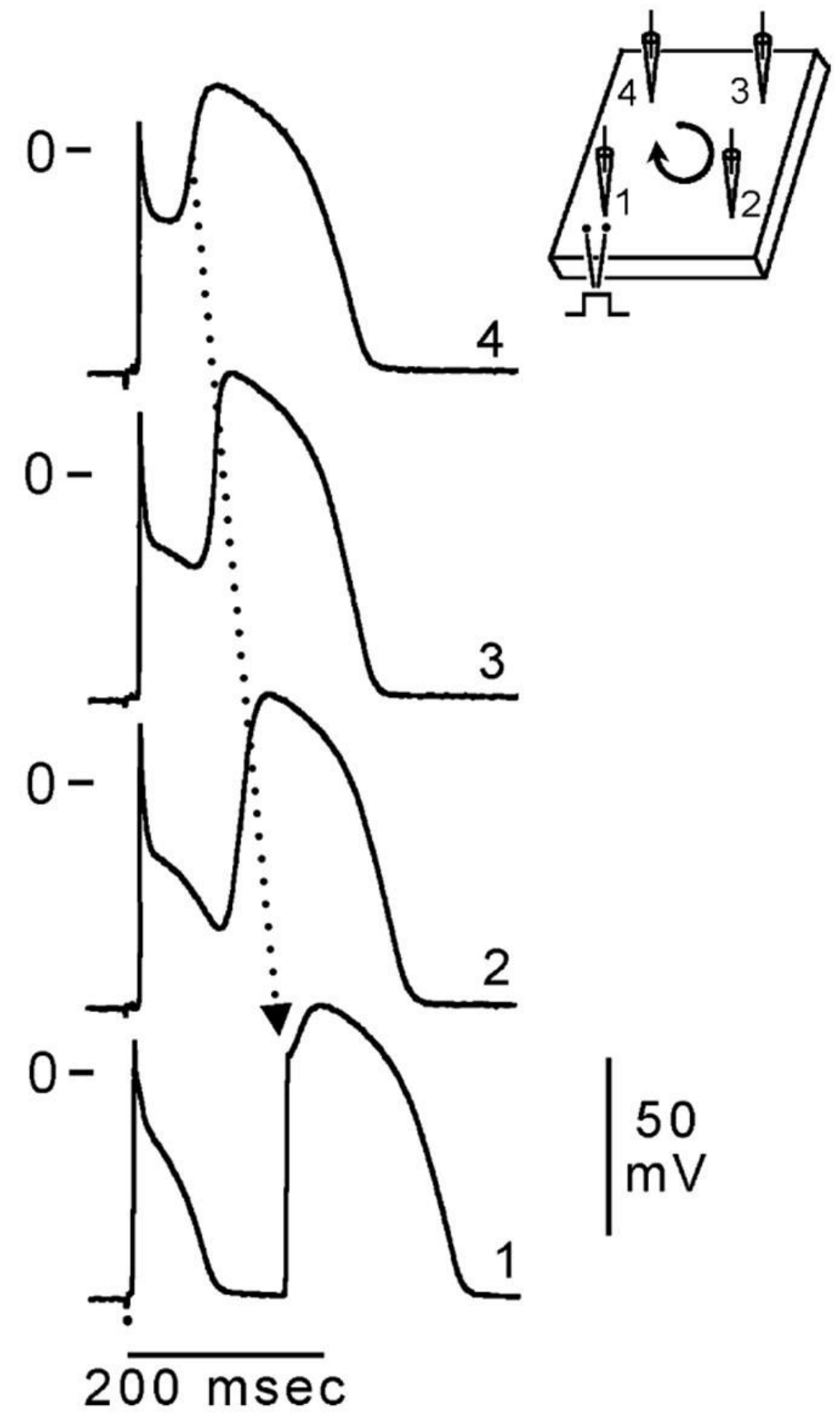

Figure 4.

Phase 2 reentry. Reentrant activity induced by exposure of a canine ventricular epicardial preparation $\left(0.7 \mathrm{~cm}^{2}\right)$ to simulated ischemia. Microelectrode recordings were obtained from four sites as shown in the schematic (upper right). After $35 \mathrm{~min}$ of ischemia, the action potential dome develops normally at site 4 , but not at sites 1,2 , or 3 . The dome then propagates in a clockwise direction re-exciting sites 3,2 , and 1 with progressive delays, thus generating a closely coupled reentrant extrasystole $(156 \mathrm{~ms})$ at site 1 . In this example of phase 2 reentry, propagation of the dome occurs in a direction opposite to that of phase 0 , a mechanism akin to reflection. BCL $=700 \mathrm{~ms}$. Modified from Lukas and Antzelevitch ${ }^{119}$ with permission. 


\section{A}

Arterially Perfused

Right Ventricular Wedge

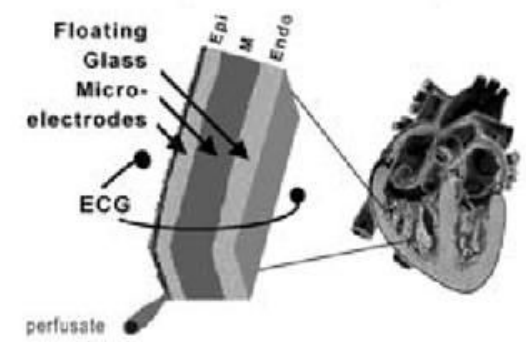

C Pinacidil (Epicardium)
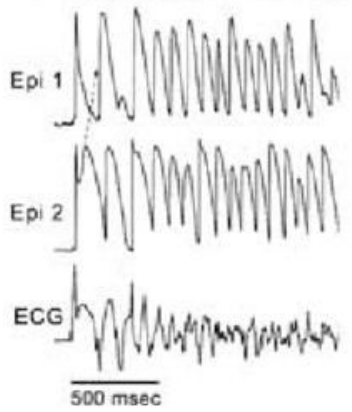
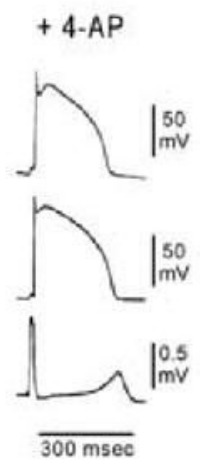

B Local Pressure Epicardium

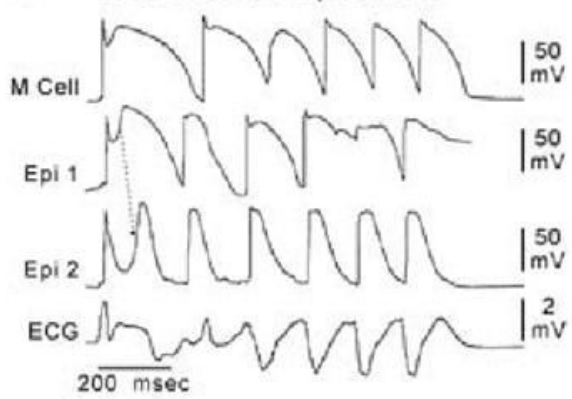

D Pinacidil $(2.5 \mu \mathrm{M}$, perfusate $)+4 \cdot A \mathrm{P}$

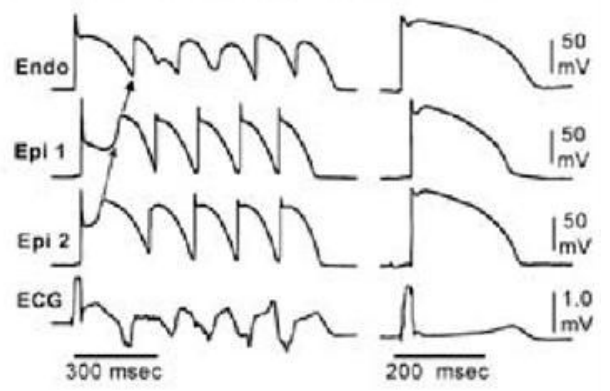

Figure 5.

ECG and arrhythmias with typical features of the Brugada syndrome recorded from canine right ventricular wedge preparations. (A) Schematic of arterially perfused right ventricular wedge preparation. (B) Pressure-induced phase 2 reentry and VT. Shown are transmembrane action potentials simultaneously recorded from two epicardial (Epi 1 and Epi 2) and one $\mathrm{M}$ region (M) sites, together with a transmural ECG. Local application of pressure near Epi 2 results in loss of the action potential dome at that site but not at Epi 1 or $\mathrm{M}$ sites. The dome at Epi 1 then re-excites Epi 2, giving rise to a phase 2 reentrant extrasystole which triggers a short run of ventricular tachycardia. Note the ST-segment elevation due to loss of the action potential dome in a segment of epicardium. (C) Polymorphic VT/VF induced by local application of the potassium channel opener pinacidil $(10 \mu \mathrm{M})$ to the epicardial surface of the wedge. Action potentials from two epicardial sites (Epi 1 and Epi 2) and a transmural ECG were simultaneously recorded. Loss of the dome at Epi 1 but not Epi 2 creates a marked dispersion of repolarization, giving rise to a phase 2 reentrant extrasystole. The extrasystolic beat then triggers a long episode of ventricular fibrillation $(22 \mathrm{sec})$. (Right panel) Addition of 4aminopyridine (4-AP, $2 \mathrm{mM}$ ), a specific $\mathrm{I}_{\text {to }}$ blocker, to the perfusate restored the action potential dome at Epi 1, thus reducing dispersion of repolarization and suppressing all arrhythmic activity. $\mathrm{BCL}=2,000 \mathrm{~ms}$. (D) Phase 2 reentry gives rise to VT following addition of pinacidil $(2.5 \mu \mathrm{M})$ to the coronary perfusate. Transmembrane action potentials form 2 epicardial sites (Epi 1 and Epi 2) and one endocardial site (Endo), as well as a transmural ECG were simultaneously recorded. (Right panel) 4-AP $(1 \mathrm{mM})$ markedly reduces the magnitude of the action potential notch in epicardium, thus restoring the action potential dome throughout the preparation and abolishing all arrhythmic activity. Panel D is from Yan and Antzelevitch 106 with permission. 


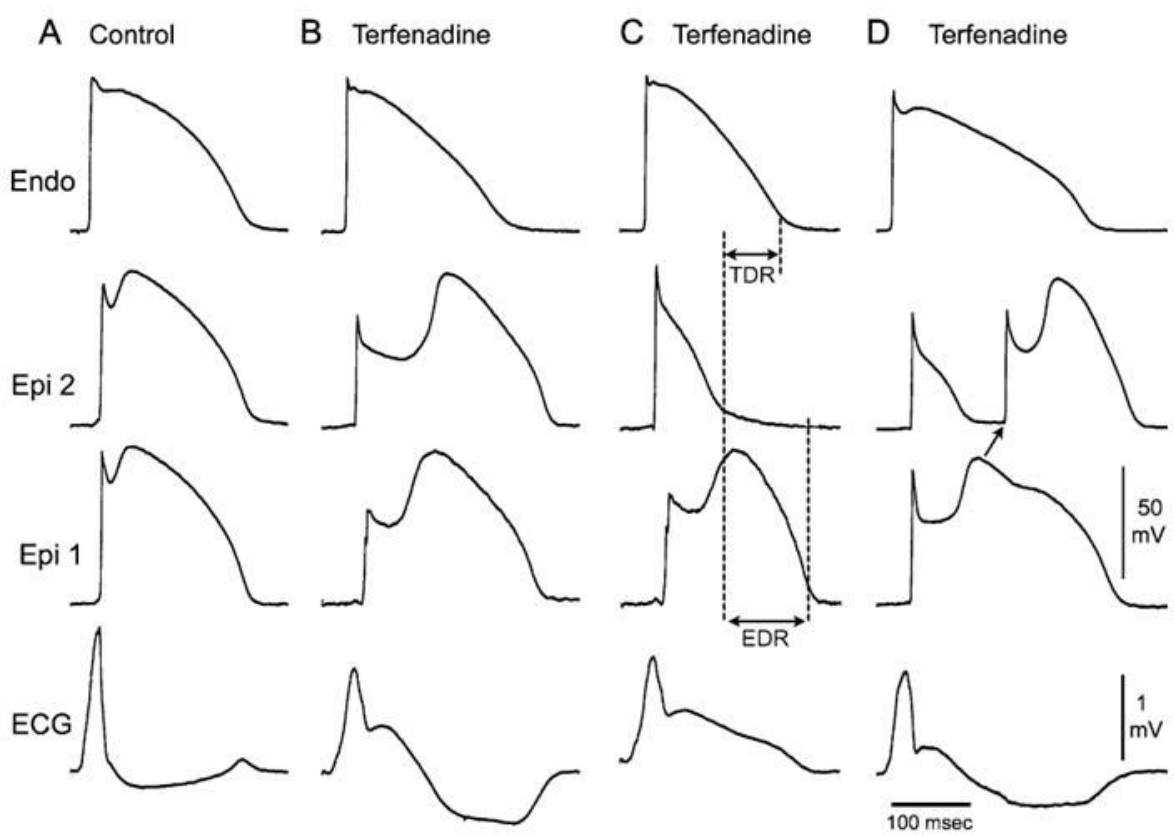

Figure 6.

Terfenadine-induced ST-segment elevation, T-wave inversion, transmural and endocardial dispersion of repolarization, and phase 2 reentry. Each panel shows transmembrane action potentials from one endocardial (top) and two epicardial sites together with a transmural ECG recorded from a canine arterially perfused right ventricular wedge preparation. (A) Control (BCL $400 \mathrm{~ms})$. (B) Terfenadine $(5 \mu \mathrm{M})$ accentuated the epicardial action potential notch creating a transmural voltage gradient that manifests as a ST-segment elevation or exaggerated $\mathrm{J}$ wave in the ECG. First beat recorded after changing from BCL $800 \mathrm{~ms}$ to BCL $400 \mathrm{~ms}$. (C) Continued pacing at BCL $400 \mathrm{~ms}$ results in all-or-none repolarization at the end of phase 1 at some epicardial sites but not others, creating a local epicardial dispersion of repolarization (EDR) as well as a transmural dispersion of repolarization (TDR). (D) Phase 2 reentry occurs when the epicardial action potential dome propagates from a site where it is maintained to regions where it has been lost. Modified from Fish and Antzelevitch ${ }^{107}$ with permission. 

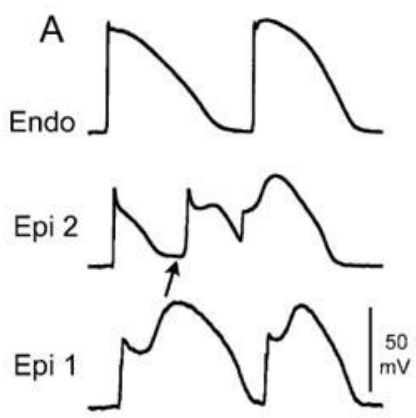

ECG
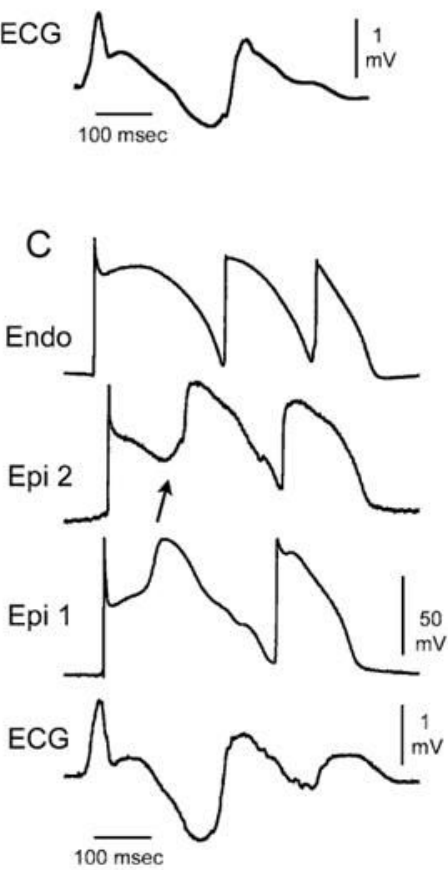

B
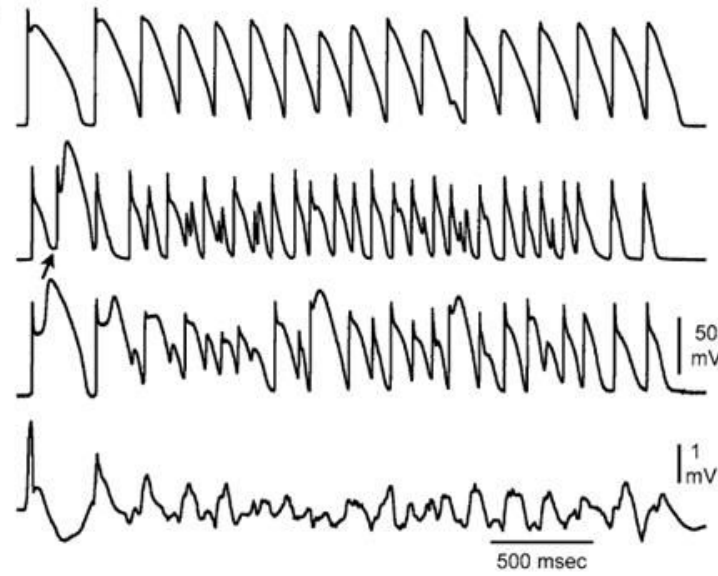

D
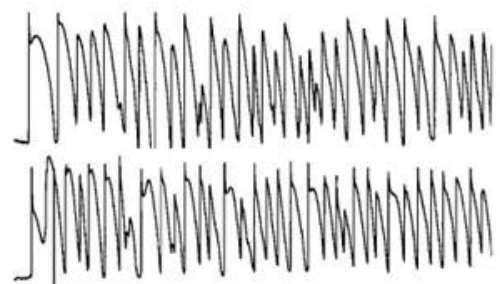

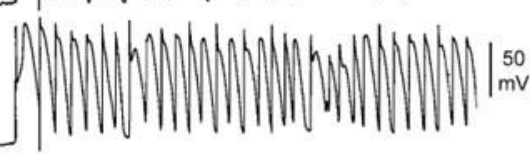

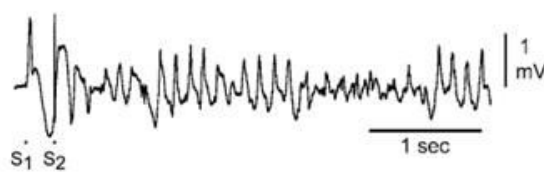

Figure 7.

Spontaneous and programmed electrical stimulationinduced polymorphic VT in RV wedge preparations pretreated with terfenadine $(5-10 \mu \mathrm{M})$. (A) Phase 2 reentry in epicardium gives rise to a closely coupled extrasystole. (B) Phase 2 reentrant extrasystole triggers a brief episode of polymorphic VT. (C) Phase 2 reentry followed by a single circus movement reentry in epicardium gives rise to a couplet. (D) Extrastimulus (S1-S2 $=250 \mathrm{~ms}$ ) applied to epicardium triggers a polymorphic VT. Modified from Fish and Antzelevitch ${ }^{107}$ with permission. 

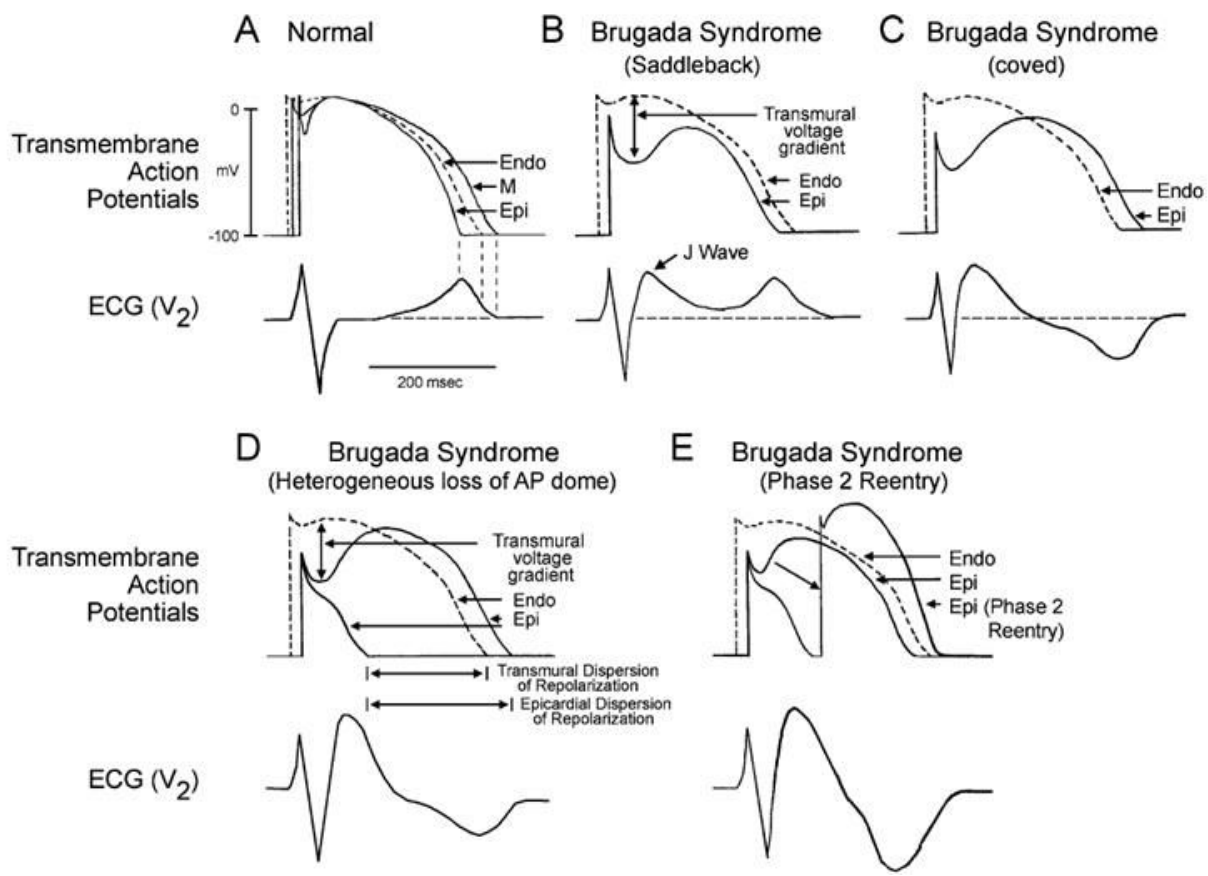

Figure 8.

Schematic representation of right ventricular epicardial action potential changes proposed to underlie the electrocardiographic manifestation of the Brugada syndrome. Modified from Antzelevitch 137 with permission. 

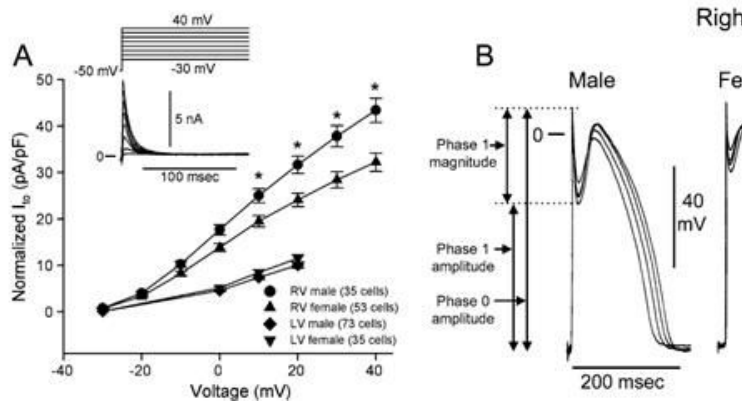

Right Ventricular Epicardium

Figure 9.

Sex-based and interventricular differences in $\mathrm{I}_{\text {to }}$. (A) Mean I-V relationship for $\mathrm{I}_{\text {to }}$ recorded from RV epicardial cells isolated from hearts of male and female dogs. (Inset) Representative $\mathrm{I}_{\text {to }}$ current traces and voltage protocol. $\mathrm{I}_{\text {to }}$ density was significantly greater in male versus female RV epicardial cells. No sex differences were observed in LV. (B) Transmembrane action potentials recorded from isolated canine RV epicardial male and female tissue slices. BCLs 300, 500, 800, and 2,000 ms. (C) Rate-dependence of phase 1 amplitude and voltage at end of phase 1 (V/phase $1, \mathrm{mV}$ ) in males (solid squares) versus females (solid circles). Modified from Di Diego et al. ${ }^{148}$ with permission. 

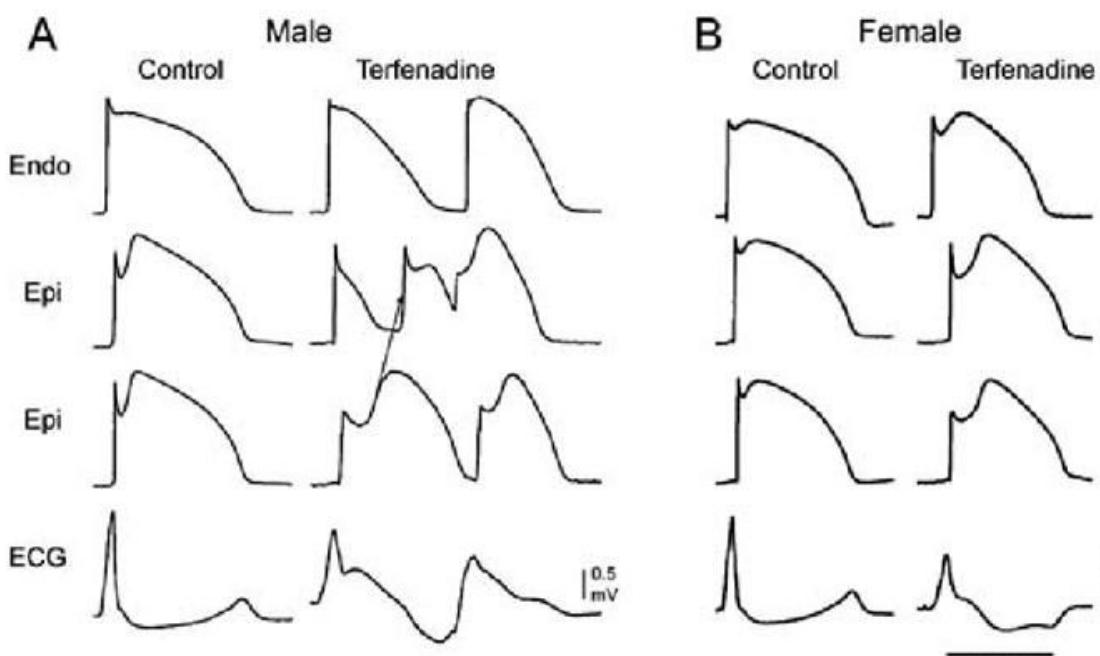

\section{C} Spontaneous Phase 2 Reentry Terfenadine $(5 \mu \mathrm{M})$
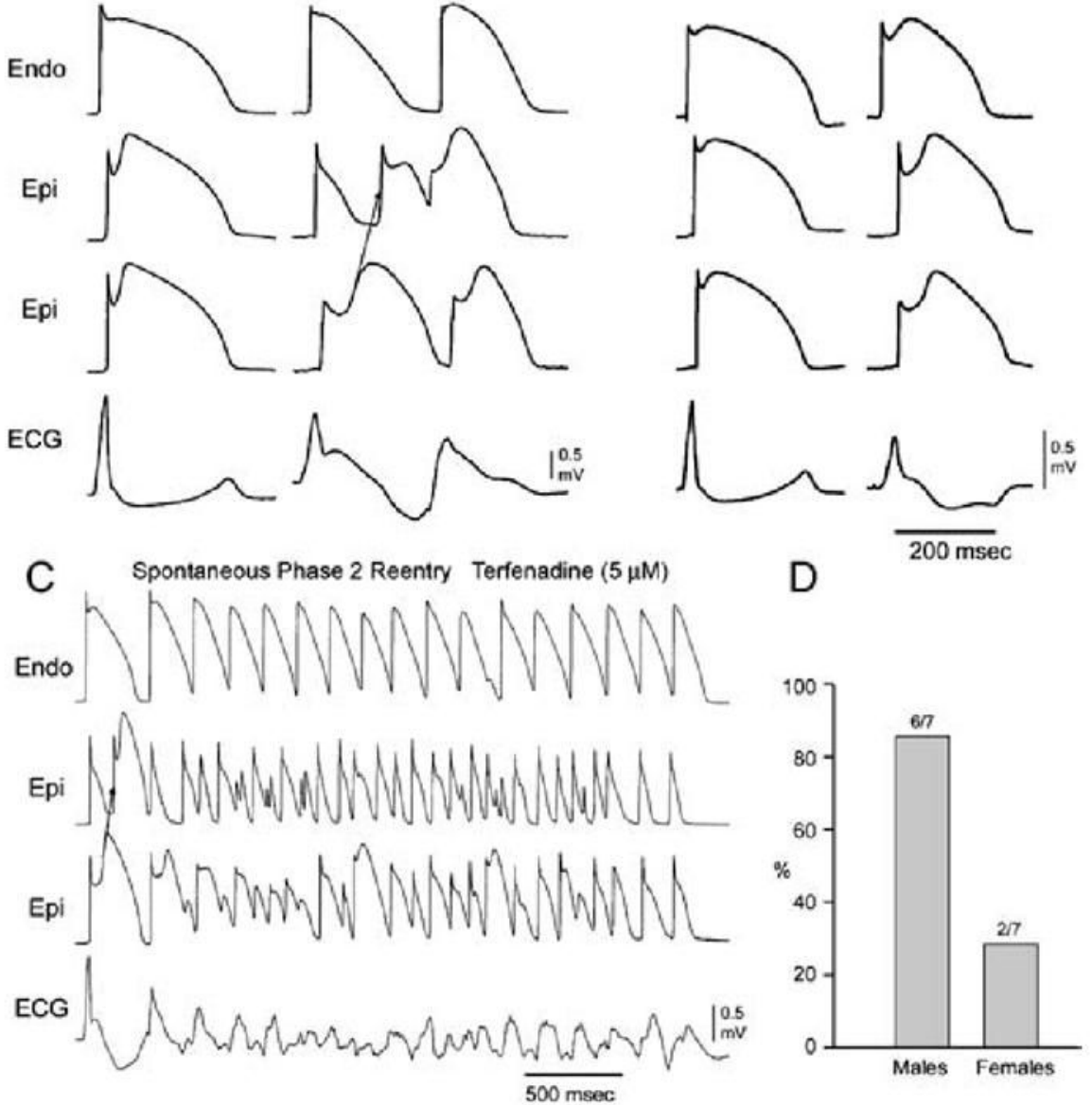

Figure 10.

Terfenadine induces Brugada phenotype more readily in male than female RV wedge preparations. Each panel shows action potentials recorded from 2 epicardial sites and 1 endocardial site, together with a transmural ECG. Control recordings were obtained at a BCL of 2,000 ms, whereas terfenadine data were recorded at a BCL of $800 \mathrm{~ms}$ after a brief period of pacing at a BCL of $400 \mathrm{~ms}$. (A) Terfenadine $(5 \mu \mathrm{M})$-induced, heterogeneous loss of action potential dome, ST-segment elevation, and phase 2 reentry (arrow) in a male RV wedge preparation. (B) Terfenadine fails to induce Brugada phenotype in a female RV wedge preparation. (C) Polymorphic VT triggered by spontaneous phase 2 reentry in a male preparation. (D) Incidence of phase 2 reentry in male (6 of 7) versus female ( 2 of 7) RV wedge preparations when perfused with $5 \mu \mathrm{M}$ terfenadine for up to 2 hours. Modified from Di Diego et al. 148 with permission. 


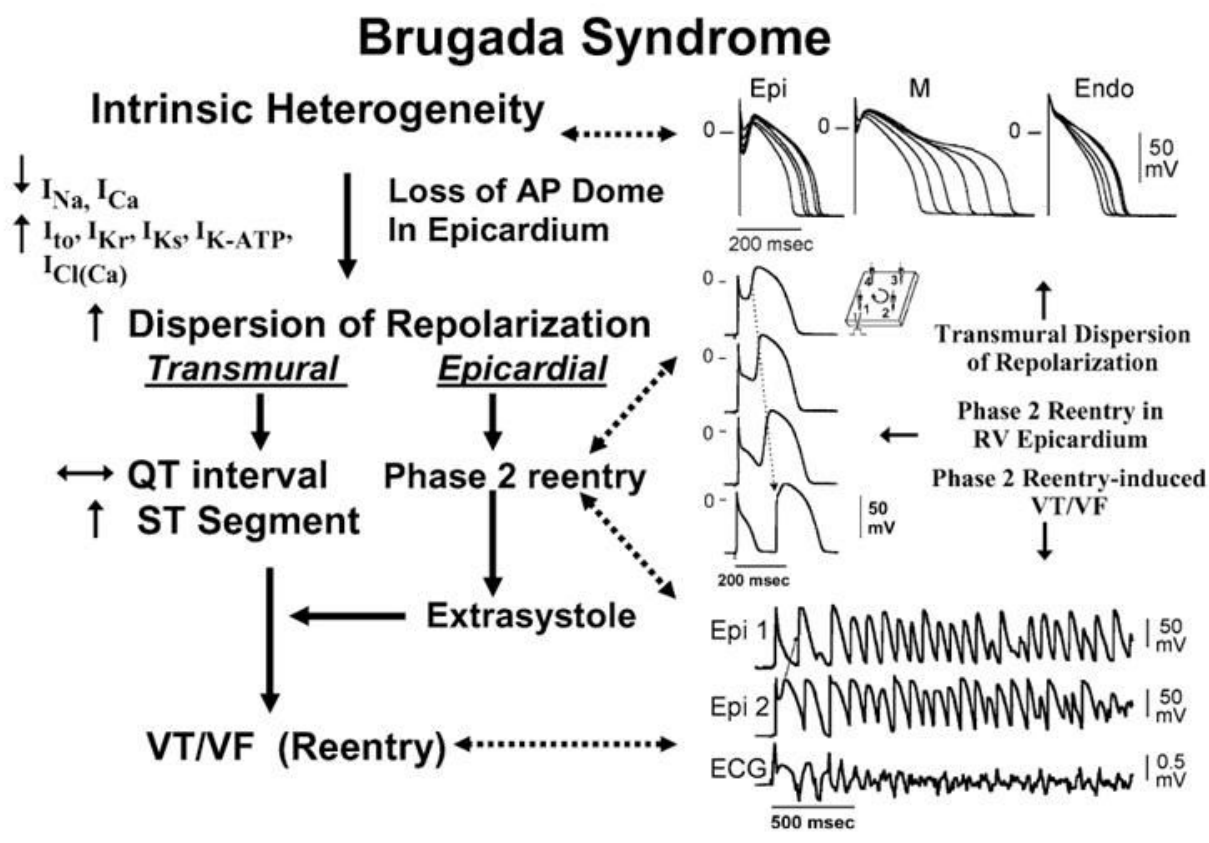

Figure 11.

Proposed mechanism for the Brugada syndrome. A shift in the balance of currents serves to amplify existing heterogeneities by causing loss of the action potential dome at some epicardial, but not endocardial, sites. A vulnerable window develops as a result of the dispersion of repolarization and refractoriness within epicardium, as well as across the wall. Epicardial dispersion leads to the development of phase 2 reentry, which provides the extrasystole that captures the vulnerable window and initiates VT/VF via a circus movement reentry mechanism. Modified from Antzelevitch ${ }^{138}$ with permission. 


\section{Pathophysiologic Mechanism of Brugada Syndrome: Predisposing Factors}

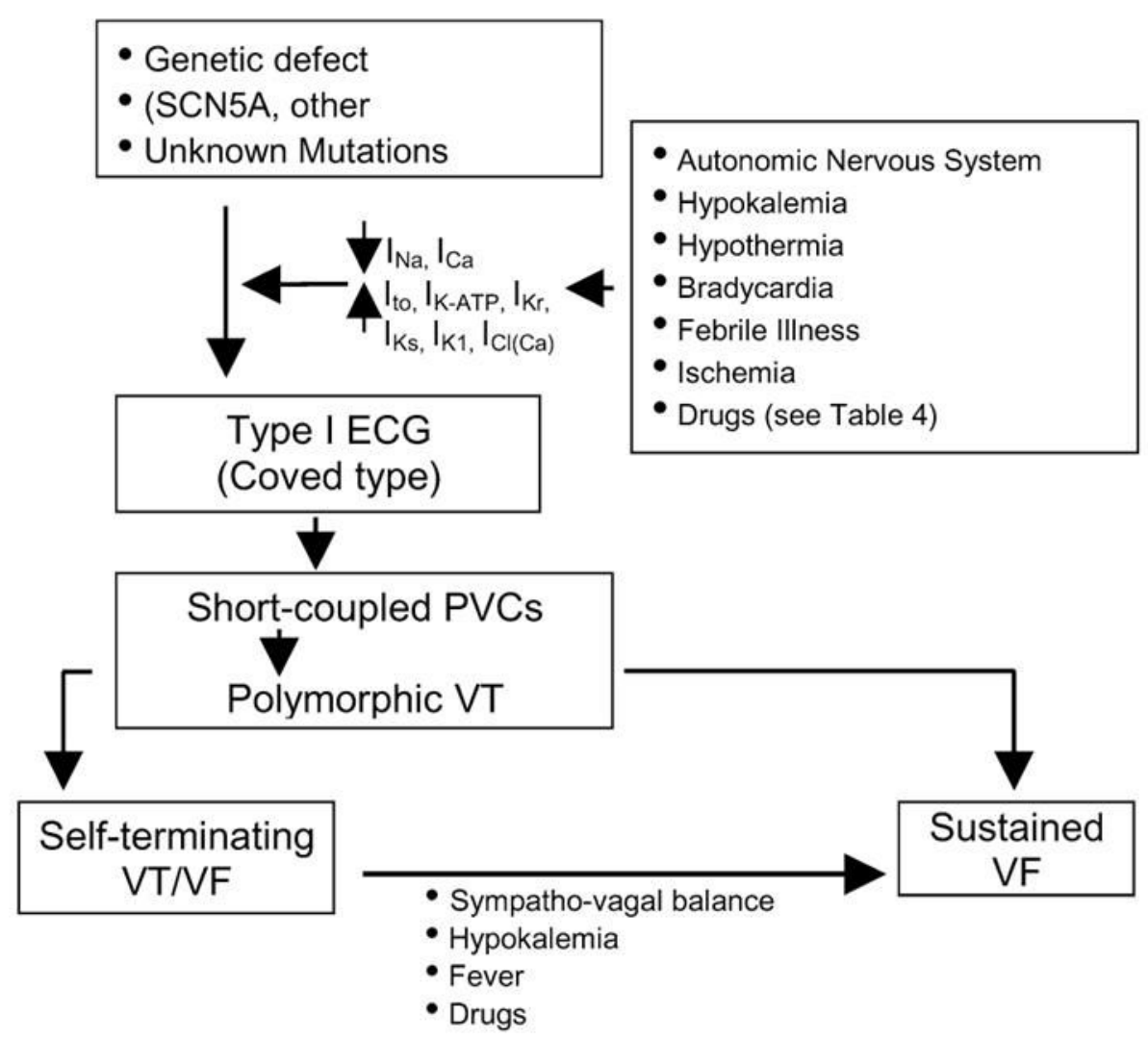

Figure 12.

Factors predisposing to the electrocardiographic and arrhythmic manifestations of the Brugada syndrome. Modified from Nademanee et al. 190 with permission. 

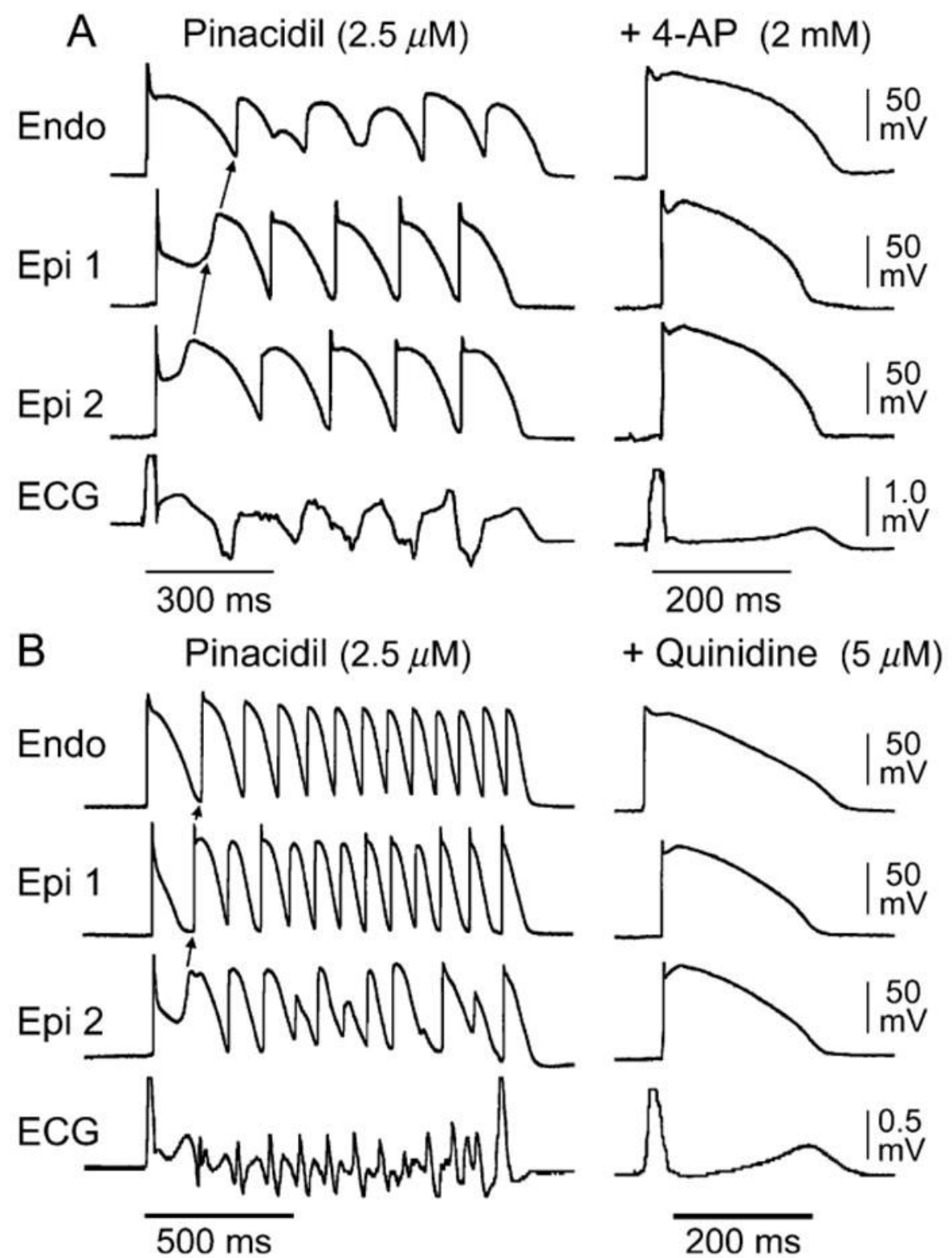

Figure 13.

Effects of $\mathrm{I}_{\mathrm{to}}$ blockers 4-AP and quinidine on pinacidilinduced phase 2 reentry and VT in the arterially perfused $\mathrm{RV}$ wedge preparation. In both examples, $2.5 \mathrm{mM}$ pinacidil produced heterogeneous loss of AP dome in epicardium, resulting in ST-segment elevation, phase 2 reentry, and VT (left); 4-AP (A) and quinidine (B) restored epicardial AP dome, reduced both transmural and epicardial dispersion of repolarization, normalized the ST segment, and prevented phase 2 reentry and VT in continued presence of pinacidil. From Yan and Antzelevitch ${ }^{106}$ with permission. 
CONTROL

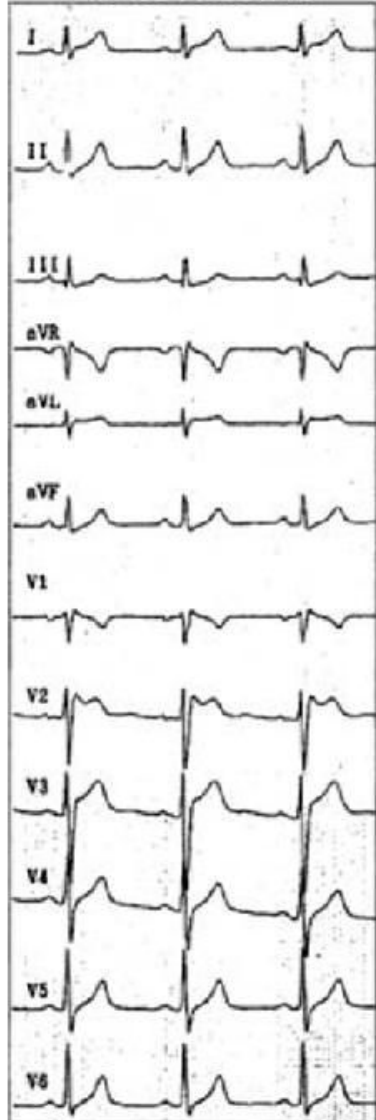

PROCAINAMIDE

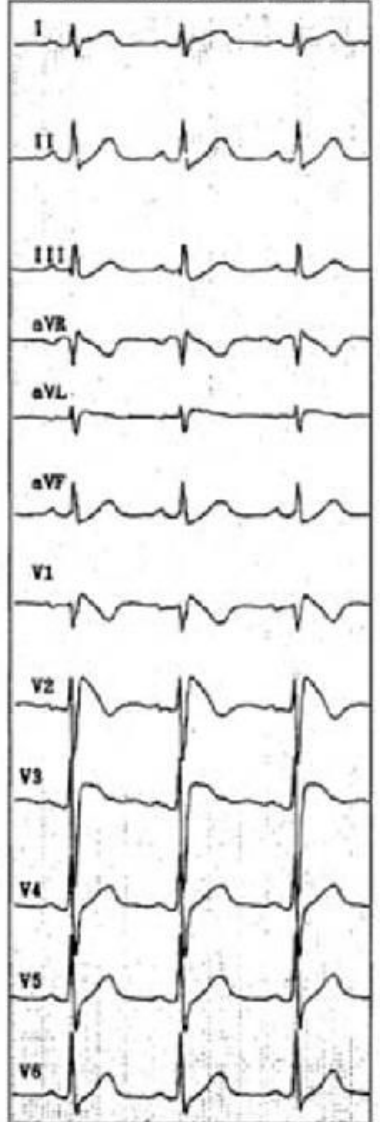

OUINIDINE

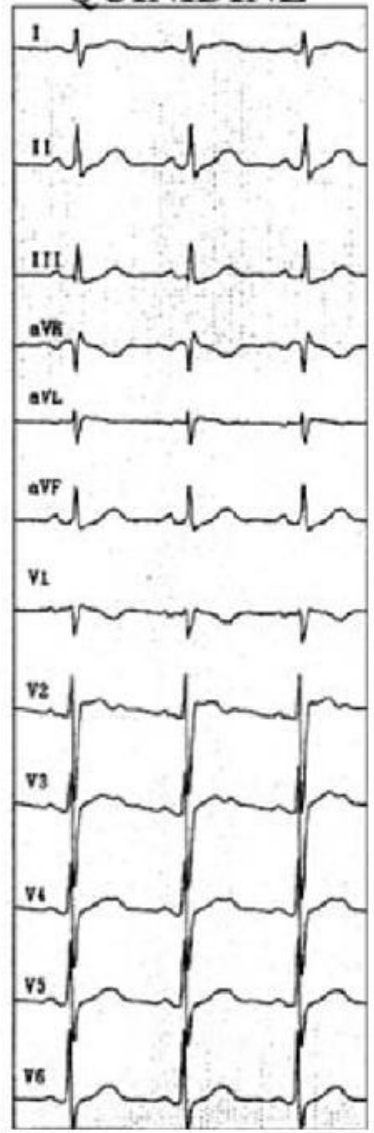

Figure 14.

Twelve-lead electrocardiogram (ECG) tracings in an asymptomatic 26-year-old man with the Brugada syndrome. (Left) Baseline: Type 2 ECG (not diagnostic) displaying a "saddlebacktype" ST-segment elevation is observed in V2. (Center) After intravenous administration of $750 \mathrm{mg}$ procainamide, the Type 2 ECG is converted to the diagnostic Type 1 ECG consisting of a "coved-type" ST-segment elevation. (Right) A few days after oral administration of quinidine bisulfate (1,500 mg/day, serum quinidine level $2.6 \mathrm{mg} / \mathrm{L})$, ST-segment elevation is attenuated in the right precordial leads. VF could be induced during control and procainamide infusion, but not after quinidine. From Belhassen et al. ${ }^{175}$ with permission. 

A Control
B terfenadine $(5 \mu \mathrm{M})$
$\mathrm{C}+$ tedisamil $(2 \mu \mathrm{M})$

<smiles>CCCC</smiles><smiles>CCCCCCCCCCCCCC</smiles>

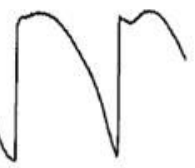

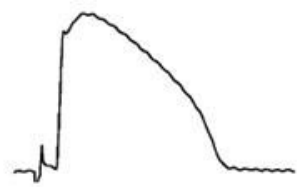<smiles>CCCCCCCCCCCCCCC</smiles><smiles>CCCCCCCC</smiles>

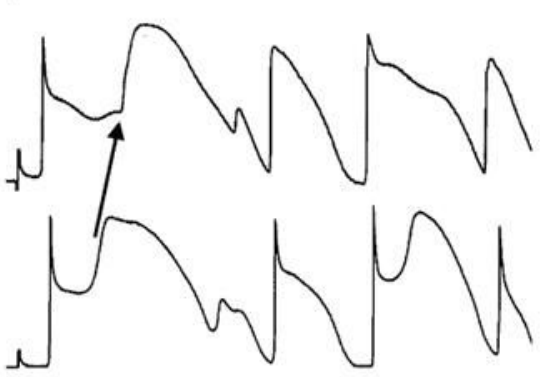
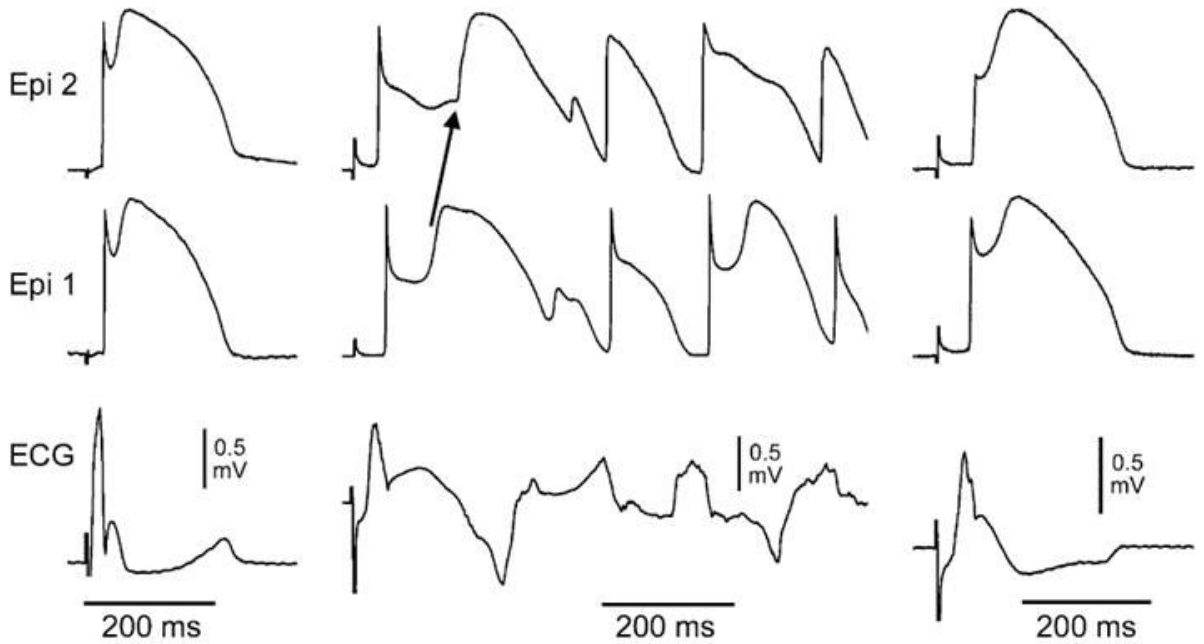

Figure 15.

Effects of $\mathrm{I}_{\text {to }}$ block with tedisamil to suppress phase 2 reentry induced by terfenadine in an arterially perfused canine RV wedge preparation. (A) Control, BCL 800 ms. (B) Terfenadine $(5 \mu \mathrm{M})$ induces ST-segment elevation as a result of heterogeneous loss of the epicardial action potential dome, leading to phase 2 reentry which triggers an episode of poly VT $(\mathrm{BCL}=800$ ms). (C) Addition of tedisamil $(2 \mu \mathrm{M})$ normalizes the ST segment and prevents loss of the epicardial action potential dome and suppresses phase 2 reentry induced and polymorphic VT $(\mathrm{BCL}=800 \mathrm{~ms})$. From Antzelevitch and Fish ${ }^{172}$ with permission. 
A Control B terfenadine $(5 \mu \mathrm{M}) \quad \mathrm{C}+\operatorname{AVE} 0118(7 \mu \mathrm{M})$
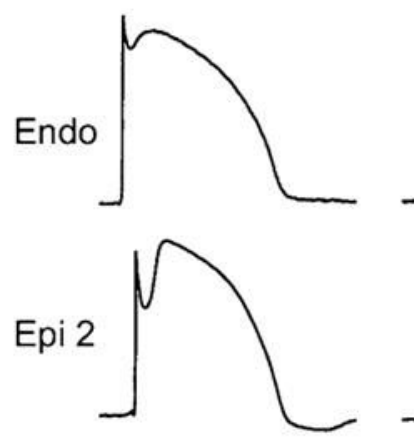

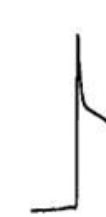
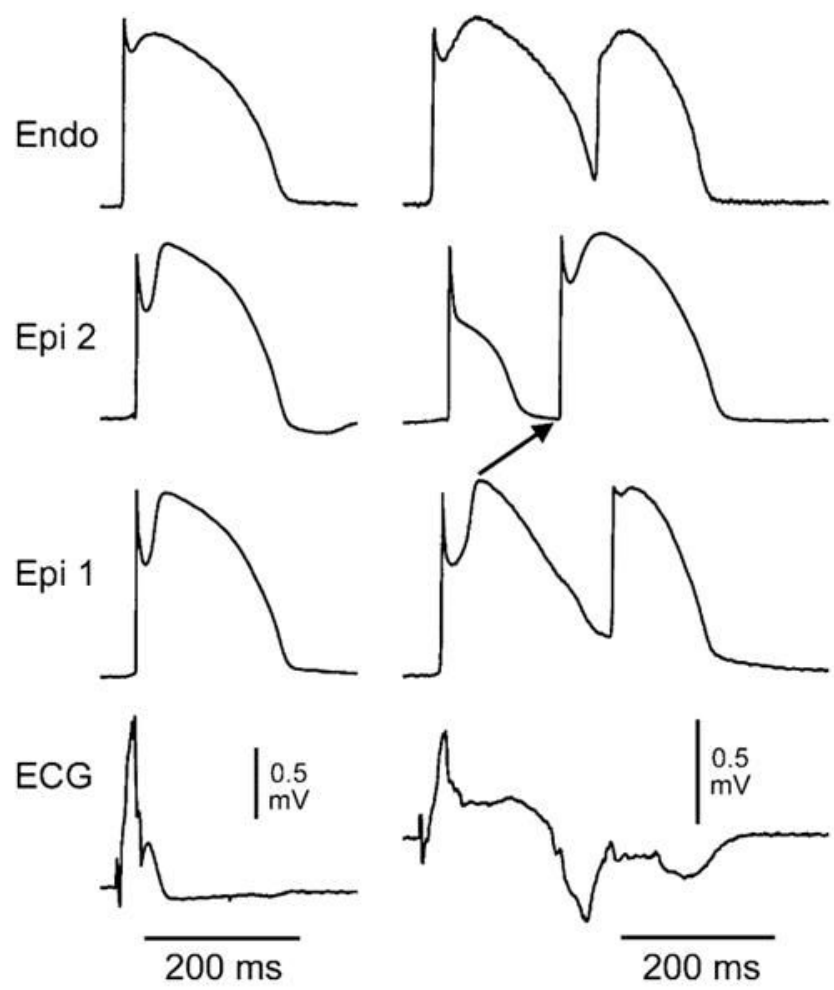
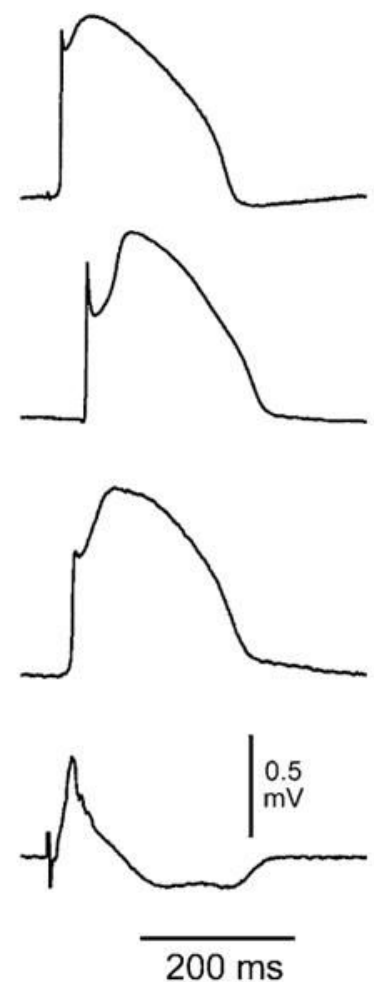

Figure 16.

Effects of $\mathrm{I}_{\text {to }}$ blockade with AVE0118 to suppress phase 2 reentry induced by terfenadine in an arterially perfused canine RV wedge preparation. (A) Control, BCL $800 \mathrm{~ms}$. (B) Terfenadine $(5 \mu \mathrm{M})$ induces ST-segment elevation as a result of heterogeneous loss of the epicardial action potential dome, leading to phase 2 reentry which triggers a closely coupled extrasystole (BCL $=800 \mathrm{~ms})$. (C) Addition of AVE0118 $(7 \mu \mathrm{M})$ prevents loss of the epicardial action potential dome and phase 2 reentry-induced arrhythmias $(B C L=800 \mathrm{~ms})$. From Antzelevitch ${ }^{172}$ with permission. 


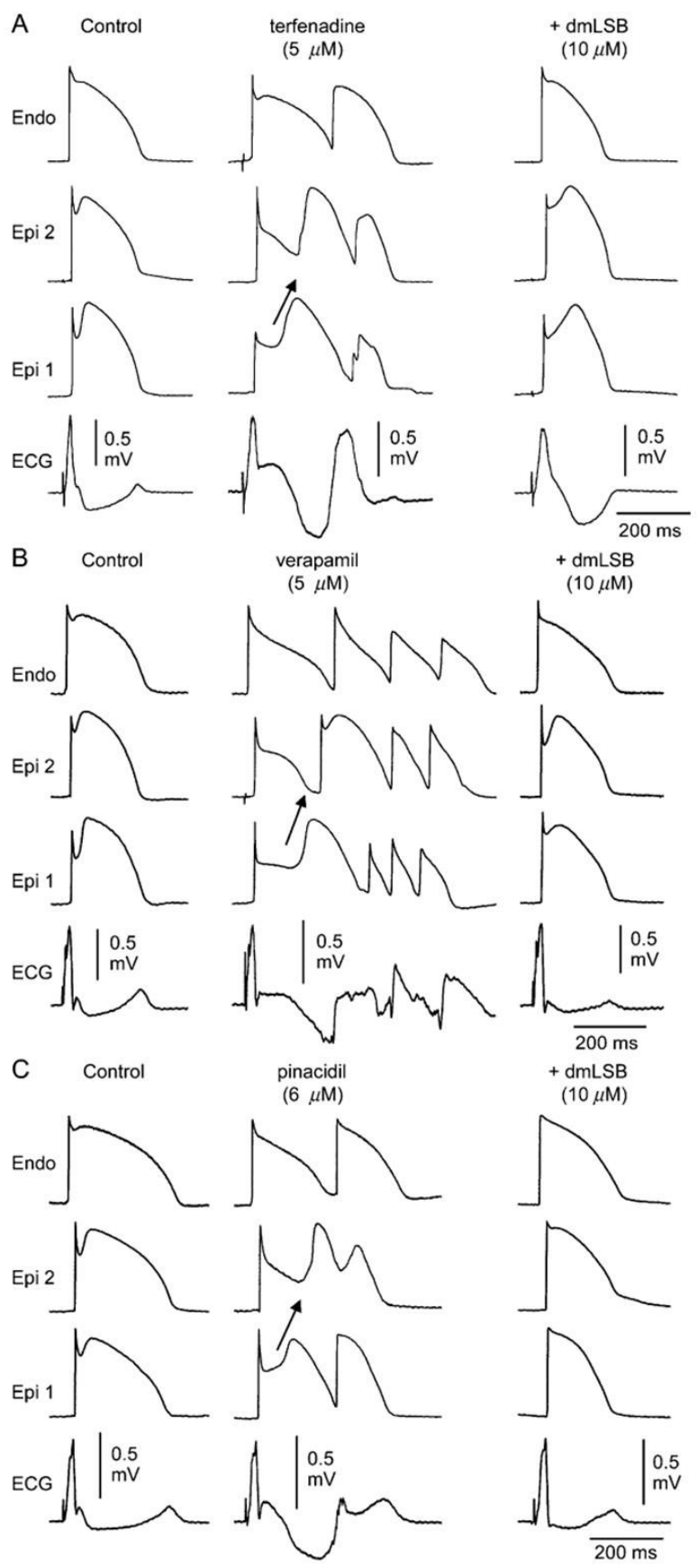

Figure 17.

Effect of dmLSB to suppress the arrhythmogenic substrate of the Brugada syndrome in three experimental models. Phase 2 reentry was induced in three separate models of the Brugada syndrome. Terfenadine (5 $\mu \mathrm{M}, \mathrm{A})$, verapamil $(5 \mu \mathrm{M}, \mathrm{B})$, or pinacidil $(6 \mu \mathrm{M}, \mathrm{C})$ induce heterogeneous loss of the epicardial action potential dome and ST-segment elevation. Phase 2 reentry occurs as the dome is propagated from Epi 1 to Epi 2, triggering either a closely coupled extrasystole or polymorphic ventricular tachycardia. In all 3 models, addition of dmLSB (10 $\mu \mathrm{M}$ ) normalizes the ST segment and abolishes phase 2 reentry and resultant arrhythmias. From Fish et al. ${ }^{115}$ with permission. 


\section{Table I}

Diagnostic Criteria for Brugada Syndrome (From $1{ }^{\text {st }}$ Consensus Document) ST-Segment Abnormalities in Leads V1-V3

\begin{tabular}{llll}
\hline & Type 1 & Type 2 & Type 3 \\
\hline J-point & $\geq 2 \mathrm{~mm}$ & $\geq 2 \mathrm{~mm}$ & $\geq 2 \mathrm{~mm}$ \\
T-wave & Negative & Positive or biphasic & Positive \\
ST-T configuration & Coved type & Saddleback & Saddleback \\
ST segment (terminal portion) & Gradually descending & Elevated $\geq 1 \mathrm{~mm}$ & Elevated $<1 \mathrm{~mm}$ \\
\hline
\end{tabular}

$1 \mathrm{~mm}=0.1 \mathrm{mV}$, the terminal portion of the ST segment refers to the latter half of the ST segment. From Wilde et al. ${ }^{3}$ with permission. 


\section{Table II}

Drugs Used to Unmask the Brugada Syndrome

\begin{tabular}{ll}
\hline Ajmaline & $1 \mathrm{mg} / \mathrm{kg} / 5 \mathrm{~min}$, i.v. \\
Flecainide & $2 \mathrm{mg} / \mathrm{kg} / 10 \mathrm{~min}$, i.v. $(400 \mathrm{mg}, \mathrm{p} . \mathrm{o})$. \\
Procainamide & $10 \mathrm{mg} / \mathrm{kg} / 10 \mathrm{~min}$, i.v. \\
Pilsicainide & $1 \mathrm{mg} / \mathrm{kg} / 10 \mathrm{~min}$, i.v. \\
\hline
\end{tabular}




\section{Table III}

ECG Abnormalities that Can Lead to or Exacerbate ST-Segment Elevation in the Right Precordial Leads

Myocarditis 47

Atypical right bundle branch block

Left ventricular hypertrophy

Early repolarization

Acute pericarditis

Acute myocardial ischemia or infarction

Pulmonary embolism

Prinzmetal's angina 191

Dissecting aortic aneurysm ${ }^{192}$

Various central and autonomic nervous system abnormalities 193,194

Duchenne muscular dystrophy 195

Thiamine deficiency 196

Hypokalemia 155,197

Hyperkalemia $192,198,199$

Hypercalcemia ${ }^{200,201}$

Arrhythmogenic right ventricular dysplasia/cardiomyopathy 45,46

Hypothermia 202,203

Mechanical compression of right ventricular outflow tract as with mediastinal tumor ${ }^{204}$

Hemopericardium 205

Fatty acid oxidation disorder (medium chain Acyl-CoA dehydrogenase deficiency) 206 


\section{Drug-Induced Brugada-Like ECG Patterns}

\section{Table IV}

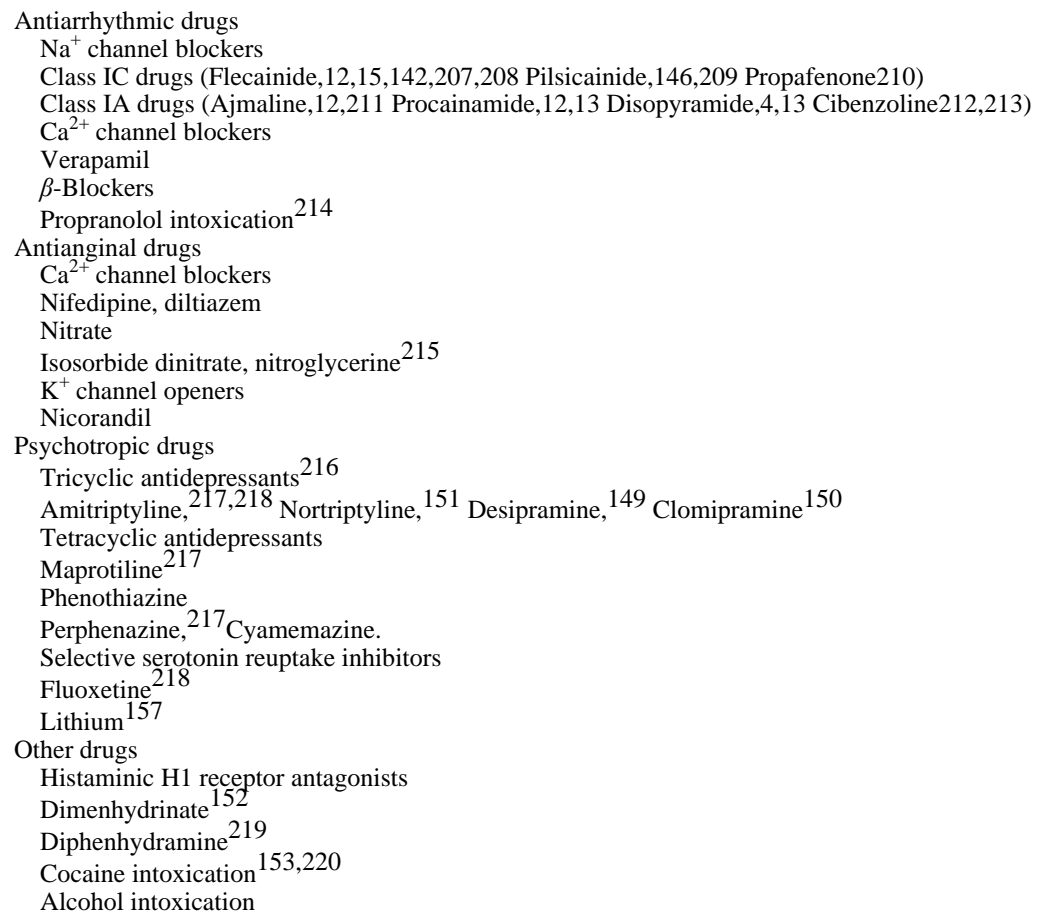

Modified from Antzelevitch et al. ${ }^{56}$ and Shimizu ${ }^{221}$ with permission. 
Table V

Device and Pharmacologic Approach to Therapy of the Brugada Syndrome

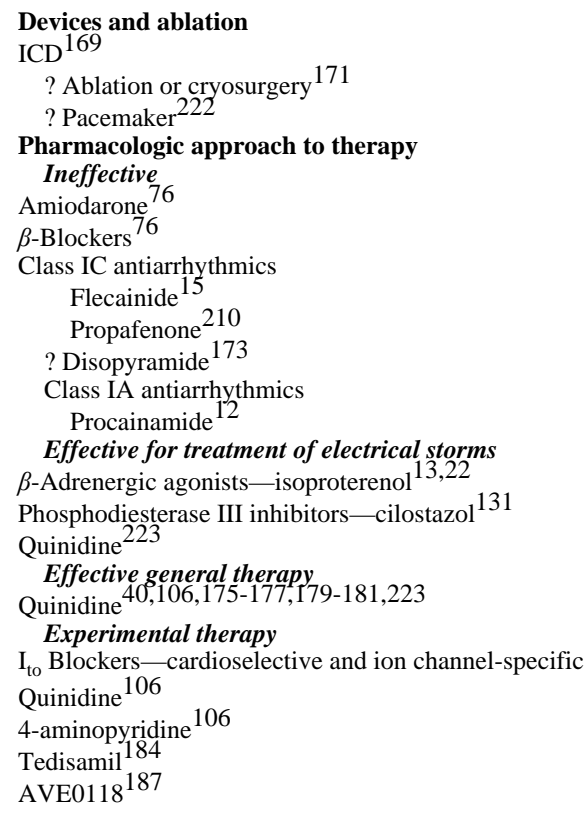


Table VI

Indications for ICD Implantation in Patients with the Brugada Syndrome

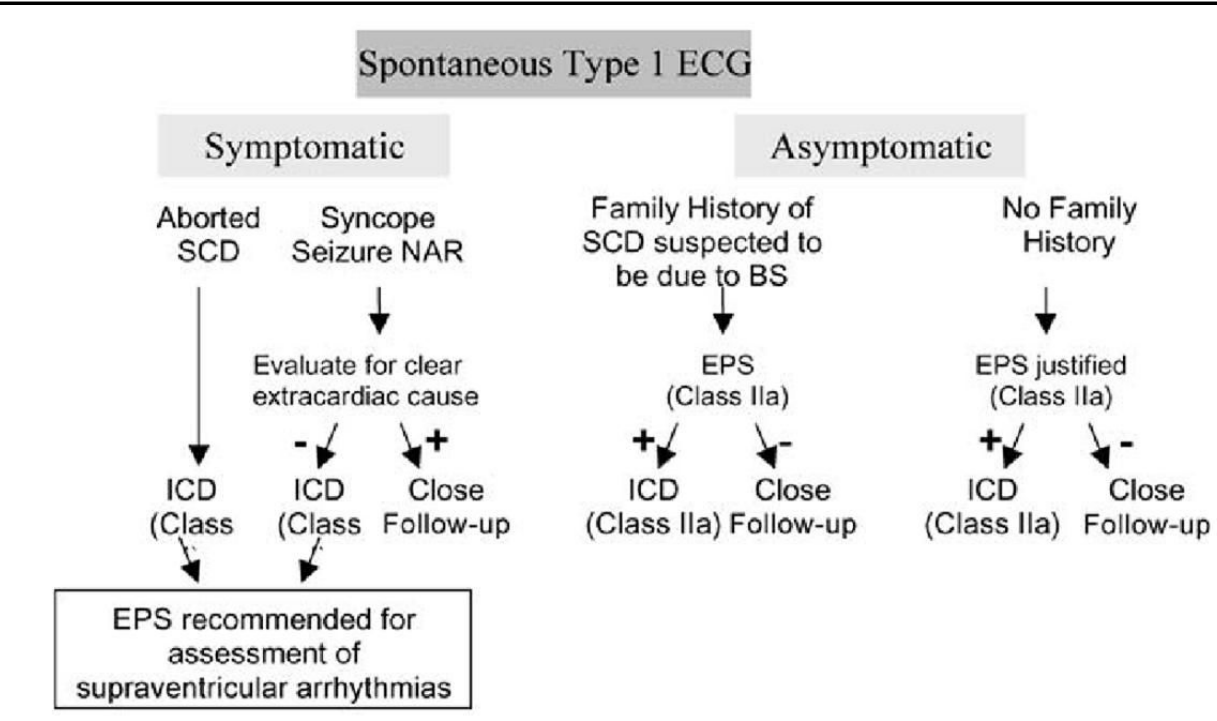

\section{Sodium Channel Block-induced Type 1 ECG}

Symptomatic

Aborted Syncope

SCD Seizure NAR

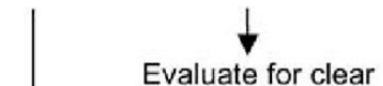

extracardiac cause

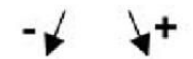

ICD

(Class I)

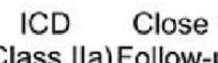

(Class Ila)Follow-up

$\checkmark$

EPS recommended for

assessment of supraventricular arrhythmias
Asymptomatic

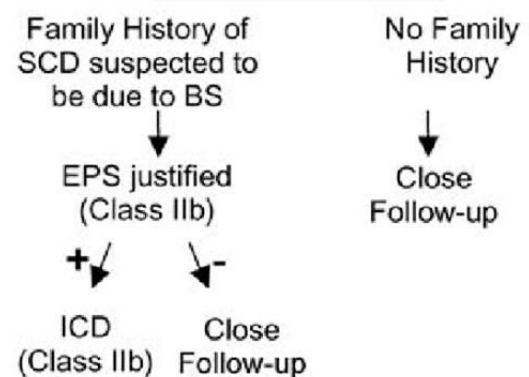

Class I: Clear evidence that procedure or treatment is useful or effective

Class II: Conflicting evidence concerning usefulness or efficacy

Class IIa: Weight of evidence in favor of usefulness or efficacy

Class IIb: Usefulness or efficacy less well established

$\mathrm{BS}=$ Brugada syndrome; $\mathrm{EPS}=$ electrophysiologic study; NAR = nocturnal agonal respiration; $\mathrm{SCD}=$ sudden cardiac death

(from Antzelevitch et al. ${ }^{5,6}$ with permission) 